\title{
Forbidden Fruits: The Political Economy of Science, Religion, and Growth
}

\author{
Roland Bénabou $^{1} \quad$ Davide Ticchi $^{2} \quad$ Andrea Vindigni $^{3}$
}

This version: December $2013^{4}$

${ }^{1}$ Princeton University, CIFAR, NBER and CEPR. rbenabou@princeton.edu.

${ }^{2}$ IMT Lucca. davide.ticchi@imtlucca.it.

${ }^{3}$ IMT Lucca and Collegio Carlo Alberto. andrea.vindigni@imtlucca.it.

${ }^{4}$ We are grateful to Eric Chaney, Will Dobbie, Massimo Firpo, Luigi Guiso, Gilat Levy, Marco Marini, Joel Mokyr, Alireza Naghavi, Ronny Razin, Julio Rotemberg, Ken Scheve, Moses Shayo and Guido Tabellini for helpful discussions and suggestions; and to seminar participants at Bocconi University, EIEF (Rome), the NBER 2009 Summer Institute, Stanford University and the Workshop on Political Economy, Economic History, and Religion at WZB (Berlin) for valuable comments. Alessandro Belmonte and Doron Ravid provided outstanding research assistance. Bénabou gratefully acknowledges financial support from CIFAR, Ticchi from the MIUR (PRIN 2009) and Vindigni from CRISIS LAB and Collegio Carlo Alberto. Vindigni also thanks MIT for its hospitality during the fall of 2013. 


\begin{abstract}
This paper analyzes the joint dynamics of religious beliefs and scientific-economic development. It emphasizes in particular how this coevolution is shaped by (and feeds back on) political conflicts and coalition formation, along both religious and income lines. As part of our motivating evidence, we also uncover a new fact: in both international and cross-state U.S. data, there is a significant negative relationship between religiosity and innovativeness (patents per capita), even after controlling for the standard empirical determinants of the latter.

To shed light on the workings of the science-religion-politics nexus and its growth and distributional implications, the paper develops a model with three key features: (i) the recurrent arrival of scientific discoveries which, if widely diffused and implemented, generate productivity gains but sometimes also erode existing religious beliefs (a source of utility for some agents) by contradicting important aspects of the doctrine; (ii) a government that can allow such ideas and innovations to spread, or spend resources to censor them and impede their diffusion; (iii) a religious organization or sector (Church or churches) that can, at a cost, undertake an adaptation of the doctrine that renders it more compatible with the new knowledge.

The model leads to the emergence of three types of long-term outcomes. The first is a "Secularization" or "Western-European" regime, with declining religiosity, unimpeded scientific progress, a passive Church and high levels of taxes and secular public spending. The second is a "Theocratic" regime with knowledge stagnation, extreme religiosity, a Church that makes no effort to adapt since its beliefs are protected by the state, and also high taxes but now used to subsidize the religious sector. In-between these two is a third, "American" regime, which generally (not always) succeeds in combining unimpeded scientific progress and stable religiosity within a range where the state does not block new discoveries and the religious sector finds it worthwhile to invest in doctrinal repair and adaptation. This regime features lower taxes than the other two, but with positive revenue or tax exemptions allocated to religious activities. We also show that, in this "American" regime, a rise in income inequality can lead the religious rich to form a "religious-right" alliance with the religious poor and start blocking belief-eroding discoveries and ideas. Inequality can thus be harmful to knowledge and growth, by inducing obscurantist, anti-science attitudes and polices.
\end{abstract}

Keywords: science, discovery, innovation, technological progress, knowledge, economic growth, religion, secularization, tolerance, religious right, theocracy, politics, blocking, Church, state, inequality, redistribution.

JEL Classification: P16, H11, H26, H41, Z12 


\section{Introduction}

"For an economy to create the technical advances that enabled it to make the huge leap of modern growth, it needed a culture of innovation, one in which new and sometimes radical ideas were respected and encouraged, heterodoxy and contestability were valued, and novelty tested, compared, and diffused if found to be superior by some criteria to what was there before." (Mokyr, 2012, p. 39)

Throughout history there have been periodic clashes between scientific discoveries and religious doctrines, and even today such conflicts remain important in a number of countries. In such cases the arbiter is often the state, which can allow the diffusion of the new knowledge, or on the contrary try to repress and contain it in order to protect religious beliefs. Its choice depends in particular on whether its power base and class interest lies more with the secular or religious segments of the population, and thus on the general level of religiosity as well as the distribution of productive abilities among agents. There is therefore a two-way interaction between the dynamics of scientific knowledge and those of religious beliefs, which evidence suggests can lead to very different long-term outcomes across countries.

History and contemporary events offer many examples of the recurring tensions between science and organized religion, and we discuss a number of them. As further motivating evidence for the economic importance of the issue we also carry out a simple empirical exercise, with rather striking results: across countries as well as across U.S. states, there is a clear negative relationship between religiosity and innovation (patents per capita). This finding is quite robust, and in particular unaffected by controlling for the standard variables used in the literature to explain patenting and technological innovation.

The aim of this paper is to shed light on the workings of the science-religion-politics nexus, as well as its growth and distributional implications. To this end, we develop a model with three key features: (i) the recurrent arrival of scientific discoveries which, if widely diffused and implemented, generate productivity gains but sometimes also erode existing religious beliefs (an important source of utility for some agents) by contradicting important aspects of the doctrine; (ii) a government that can allow such ideas and innovations to spread, or spend resources to censor them and impede their diffusion. Subsequently, it also chooses the level of public spending and its allocation between secular public goods (or transfers) and subsidies (or tax exemptions) for religious activities; (iii) a religious organization or sector (Church or churches) that can, at a cost, undertake an adaptation of the doctrine -new interpretation, reformation, entry of new cults, etc.- that renders it more compatible with the new knowledge, thereby also alleviating the need for ex-ante blocking by the state.

The game then unfold as follows. Each generation of agents, living for two periods, is composed of (up to) four social classes, corresponding to the religious/secular and rich/poor divides.

At both stages of life these groups compete for power, which may involve forming strategic 
(coalition-proof) alliances with others. The candidate or leader of the group that emerges victorious from the political competition governs the state and implements his preferred policy. In the first period (youth), policy choice is over the control of knowledge, namely whether or not to set up a repressive and propaganda apparatus that will block any belief-eroding discoveries or innovations emanating from the sciences. This decision is forward-looking, taking into account the Church's optimal repairing behavior and how an erosion of religious agents' beliefs would affect subsequent political outcomes. In the second period (old age), the choice is over fiscal and social policy: choosing the level of taxes and allocating spending between secular and religious (belief-complementary) public goods. After each generation dies a new one takes over, inheriting its predecessor's final stocks of scientific and (for non-secular agents) religious capital.

We characterize the outcome of these strategic interactions and the resulting joint dynamics of scientific knowledge, TFP, and religious beliefs. We show in particular the emergence of three "basins of attraction": (i) a "Western-European" or "Secularization" regime, with unimpeded scientific progress, declining religiosity, a passive Church and high levels of taxes and secular spending; (ii) a "Theocratic" regime with knowledge stagnation, persistently extreme religiosity, a Church that makes no effort to adapt since its beliefs are protected by the state, and also high taxes but now used to subsidize the religious sector; (iii) in-between these two, an "American" regime that generally (not always) succeeds in combining unimpeded scientific progress and stable religiosity within an intermediate range where the state does not block new discoveries and the Church sector finds it worthwhile to invest in doctrinal repair and adaptation. This regime features lower taxes than the other two, but with revenue or tax exemptions allocated to religious activities.

We also examine how income inequality interacts, through coalition formation, with the religious / secular divide, and how this in turn affects equilibrium dynamics. We show in particular how, in the "American" regime, a rise in income inequality can lead the religious rich to form a religious-right alliance with the religious poor and start blocking belief-eroding discoveries and ideas. Inequality can thus be harmful to knowledge and growth, by inducing obscurantist, anti-science attitudes and polices.

\subsection{Related Literature}

Our paper relates to three main lines of work. First, within the large literature on the political economy of growth, the most closely related papers are those in which governments sometime resist of delay the adoption of productivity-enhancing technological innovations, due to the pressure exerted by vested economic interests who would lose from it (e.g., Krusell and RíosRull (1996), Parente and Prescott (1999), Restuccia (2004), Bellettini and Ottaviano (2005), 
Acemoglu and Robinson (2006) and Bridgman et al. (2007)). Through the "adaptation" work of the Church, the paper also relates to those in which new technologies diffuse only slowly because they require costly learning (e.g., Chari and Hopenhayn (1991), Caselli (1999)). Unlike the previous literature, we focus on fundamental science rather than specific technological devices, and on religious beliefs as a coevolving form of (social) capital occasionally threatened by new discoveries; such conflicts, moreover, can lead to either blocking by the state or to doctrinal revisions by the Church. Our study thereby relates to and draws on historical work pertaining to scientific-economic progress and religion, such as Koyré (1957), Mokyr (1992, 1998, 2004), Landes (1998), Greif (2005), Chaney (2008, 2011 2013), Deming (2010), Vander Hook (2010), Saleh (2012a,b).

Second, our paper also contributes to the literature on the persistence of power, policies and institutions in a context of distributional conflict (e.g., Bénabou (1996, 2000), Acemoglu and Robinson (2008), Persson and Tabellini (2009) and Acemoglu et al.(2011). We focus on a very different source of persistence, however, namely the (endogenous) religiosity of the population. In this respect, the paper also relates to work on the dynamics of political beliefs and culture (e.g., North (1990), Greif (1994), Piketty (1995), Bisin and Verdier (2000), Alesina and Angeletos (2005), Bénabou and Tirole (2006), Tabellini (2008, 2010), Bénabou (2008), Saint-Paul (2010), Gorodnichenko and Roland (2011), Aghion et al. (2011), Ticchi et al. (2013), Guiso et al. (2013), Alesina and Giuliano (2013)).

Finally, because religion plays a crucial role in affecting technological and economic growth (and vice-versa), as well as distributive outcomes, the paper contributes to the literature on the socioeconomic determinants and consequences of religiosity pioneered by Weber (1905). Modern contributions include Barro and McCleary (2003a, 2005), Guiso et al. (2003), Cavalcanti et al. (2007), Glaeser and Sacerdote (2008), Becker and Woessmann (2009), Kuran (2011), Botticini and Eckstein (2012) and Levy and Razin (2012), who emphasize the relationship to growth through the accumulation of human and physical capital; Stark et al. (1996) and Swatos and Christiano (1999), whose main concern is the "secularization hypothesis"; and Roemer (1998), Scheve and Stasavage (2006) and Huber and Stanig (2011), who focus on the interplay between religiosity and the demand for redistribution.

The paper is organized as follows. Sections 2 and 3 present motivating and supporting evidence, including our empirical findings, for the questions and mechanisms which the papers investigates. Section 4 develops our basic model of religion, science and politics, which is then solved in Section 5 for equilibrium policies and the resulting coevolution of religiosity and knowledge. Section 6 extends the model, in particular the political-competition game, to incorporate the interplay of religious and income differences and thus study the effects of inequality on coalition formation, science policy and equilibrium outcomes. Section 7 concludes. All proofs are gathered in the Appendix. 


\section{Historical and Contemporary Examples}

This section discusses important instances, from the Middle Ages to modern times, of conflicts between religion and scientific discoveries, initially arbitrated (often in favor of dogma) by the ruling powers, and sometimes later resolved through doctrinal revisions and adaptations ${ }^{1}$

\subsection{Science and Religion in the Muslim World}

The Muslim expansion in the Middle East, North Africa and Southern Europe occurred during the period 632-732 C.E. The resulting confrontation with the "rational sciences" such as philosophy, mathematics and astronomy cultivated in the newly conquered areas posed a difficult challenge for Muslim religious authorities. On the one hand, they viewed "foreign" or "rational" science as an "unnecessary addition to the Islamic and 'Arab' science and a potential danger to their faith" (Chaney (2008), p. 3). On the other hand, being prevented by the Koran and the teachings of Muhammad from implementing forceful conversions, they felt compelled to engaged in "logical" debates with non-Muslims in the process of proselytizing Islam. ${ }^{2}$ Scientific progress flourished in this environment of religious and intellectual pluralism and confrontation, with major developments in algebra, trigonometry, the introduction of Indian numerals and the essentials of decimal reckoning. Progress also occurred in chemistry and in medicine, and the use of the experimental method became widespread. Technological innovations of the Muslim civilization include the double-acting suction pump, navigational instruments (astrolabes, quadrants, globes and the magnetic compass) and important progress in the development of the clock. ${ }^{3}$

The initial willingness of Muslim rulers to engage with logic and rational sciences rapidly declined between the $11^{\text {th }}$ and the $12^{\text {th }}$ centuries, however, and was followed by centuries of active opposition to the generation and diffusion of new knowledge. ${ }^{4}$ "In the eleventh century

\footnotetext{
${ }^{1}$ The persecution of scholars who challenged prevailing religious views, for instance on astronomy and cosmology, dates back much further. Thus, Anaxagoras of Clazomenae (c. 500-428 B.C.) was attacked and forced into exile (where he eventually committed suicide) because he believed that the sun was a mass of red and hot material, which was not deemed to be characteristic of divine celestial bodies (Grant (2004), pp. 15-16).

${ }^{2}$ According to Lewis (2003, p. 33-34), the degree of tolerance for non-Muslim populations at that time was "without precedent or parallel in Christian Europe."

${ }^{3}$ See Maddison, 2007, ch. 4, pp. 190-191, and Chaney, 2008, p. 6. In addition, translations of Greek and Indian works in philosophy and science were financed by the Caliphs, who also created libraries, observatories and other centers of learning, especially in Baghdad.

${ }^{4}$ According to Chaney (2008), as the majority of the people living in the conquered territories eventually converted to Islam between the $11^{\text {th }}$ and the $12^{\text {th }}$ centuries, science, and rational thought in general, lost their main purpose of supporting such conversions, leaving no reason for religious authorities to even tolerate them. Similarly, McClellan III and Dorn (2006, p. 114) write that, "Islam began as a colonial power, and especially at the edges of the Islamic imperium multicultural societies flourished at the outset, mingling diverse cultures and religions - Persian, Indian, Arab, African, Greek, Chinese, Jewish, and Christian. As time went on, conversions increased, and Islam became religiously more rigid and culturally less heterogeneous."
} 
A.D., Hellenistic studies in the Islamic civilization were on the wane, and by the end of the twelfth century A.D. they were essentially extinct." (Deming (2010), p. 105). Greek science and philosophy were excluded from the subjects taught in the madrasas, and "any private institution that might teach the 'foreign' sciences was starved out of existence by the laws governing waqfs [charitable endowments]". Remarkably, this follows the same path taken by the Roman Church in the late $4^{\text {th }}$ century: as Christianity became the official and dominant religion of the late Empire, the tolerant Greek scientific and philosophical traditions were increasingly repressed, and reason made subservient to faith (Freeman (2005)).

The most striking and long-lasting case of knowledge blocking in the Muslim world is undoubtedly that of the printing press. Johannes Gutenberg began working on his invention in 1436. The high quality and relatively low price of the first printed Bible (1455) established the superiority of his movable-type technique, and printing presses spread very rapidly across Europe $5^{5}$ Little opposition came from the Roman Catholic Church (at that time still largely hegemonic as a spiritual authority), which saw it as a useful device to standardize, reproduce and disseminate at low cost the Holy Scriptures and religious manuals, as well as profit from the sale of letters of indulgence (Childress (2008), ch. 6). Ironically, half a century later printing also proved to be a decisive factor in the rapid diffusion of the Protestant Reformation that radically undermined the Church's hegemony and power in much of Europe ${ }^{6}$ Later on, printing also played a key role in spreading the ideas that flourished during the Scientific Revolution and the Enlightenment (e.g., Diderot and d'Alembert's Encyclopedie, first published in 1751) and which set the West on a widely different path from the rest of the world.

In Muslim lands, by contrast, printing -especially in Arabic and Turkish- was strongly opposed throughout the early-modern and modern periods. In 1515, Sultan Selim I issued a decree under which the practice of printing would be punishable by death. Printing only started in the Islamic World at the beginning of the $19^{\text {th }}$ century, partly due to the need for defensive modernization against the West.

What accounts for the divergent paths of diffusion of the printing press in Europe and the Muslim world? In Catholic Europe, where various minor schisms and heretical movements had been fairly easily suppressed, there was -overoptimistically- little fear that innovations such as

\footnotetext{
5 "By 1500, more than 1,000 printing shops had sprung up in Europe. Printers were turning out an average of 500 books per week. No other invention had spread so quickly or had such far-reaching effects until that moment" (Vander Hook, 2010, p. 12). It is estimated that during 1436-1500 approximately 15,000 different texts were printed in 20 million copies, and in the $16^{\text {th }}$ century $150,000-200,000$ different books and book editions were printed, totaling more than 200 million copies (see Kertcher and Margalit, 2005).

${ }^{6}$ Martin Luther, whose 95 Theses (originally posted in 1517) were widely reprinted and circulated, called printing "God's highest and most extreme gift, by which the business of the Gospel is driven forward" (Childress, 2008, ch. 6). Kertcher and Margalit (2005, pp. 17-18) note that over time the Roman Catholic Church realized how pernicious the printing press was for its own hegemony. In 1479, Pope Sixtus IV thus authorized the University of Cologne to use ecclesiastical censure against printers, purchasers, and readers of heretical books.
} 
printed books could undermine religious unity. In contrast, as suggested by McClellan III and Dorn (2006) and by Chaney (2008), starting in the $12^{\text {th }}$ century Muslim authorities became increasingly suspicious of innovations, perceiving them as potential threats to their relatively recent success at converting the conquered populations. By this time Muslims were also already split between Sunni, Shi'ite and Sufi branches, whereas Catholics were still essentially united. Printing was also less profitable in the Ottoman Empire, due to lower wages and literacy rates that reduced the demand for books 7

The persistence and legacy of the anti-printing, anti-scientific attitudes and policies that took hold in the Muslim world eight centuries ago are still easily discernible today. The United Nations' 2002 Arab Human Development Report (see, e.g., Diner (2009), p. 19) thus found that during the 1970's, the total number of books translated into Arabic was about one-fifth of the equivalent figure for books translated into modern Greek. In the 1980's, over a five-year period, only 4.4 books per million inhabitants were translated in the Arab world, versus 519 for Hungary and 920 for Spain. Focusing on science, the Pakistani nuclear physicist Pervez Hoodbhoy (2007) reports that the top 46 Muslim countries combined produced $1.17 \%$ of world scientific literature, versus $1.48 \%$ for Spain; half of the 28 lowest producers of scientific articles in 2008 were members of the Organization of Islamic States. At the major University in Islamabad where he taught at the time, there were three mosques and a fourth one planned, but no bookstore 8

\subsection{The Discovery of Aristotle's Natural Philosophy in $\mathbf{1 2}^{\text {th }}$ Century}

Part of Aristotle's (384-322 B.C.) works, namely two books of the Organon: Categories and Interpretation, were first translated into Latin in the early $6^{\text {th }}$ century and became widely read in Europe. In particular, these works "had been regularly taught in the Church's schools since the time of Charles the Great [742-818]" (Deming, ch. 4, p.135). When the other books of the Organon (Prior Analytics, Posterior Analytics, Topics, Sophistical Refutations) were later translated into Latin, they were also readily incorporated into the Church's school curriculum and become known as the New Logic.

During the $12^{\text {th }}$ century, Aristotle's previously lost works in "natural philosophy" such as Physics, On the Soul, On Generation and Corruption, Metaphysics, Meteorology, and On

\footnotetext{
${ }^{7}$ Al-Khalili (2010, p. 235) also reports that potential misspelling in the printing of the Koran was regarded as sacrilegious by the Muslim religious authorities, as was "compressing" the word of God.

${ }^{8}$ The Economist (2013) similarly reports that "The world's 1.6 billion Muslims have produced only two Nobel laureates in chemistry and physics. Both moved to the West. The 57 countries in the Organization of the Islamic Conference spend a puny $0.81 \%$ of GDP on research and development, about a third of the world average." Investment in areas at the interface between pure and applied science is about 5\% of GDP in developed countries, versus a very meager $0.2 \%$ in the Arab world. The article also points to some hopeful recent prospects for a comeback of science in certain (mostly oil-rich) parts of the Islamic world.
} 
the Heavens, were rediscovered and translated. Unlike the books on logic, which dealt with abstract principles and rules of thought, these contained doctrines regarding the physical world, human life and the universe, many of which seemed incompatible with crucial statements in the Bible. For instance, in Meteorology it is written that "there will be no end to time and the world is eternal," a conclusion that follows out of logical necessity from Aristotle's system but directly contradicts the description of Creation in the book of Genesis. Similarly, in On the Heavens, Aristotle declared that "the world must be unique." In Aristotelian physics, this follows from the principle that all natural motions of elements are directed toward the center of the universe, corresponding with the center of the Earth. However, "limiting the possible worlds to one was seen as heretical, because it implied that God was not omnipotent" (Deming (2010), pp. 138-139). Aristotle's writings also denied other fundamental pillars of the Christian faith, such as the possibility of salvation and the immortality of the soul. He further claimed that it was possible to know God on rational grounds only, whereas the Christian faith rested upon the principle of divine revelation.

The diffusion of these "heretical" writings was quickly opposed by the Church; in 1210 the Synod of Paris (the main center of learning of Aristotle's philosophy at the time) issued a declaration that "nor shall the books of Aristotle on natural philosophy, and the commentaries [of Averroes] be read in Paris in public or secret; and this we enjoin under pain of excommunication," (Deming (2010), p. 137). In 1277 the Bishop of Paris issued a list of 219 heretical propositions, also backed by threat of excommunication. His influence waned over time and his decree was overturned in 1325, thanks to the work of Thomas Aquinas, whose Summa Theologica successfully merged Aristotelianism with the doctrine of the Church. Aquinas' ingenuous intellectual construction represents a perfect example of theological "repair and adaptation" following a belief-eroding discovery (or re-rediscovery), namely that of Aristotelian natural philosophy $9^{9}$ It allowed the Aristotelian corpus to be accepted and taught by the Church, temporarily ending the conflict that had emerged between science and religion 10 The conflict resurfaced three centuries later, however, when Copernicus' (1473-1543) work upended the whole Aquinian synthesis, which the Church had by then become heavily vested in.

\footnotetext{
${ }^{9}$ Aquinas introduced a fundamental distinction between the domain of reason and the domain of faith. All ultimate truths are elements of faith, but human reason can play an ancillary role. For instance, the doctrine of Divine Revelation is not acceptable unless it is preceded by a demonstration of the existence of God, an accomplishment of human reason.

${ }^{10}$ According to Freeman (2005), Aquinas' work marks the end of the West's "long sleep of reason" that begun in the $4^{\text {th }}$ century, when Christianity was established as the official religion of the Roman Empire by Theodosius I. His Edict of Thessalonica (380) was soon followed by persecutions of both pagan (Greek and Roman) religions and "heretical" (non-Catholic) Christian sects.
} 


\subsection{Copernicus, Galilei, Newton and the Roman Inquisition}

"The indivisible atoms could be imagined as moving in a continuum with knowable trajectories. In the seventeenth century, in the worlds celestial and terrestrial, everything seemed up for grabs; none of the old certainties about the land masses of our planet, or about the way space and bodies should be described, could be taken as given." (Jacob and Stewart, 2004, pp. 2-3).

Nicolaus Copernicus' On the Revolution of Celestial Spheres (1543) was important not only in its own sake, but also because it provided one of the pillars for the forthcoming Scientific Revolution of the $17^{\text {th }}$ century. While Copernicus (prudently) presented his heliocentric model of the universe as a pure mathematical hypothesis, for which he "could provide no empirical support", it stood in sharp contrast with the Aristotelian-Ptolemaic cosmological model endorsed by the Church as a cornerstone of its own world view. Due to its mathematical simplicity and power, Copernicanism quickly attracted the attention of many astronomers, among them Galileo Galilei (1564-1642).

In 1632, Galilei published the Dialogue on the Two Chief World Systems, which immediately caught the attention of the Church. The book, "made the clearest, fullest and most persuasive yet of arguments in favor of Copernicanism and against traditional AristotelianPtolemaic astronomy and natural philosophy," (McClellan III and Dorn (2006), p. 230). As a result, on April 12, 1633, Galileo was forced to stand trial before the Holy Inquisition in Rome, which found him guilty of "vehemently suspected heresy," forced him to "abjure, curse and detest" his opinions and placed all his works, past and future, in the Index of Prohibited Books. The trials of Galileo and other "heretical" scientists like the mathematician and astronomer Giordano Bruno, burnt at the stake in 1600, had wide-ranging consequences. While scientific inquiry did not entirely die in 1633, the Inquisition was an important cause of the waning of science in Italy and the displacement of the center of the Scientific Revolution toward Central and Northern Europe -Holland, France and, most importantly, England (Gusdorf (1969), Trevor-Roper (1967)) I1 In a recent study focusing on Spain, Vidal-Robert (2011) provides econometric evidence consistent with this argument (and our model), showing that the Inquisition had significant and long-lasting negative effects on Spanish economic development, through the delayed adoption of new technologies 12

In England, on the other hand, The Royal Society of London for Improving Natural Knowledge accepted Galileo's work with enthusiasm, not long after his condemnation by the Roman Inquisition (Boas Hall, 1982). As Goldstone (2000, p. 184) writes, "Only in Protestant Europe

\footnotetext{
${ }^{11}$ Gusdorf argues that the Italian economic crisis and stagnation of the $17^{\text {th }}$ century ("crisi del Seicento") was largely due to a decline of scientific inquiry and technical innovation caused by the Inquisition. Trevor-Roper emphasizes the exile of skilled craftsmen fleeing religious persecutions. Braudel (1991) offers a critical discussion.

${ }^{12}$ Inquisition tribunals persisted in Spain until 1834 (in Portugal, until 1821) The last execution took place in 1826, in Valenzia; it was that of a school teacher, Cayetano Ripoll, hanged for teaching Deism in his classes.
} 
was the entire corpus of classical thinking called into question; Catholic regions under the Counter-Reformations preferred to hold to the mix of Aristotelian and Christian cosmologies received from Augustine, Ptolemy, and Aquinas. And only in England, for at least a generation ahead of any other nation in Europe, did a Newtonian culture -featuring a mechanistic worldview, belief in fundamental, discoverable laws of nature, and the ability of man to reshape his world by using those laws- take hold. The spread of such set of beliefs to a wide variety of engineers, merchants, ministers, and craftsmen reshaped the entire nation's approach to knowledge and technology."

Newton's Mathematical Principles of Natural Philosophy first appeared in 1687. Newton's work showed that universal laws of gravitation could explain the elliptical motion of the celestial bodies according to the same principles used to explain the motion of falling bodies on the earth, a result which again subverted the Aristotelian-Ptolemaic cosmology. Newton's theories were nonetheless quickly adopted in Britain, including by some authorities of the Church of England, which eventually accepted his scientific world-view as compatible with the "spirit" of the Biblical account of the origin and workings of the universe. In 1727, following a state funeral, Newton was buried at Westminster Abbey among great statesmen and poets, with the endorsement of the Church. Newton's work was also very well received in most areas of Europe outside the reach of the Inquisition (Jacob and Stewart (2004), pp. 14-15).

There are two complementary explanations why the new scientific ideas encountered much less opposition in England than in countries such as Italy and Spain. First, England already experienced significant economic growth during the $16^{\text {th }}$ century, due to the expansion of trade and industry, while these other countries stagnated under the Inquisition. The opportunity costs (foregone income) as well as the direct costs (censorship, repression, etc.) of limiting the circulation of new productivity-enhancing ideas are naturally higher in a more dynamic and mobile economy; this will also be a key feature of our model 13 Second, as argued by Merton (1938), Protestant values encouraged scientific inquiry by allowing scientists to identify and celebrate the influence of God on the world 14 Through its technological applications, the new science developed by Isaac Newton was a precursor to the Industrial Revolution. The use of scientific principles and laws of mechanics in craftwork industries, which until then had relied on rule-of-thumb formulas and trial-and-error methods, allowed England to become the world's

\footnotetext{
${ }^{13}$ A similar argument is made by Al-Khalili (2010, p. 231) to explain the earlier European Renaissance and Muslim-world stagnation. "In comparison with Renaissance Europe, awash with the riches from the New World, confident in a new found self-belief so reminiscent of al. Ma'mūn's [ $8^{\text {th }}$ century] Baghdad, the many dynasties of the Islamic world were facing an uphill struggle against fragmentation and religious conservatism." On the role of the Atlantic trade in shaping the institutions of major European powers, see also Acemoglu et al. (2005).

${ }^{14}$ Merton (1938, p. 495) thus writes: "The formal organization of values constituted by Puritanism led to the largely unwitting furtherance of modern science. The Puritan complex of a scarcely disguished utilitarianism; of intramundane interests; methodical, unremitting action; thoroughgoing empiricism; of the right and even the duty of libre examen; of anti-traditionalism - all this was congenial to the same values in science."
} 
first industrialized nation (see Jacob and Stewart (2004), p.15).

\subsection{Creationism, Stem Cell Research and the Politics of Science in the U.S.}

"All that stuff I was taught about evolution and embryology and the big bang theory, all that is lies straight from the pit of Hell... It's lies to try to keep me and all the folks who were taught that from understanding that they need a savior... You see, there are a lot of scientific data that I've found out as a scientist that actually show that this is really a young Earth. I don't believe that the earth's but about 9,000 years old. I believe it was created in six days as we know them. That's what the Bible says." Rep. Paul Broun (R-Ga.) also an M.D., June 2012.

Charles Darwin's On the Origin of Species (1859) initially met some opposition, but within a few decades became widely accepted by the scientific community and in many Western countries, especially more secularized ones where a literal reading of Genesis had already been undermined by developments in geology and natural sciences. In more religious parts of the world, human evolution was and remains highly controversial, and a minority view. For instance, a recent survey (Hameed (2008)) found that fewer than $20 \%$ of adults in Indonesia, Malaysia and Pakistan believed Darwin's theory to be "true or possibly true", and only $8 \%$ in Egypt. In Europe, the Vatican kept silent on the issue for nearly a century, until Pope Pius XII's 1950 encyclical Humani Generis. While still not accepting evolution as an established fact, it allowed important doctrinal adaptation (in our model, "repair") by introducing a distinction between the possibly material origins of the human body and the necessarily divine and immediate imparting of the soul 15

The United States is a striking case of a rich and technologically highly advanced country in which significant opposition to evolution still persists, and interacts importantly with politics. Less than 90 years ago, Tennessee's Butler Act (1925) prohibited the teaching in schools of any theory of the origins of humans contradicting the teachings of the Bible, and John Scopes was tried and convicted for violating it. The law remained on the books until 1967. As reported by Ruse (2006, p. 249) "A 2001 Gallup poll reported that $45 \%$ of Americans thought that God created humans as they are now, $37 \%$ let some kind of guided evolution do the job, and $12 \%$ put us down to unguided natural forces... A 2001 National Science Foundation survey on science literacy similarly found that $47 \%$ of Americans think that humans were created instantaneously, and $52 \%$ believe that humans and dinosaurs coexisted." A well organized and well-funded movement has successfully pushed for the teaching and dissemination of "creation science", and today creationism is taught in 15 to $20 \%$ of American schools.

\footnotetext{
15 "The Teaching Authority of the Church does not forbid that... research and discussions, on the part of men experienced in both [human sciences and sacred theology], take place with regard to the doctrine of evolution, in as far as it inquires into the origin of the human body as coming from pre-existent and living matter -for the Catholic faith [only] obliges us to hold that souls are immediately created by God."
} 
Does this matter in practice? Indeed it does, through the political process - the coalitions it gives rise to and their consequences for science policy, innovation and informed decision-making. Over the last few decades, a powerful coalition of religious conservatives and antigovernment activists - the "Religious Right" - has arisen and exerted considerable power in American politics, both at the local and at the national levels, imposing constraints on education and research in certain areas of the life sciences, biotechnology and climatology. Its influence can be seen, for instance, in the science policies of President George W. Bush, whose election and reelection relied in great part on this constituency. Almost immediately after coming to office, President Bush severely restricted federal funding for research on embryonic stem cells, invoking in explicitly religious terms the sacrality and inviolability of all human life. During his second term, in July 2006, he used his first Presidential veto on the Stem Cell Research Enhancement Act. Only after eight years -a long time given the pace of modern researchwere most of these restrictions lifted, as President Barack Obama came to power.

It is worth noting that the rise of the Religious Right coalition between religious conservatives and small-government, anti-tax interests groups (starting with President Reagan but really culminating with the 2000 election of President Bush) coincided with a sharp and lasting rise in US income inequality, especially since the 90's. Explaining this "coincidence" is another motivation of our paper. The model will indeed show that greater inequality can cause some of the richer classes, whose productive interests normally lead them to favor technical progress, to form a science-unfriendly alliance with the religious poor in order to prevent a secular-left coalition from gaining power and implementing substantial redistribution 16

Religion-politics-science dynamics are also quite powerful at the local level. Eight states (Arkansas, Iowa, Louisiana, Michigan, Nebraska, North Dakota, South Dakota and Virginia) currently still ban or limit human stem-cell research; all but Michigan, are "red states," whose residents predominantly vote for the Republican party. In 2011, the state of Kentucky allocated more than $\$ 40$ million in tax incentives for a planned expansion of the Creation Museum, through the addition of a theme park designed to demonstrate the literal truth of the story of Noah's ark. Following evolution and biotechnology, the latest front in the push-back against science by religious-conservative alliances is climate change. In 2012, for instance, North Carolina passed a law banning its state agencies from basing coastal policies on the latest scientific predictions concerning the rise in sea level. The next section will show that such policies, or more precisely the high levels of religiosity that bring them about, are systematically associated with lower innovation.

\footnotetext{
${ }^{16} \mathrm{On}$ the rise and influence on American politic of the alliance between religious-fundamentalist and antigovernment forces, see Mooney (2005) Phillips (2006), Gelman (2008) and Wuthnow (2012).
} 


\section{Innovation and Religiosity Across Countries and States}

\subsection{Cross-Country Patterns}

We use international data to analyze the relationship between religiosity and innovativeness, both in raw form and controlling for the standard determinants of technological innovation used in the empirical literature. To our knowledge, these are entirely new analyses and findings.

We use two measures of religiosity, taken from Barro and McCleary (2003b) and corresponding respectively to the answers to the World Values Survey (WVS) questions: (i) "Independently of whether you go to church or not, would you say you are: a religious person, not a religious person, a convinced atheist, don't know", and: (ii) "Do you believe in God? - Yes, No, Don't Know". These variables are scaled to [0,1], corresponding to the shares of people who consider themselves religious, or believe in God; their sample correlation is 0.8 ${ }^{17}$

To measure innovation, we use (log-) patents per capita. The patent counts, taken from the World Intellectual Policy Organization (WIPO), are total patent applications filed in a country by both residents and foreigners (using only residents leads to similar results). They are measured in the same years as the religion data, namely 1980, 1990, 1995, 2000, as are the control variables described below.

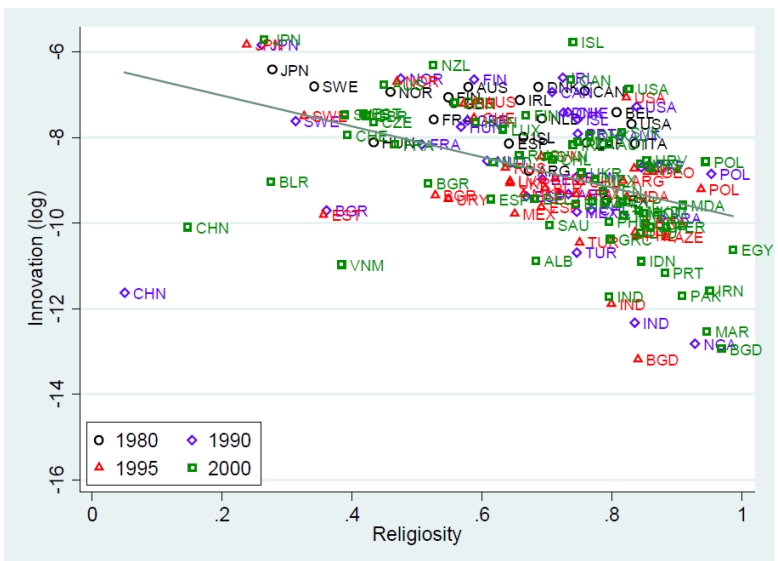

Figure 1

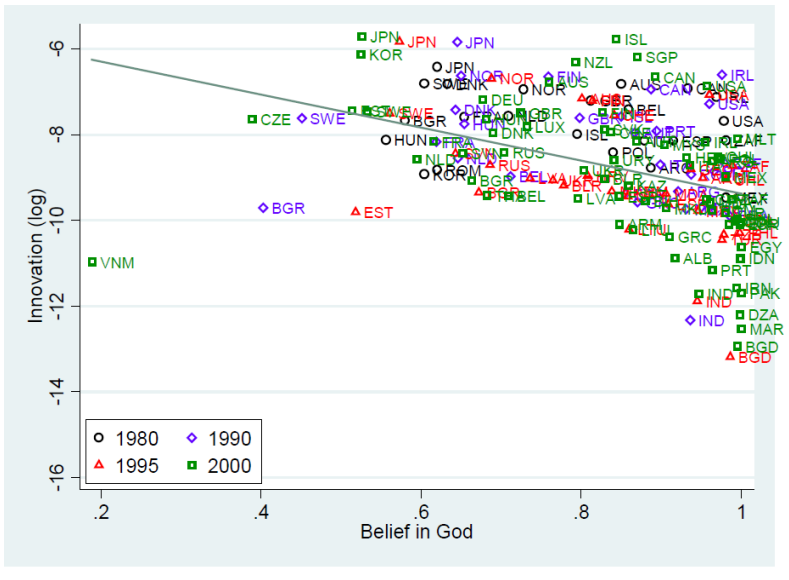

Figure 2

Figures 1 and 2 report the basic scatterplot between national measures of religiosity and innovation: a strong negative relationship is clearly apparent in both cases. Columns 1 and 2 of Table 1 report the regression estimates of these relationships.

\footnotetext{
${ }^{17}$ Barro and McCleary's dataset uses four waves of the World Value Survey (WVS), from 1980 to 2000. They complete this data (corresponding to about $95 \%$ of our sample) by using the International Social Survey Programme (ISSP, 1990-93 and 1998-2000) and the Gallup Millennium Survey (GMS, 1999). Our results are robust to: (i) using as alternative measures from the WVS "Importance of religion in your life" and "Importance of God in your life"; (ii) incorporating the 2005 WVS data, available for all but the "Belief in God" question.
} 


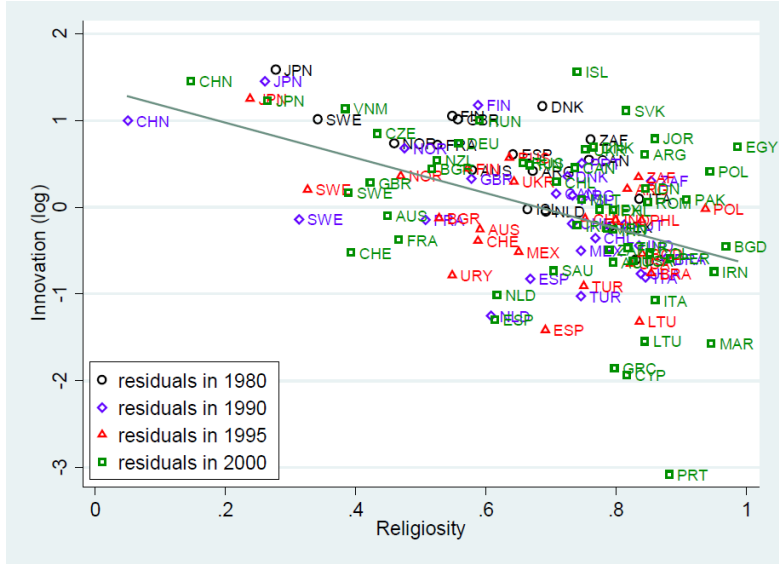

Figure 3

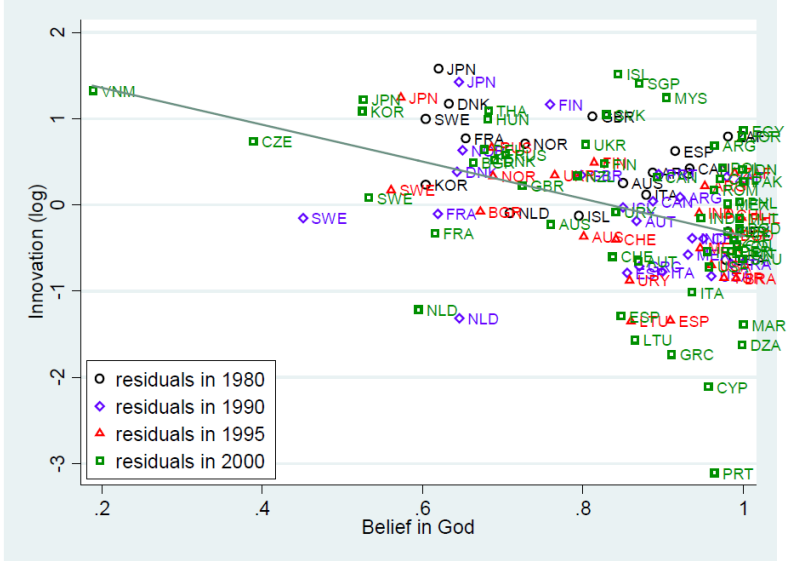

Figure 4

We next include a religious-freedom index (Norris and Inglehart (2011)), since such a variable -doctrinal adaptability - also plays an important role in our model, and control for the main variables typically used as regressors in empirical work on innovation: (i) the level of economic development, measured by (log) GDP per capita, from the World Development Indicators; (ii) log-population (from the World Development Indicators), to take into account possible scale effects in the process of innovation; (iii) the protection of intellectual property, as measured by Park's (2008) index of patent rights; (iv) years of tertiary schooling, from Barro and Lee (2013); (v) the net inflow of foreign direct investment as a percentage of GDP, taken from the WDI. Figures 3 and 4 display the scatterplots of each measure of religiosity with the residuals obtained from regressing innovation on these six variables; Columns 3 and 4 of Table 1 report the corresponding regressions. The strong negative relationship found in the raw data is clearly confirmed. The estimation results also show the role played by religious freedom, which as shall see is also in line with our model 18

A number of robustness checks leave the key findings unchanged. Columns 5-6 add year fixed effects and Columns 7-8 dummy variables for a country's predominant religion, namely that professed by a relative majority of the population (as reported in Norris and Inglehart (2011), based on the CIA World Factbook). In all cases, religiosity is significantly and negatively associated with innovation per capita, and religious freedom positively. ${ }^{19}$

\footnotetext{
${ }^{18}$ The control variables have the expected sign and are significant (except for intellectual property protection, which is not). GDP per capita, tertiary education and FDI are all negatively correlated with religiosity, explaining why its coefficient falls (though remaining highly significant) when they are included. These effects can be seen as intervening mechanisms fully consistent with our model: high religiosity and the associated restrictions on free inquiry and knowledge flows discourage investment in both human and physical inputs into innovation.

${ }^{19}$ Having a predominant religion is, unsurprisingly, highly correlated with average religiosity. These dummies thus also reduce the latter's (still significant) coefficient as they are in large part capturing the same effect.
} 
Table 1: Religiosity and Innovation: Cross-Country Estimates (OLS)

\begin{tabular}{|c|c|c|c|c|c|c|c|c|}
\hline $\begin{array}{l}\text { Dep. var: } \\
\text { Patents per capita (log) }\end{array}$ & (1) & (2) & (3) & (4) & (5) & (6) & (7) & (8) \\
\hline Religiosity & $\begin{array}{l}-3.584 \\
(1.314)^{* * *}\end{array}$ & & $\begin{array}{l}-2.23 \\
(0.424)^{* * *}\end{array}$ & & $\begin{array}{l}-2.079 \\
(0.449) * * *\end{array}$ & & $\begin{array}{l}-1.478 \\
(0.589)^{* *}\end{array}$ & \\
\hline Belief in God & & $\begin{array}{l}-3.853 \\
(1.235)^{* * *}\end{array}$ & & $\begin{array}{l}-2.444 \\
(0.56)^{* * *}\end{array}$ & & $\begin{array}{l}-2.302 \\
(0.566)^{* * *}\end{array}$ & & $\begin{array}{l}-1.581 \\
(0.66)^{* *}\end{array}$ \\
\hline Religious freedom & & & $\begin{array}{l}0.024 \\
(0.007)^{* * *}\end{array}$ & $\begin{array}{l}0.028 \\
(0.006)^{* * *}\end{array}$ & $\begin{array}{l}0.021 \\
(0.007)^{* * *}\end{array}$ & $\begin{array}{l}0.025 \\
(0.006)^{* * *}\end{array}$ & $\begin{array}{l}0.015 \\
(0.008)^{*}\end{array}$ & $\begin{array}{l}0.021 \\
(0.008)^{* * *}\end{array}$ \\
\hline GDP per capita (log) & & & $\begin{array}{l}1.074 \\
(0.1)^{* * *}\end{array}$ & $\begin{array}{l}1.199 \\
(0.107)^{* * *}\end{array}$ & $\begin{array}{l}0.928 \\
(0.106)^{* * *}\end{array}$ & $\begin{array}{l}1.114 \\
(0.116)^{* * *}\end{array}$ & $\begin{array}{l}0.909 \\
(0.133)^{* * *}\end{array}$ & $\begin{array}{l}1.071 \\
(0.138) * * *\end{array}$ \\
\hline Population (log) & & & $\begin{array}{l}-0.135 \\
(0.062)^{* *}\end{array}$ & $\begin{array}{l}-0.09 \\
(0.071)\end{array}$ & $\begin{array}{l}-0.141 \\
(0.059)^{* *}\end{array}$ & $\begin{array}{l}-0.097 \\
(0.068)\end{array}$ & $\begin{array}{l}-0.144 \\
(0.059)^{* *}\end{array}$ & $\begin{array}{l}-0.137 \\
(0.061)^{* *}\end{array}$ \\
\hline Protection intellectual properts & & & $\begin{array}{l}-0.013 \\
(0.095)\end{array}$ & $\begin{array}{l}-0.11 \\
(0.109)\end{array}$ & $\begin{array}{l}0.116 \\
(0.104)\end{array}$ & $\begin{array}{l}-0.048 \\
(0.114)\end{array}$ & $\begin{array}{l}0.102 \\
(0.103)\end{array}$ & $\begin{array}{l}-0.001 \\
(0.108)\end{array}$ \\
\hline Tertiary education (years) & & & $\begin{array}{l}0.791 \\
(0.25)^{* * *}\end{array}$ & $\begin{array}{l}0.873 \\
(0.277)^{* * *}\end{array}$ & $\begin{array}{l}0.985 \\
(0.253)^{* * *}\end{array}$ & $\begin{array}{l}1.006 \\
(0.288)^{* * *}\end{array}$ & $\begin{array}{l}1.013 \\
(0.28)^{* * *}\end{array}$ & $\begin{array}{l}1.043 \\
(0.328)^{* * *}\end{array}$ \\
\hline Foreign direct investment & & & $\begin{array}{l}-0.056 \\
(0.016)^{* * *}\end{array}$ & $\begin{array}{l}-0.041 \\
(0.02)^{* *}\end{array}$ & $\begin{array}{l}-0.043 \\
(0.022)^{* *}\end{array}$ & $\begin{array}{l}-0.036 \\
(0.023)\end{array}$ & $\begin{array}{l}-0.039 \\
(0.017)^{* *}\end{array}$ & $\begin{array}{l}-0.034 \\
(0.018)^{*}\end{array}$ \\
\hline Years fixed effects & & & & & YES & YES & YES & YES \\
\hline Predominant religion & & & & & & & YES & YES \\
\hline Observations & 146 & 151 & 115 & 116 & 115 & 116 & 115 & 116 \\
\hline$R$-squared & 0.184 & 0.165 & 0.815 & 0.797 & 0.834 & 0.809 & 0.85 & 0.832 \\
\hline
\end{tabular}

Notes: Standard errors are clustered by country. Predominant religion includes the following religions: Protestant, Catholic, Muslim, Orthodox. *Significant at $10 \%$; * significant at $5 \%$; *** significant at $1 \%$.

\subsection{The United States}

We now carry out a similar investigation across U.S. states. This is instructive for several reasons. First, it keeps constant a host of political, historical and institutional factors that vary significantly across countries. Second, the United States is a scientific leader in many domains, but also the advanced country with a long -and recently intensifying- history of clashes between politicized religious interests and science. We mentioned earlier several important cases of "blocking" affecting scientific education, research, and public policy at the national and, especially, local levels. It is therefore important to understand whether and how religiosity and innovation covary across the major political decision units within the country, namely the States. Finally, like the cross-country patterns identified above, this question and the findings it leads to are novel to both the innovation and religion literatures. 


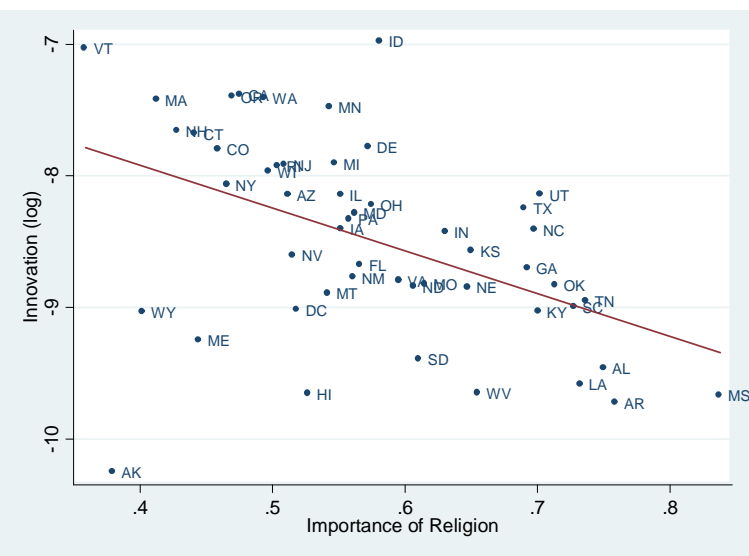

Figure 5

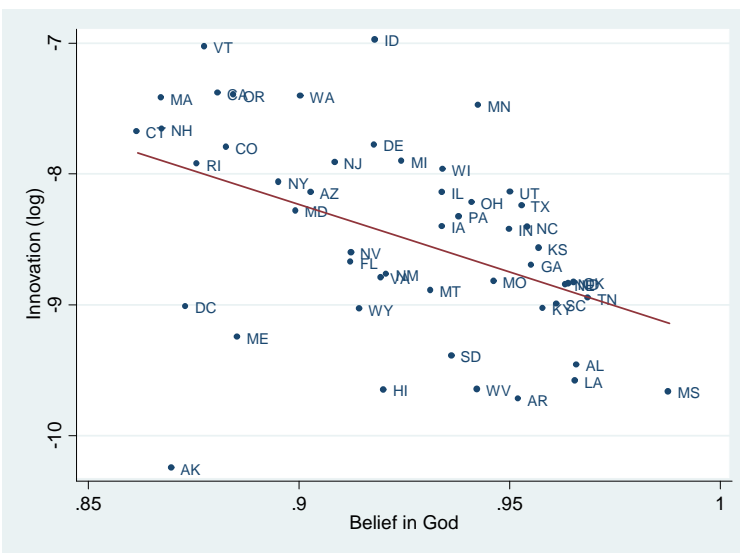

Figure 6

The measures of religiosity are constructed from the 2008 Religious Landscape Survey, conducted by the Pew Forum on Religion and Public Life 20 The questions asked were: (i) "How important is religion in your life -very important, somewhat important, not too important, or not at all important?"; (ii) "Do you believe in God or a universal spirit -yes, no, other, don't know/refused?" Our first index, which we call Importance of Religion, is the share of individuals who answered "very important" to question (i). Our second measure, Belief in God, is the share who answered "Yes" to question (ii). The correlation between them is 0.82 . Innovation is again measured by (log) patents per capita, defined as the ratio between the total number of patents submitted by State residents to the U.S. Patent and Trademark Office and the State's population, both taken in 2007.

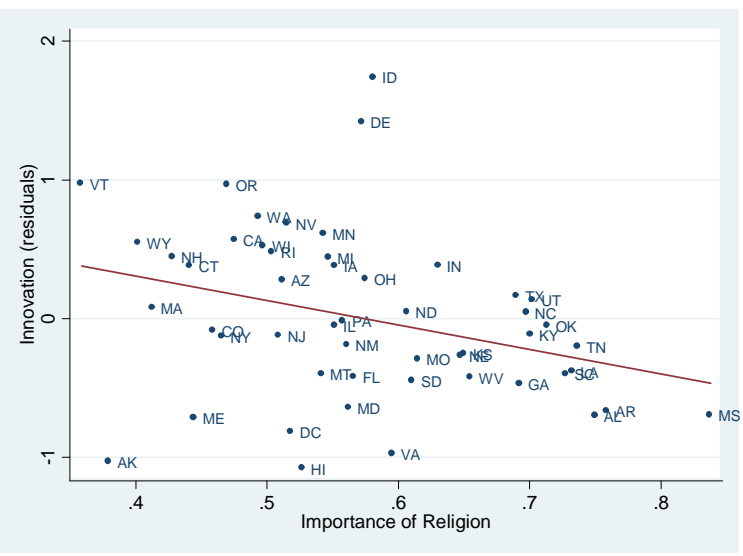

Figure 7

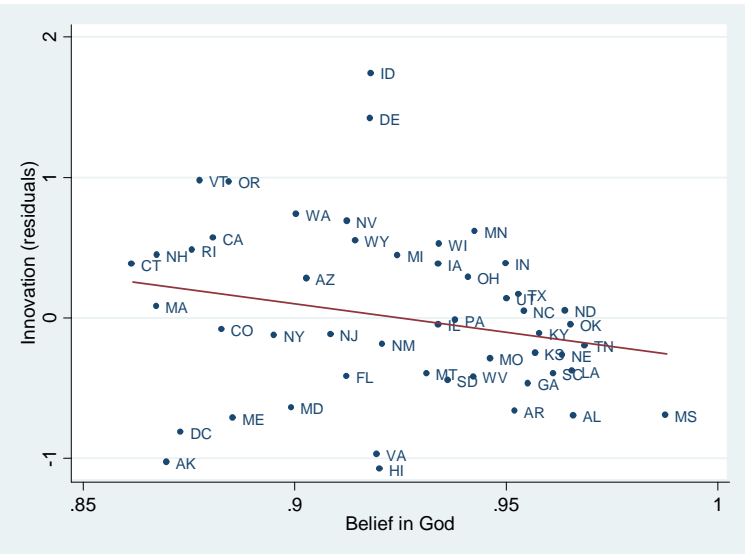

Figure 8

\footnotetext{
${ }^{20} \mathrm{~A}$ representative sample of 35,556 adults living in the continental states was surveyed in the summer of 2007, and supplemental samples of 200 adults living in Alaska and 201 living in Hawaii in the spring of 2008.
} 
Table 2: Religiosity and Innovation in the US: Cross-State Estimates (OLS)

\begin{tabular}{|c|c|c|c|c|c|c|}
\hline $\begin{array}{l}\text { Dep. var: } \\
\text { Patents per capita (log) }\end{array}$ & (1) & (2) & (3) & (4) & (5) & (6) \\
\hline Importance of religion & $\begin{array}{l}-3.245 \\
(1.064)^{* * *}\end{array}$ & & $\begin{array}{l}-2.803 \\
(0.947)^{* * *}\end{array}$ & & $\begin{array}{l}-3.922 \\
(0.737)^{* * *}\end{array}$ & \\
\hline Belief in God & & $\begin{array}{l}-10.324 \\
(3.289)^{* * *}\end{array}$ & & $\begin{array}{l}-7.766 \\
(3.861)^{* *}\end{array}$ & & $\begin{array}{l}-11.238 \\
(3.275)^{* * *}\end{array}$ \\
\hline GSP per capita (log) & & & $\frac{-1.112}{(0.607)^{*}}$ & $\begin{array}{l}-1.104 \\
(0.64)^{*}\end{array}$ & $\begin{array}{l}-0.503 \\
(0.513)\end{array}$ & $\begin{array}{l}-0.561 \\
(0.62)\end{array}$ \\
\hline Population (log) & & & $\begin{array}{l}0.23 \\
(0.078)^{* * *}\end{array}$ & $\begin{array}{l}0.21 \\
(0.079) * *\end{array}$ & $\begin{array}{l}0.185 \\
(0.079) * *\end{array}$ & $\begin{array}{l}0.166 \\
(0.083)^{*}\end{array}$ \\
\hline Tertiary education & & & $\begin{array}{l}0.071 \\
(0.027)^{* *}\end{array}$ & $\begin{array}{l}0.072 \\
(0.032)^{* *}\end{array}$ & $\begin{array}{l}0.028 \\
(0.021)\end{array}$ & $\begin{array}{l}0.031 \\
(0.03)\end{array}$ \\
\hline Foreign direct investment & & & & & $\begin{array}{l}-29.877 \\
(5.73)^{* * *}\end{array}$ & $\begin{array}{l}-26.677 \\
(6.716)^{* * *}\end{array}$ \\
\hline Observations & 51 & 51 & 51 & 51 & 51 & 51 \\
\hline$R$-squared & 0.222 & 0.203 & 0.475 & 0.43 & 0.597 & 0.523 \\
\hline
\end{tabular}

A strong negative relationship between religiosity and innovation is again evident on Figures 5 and 6 , as well from the estimates reported in Columns 1 and 2 of Table 2.

As in the cross-country analysis, we next control for: (i) the (log) Gross State Product per capita; (ii) the (log) population of the State; (iii) the level of tertiary education, measured here by the share of population over 25 with at least a Bachelor's degree. All variables refer to 2007 and are taken from the Indiana Business Research Center at Indiana University. Figures 7 and 8 display the scatterplots of each measure of religiosity with the residuals obtained from regressing innovation on the set of control variables. The corresponding regressions are reported in Columns 3 and 4 of Table 2. In both cases, the strong negative relationship displayed in the raw data is confirmed ${ }^{21}$ Innovation, unconditional or conditional, is especially low in the "Bible Belt" states, but the negative association holds throughout the sample.

Naturally, neither the cross-country nor the cross-state regressions allow definite causal inferences to be drawn. The controls used eliminate some first-order sources of potential misspecification, but only instrumental variables or natural experiments would allow for proper identification. While this may be a route worth pursuing in future work, the purpose of the empirical exercises carried out here is different: to bring to light a rather striking "new" fact that strengthens / adds to the need for or a formal analysis of the coevolution of science and religiosity. In the framework we develop, causality actually goes both ways, leading societies to different long-term regimes (depending on initial conditions and historical accidents), which is consistent with the stable cross-sectional patterns found in the data.

\footnotetext{
${ }^{21}$ Adding FDI inflows (from the BEA) as a share of GSP leaves the results unchanged (Columns 5-6), as does running the unconditional regression of Columns 1-2 on the same sample as the conditional ones.
} 


\section{The Model}

\subsection{Agents}

Preferences and endowments. We consider an economy in discrete time, populated by nonoverlapping generations of agents living for two periods: youth $(t$ even $)$ and old age $(t+1$ odd). There is no population growth. Each generation is formed by a continuum of riskneutral individuals $i \in[0,1]$ with preferences

$$
U_{t}^{i}=\mathbb{E}_{t}\left[c_{t}^{i}+c_{t+1}^{i}+\beta^{i} b_{t+1} G_{t+1}\right]
$$

where $\left(c_{t}^{i}, c_{t+1}^{i}\right)$ denote agent $i$ 's post-tax-and-transfer consumption levels while $\beta^{i} b_{t+1} G_{t+1}$ is the utility which he derives (in old age only, for simplicity) from organized religion, as follows. A fraction $1-r$ of agents are non-religious or "secular" and thus have $\beta^{i}=0$, whereas $\beta^{i}=1$ for "religious" individuals, who are in the majority: $r>1 / 2$. While the distribution of types is fixed, the intensity of religious agents' beliefs during their lifetimes, $\left(b_{t}, b_{t+1}\right)$, will be endogenous. In old age, beliefs are complementary with a "religious public good" $G_{t+1}$ such as sanctuaries (churches, temples, mosques) and priests who perform rituals, offer spiritual help, etc. The uncertainty at date $t$ concerns next period's levels of TFP and religiosity, which will depend on the occurrence, nature and implementation of scientific discoveries.

For both simplicity and realism, we shall model faith not as a probability distribution over some state of the (after)world that is updated in a Bayesian manner, but as a durable stock of "religious capital" $b_{t}$ that may be eroded by certain shocks -especially, scientific news- and augmented by others, as detailed in the next subsection 22

For the moment we take agents to differ only in their attitudes or propensities toward religion, $\beta^{i}=0,1$. Thus all have the same income, normalized to the economy's total factor productivity, denoted $\left(a_{t}, a_{t+1}\right)$ in each period of their life. All real magnitudes such as $c_{t}^{i}, c_{t+1}^{i}, G_{t+1}$, etc., will be measured in units of contemporary TFP.

Taxes and public expenditures. Given a linear income tax rate $\tau$, government revenues (per unit of TFP) are equal to $R(\tau)$, with the following properties:

Assumption $1: R(\tau)$ is $\mathcal{C}^{3}$ and strictly quasiconcave, with $R(0)=0, R^{\prime}(0)=1$ and $R^{\prime}(\hat{\tau})=$ 0 , where $\hat{\tau}$ is the revenue-maximizing tax rate. Furthermore $R^{\prime \prime \prime}(\tau) \leq 0$ for all $\tau \in[0, \hat{\tau}]$.

Religious agents are the most numerous and thus always control the state (whether through the sword or the ballot box), choosing the tax rates $\left(\tau_{t}, \tau_{t+1}\right)$ levied on agents' incomes as well

\footnotetext{
${ }^{22}$ For explicit models of religious beliefs as probabilistic beliefs responding to new information, see Bénabou and Tirole (2006) and Levy and Razin (2013).
} 
as how to allocate spending ${ }^{23}$ In the second period of life, agents potentially value two types of public expenditures. The first one is the religious public good $G_{t+1}$, which can be provided either directly (state religion) or through tax exemptions, subsidies and other advantages conceded to the religious sector to help sustain its activities. For expositional clarity we shall treat $G_{t+1}$ as directly financed from government revenues, but other channels of subsidization are equivalent. What is key is that only part of the population benefits from it, so that it involves a form of redistribution from the secular to the religious ${ }^{24}$ In contrast, the second type of public expenditures, denoted $T_{t+1}$, is valued equally by those with $\beta^{i}=1$ and $\beta^{i}=0$. These are standard public goods and services such as infrastructure, safety, basic education, etc. Alternatively, $T_{t+1}$ may correspond to lump-sum transfers (e.g., pensions), and we shall also refer to it as such in anticipation of Section 6, where it will be demanded by the poor but not by the rich (thus introducing a second dimension of political conflict). A unit of $T_{t+1}$ is worth $\nu>1$ units of numeraire-good consumption to old agents, so that the net consumption levels of generation $t$ are

$$
c_{t}^{i}=1-\tau_{t} \text { and } c_{t+1}^{i}=1-\tau_{t+1}+\nu T_{t+1}
$$

During youth (period $t$ ) there is no public-goods consumption. Instead, the state's only decision, $\chi_{t} \in\{0,1\}$, is whether or not to invest resources in a control and repression apparatus designed to block the diffusion of any new ideas deemed sacrilegious and dangerous to the faith. The technology and incentives for blocking are described below; denoting by $\varphi_{t}$ the direct resource cost required to set up a repressive apparatus, we can already write the (TFPnormalized) government's budget constraints as

$$
\chi_{t} \varphi_{t} \leq R\left(\tau_{t}\right) \quad \text { and } \quad T_{t+1}+G_{t+1} \leq R\left(\tau_{t+1}\right)
$$

\subsection{Discoveries, Productivity Growth, and Blocking}

Innovations. Scientific discoveries occur, with some exogenous Poisson arrival rate $\lambda$, during the first subperiod in the life-cycle of each generation 25 If allowed to diffuse widely they will produce, at the start of the second subperiod, advances in practical knowledge and technology that raise TFP from $a_{t}$ to $a_{t+1}=(1+\gamma) a_{t}$. Besides shifting out the production possibility

\footnotetext{
${ }^{23}$ This will no longer be the case when there are also income differences between agents. Note also that the political system need not be democratic: group sizes are to be understood as power-weighted, and outcomes may be determined through violent conflict (e.g., the larger military force wins) rather than voting.

${ }^{24}$ It could even be that everyone benefits from $G_{t+1}$, or from $G_{t+1} \int b_{t+1}^{i} d i$, for instance if religiosity has positive spillovers, as long as some citizens benefit more than others. On intergroup conflict over the mix of public goods see, e.g., Alesina et al. (1999), Luttmer (2001) and Alesina and La Ferrara (2005).

${ }^{25}$ It would be easy to endogenize $\lambda$. The risk of having their discoveries blocked would then reduce scientists' incentives to do research, thus reinforcing the adverse impact of blocking policies on knowledge and TFP growth.
} 
frontier, scientific advances can also have major effects on religious beliefs, as discussed earlier. In particular, new scientific findings that contradict the professed doctrine and sacred texts' statements about the natural world (from the origins of the universe or mankind to the determinants of moral behavior or the cognitive abilities of women) tend to shake and weaken the faith of religious agents. Not all discoveries have such effects, of course, and we accordingly distinguish between two main types:

- A fraction $p_{N}$ of them are belief-neutral $(B N)$, meaning that they have no impact on $b$.

- A fraction $p_{R}=1-p_{N}$ are belief-eroding $(B R)$ : if they diffuse widely in the population, they reduce the stock of religious capital from $b_{t}$ to $b_{t+1}=(1-\delta) b_{t}$.

Later on we shall also allow for belief-enhancing $(B E)$ shocks, which increase $b$. While religiosity occasionally benefits from certain technological innovations (e.g., televised evangelism, videotapes), one is hard-pressed to think of cases where a discovery in basic science had such an effect. Increases in religiosity generally arise instead from very different sources, such as immigration, cultural change, or increased demand for reassurance, divine forgiveness and salvation following major disasters (Great Plague, famine, war, humiliating defeat, etc.) ${ }^{26}$ We shall therefore introduce belief-enhancing shocks only later on, as events occurring between rather than within generations, independently of scientific discoveries and political developments ${ }^{27}$ For the moment, we abstract from them.

Blocking. If allowed to disseminate, a $B R$ discovery will reduce the utility $b_{t+1} G_{t+1}$ of religious agents, through both its direct erosion of their faith and the ensuing reduction in $G_{t+1}$. If this loss more than offsets the gains to be reaped from higher TFP, the government, representing here the religious majority, may want to block -censor, deny, restrict access to, etc.- the new knowledge. We assume that blocking can be targeted at $B R$ innovations and that it is then fully effective, so that the beliefs of religious citizens (and of the government representing them) remain unchanged, as does TFP: $a_{t+1}=a_{t}$ and $b_{t+1}=b_{t}{ }^{28}$

Censoring "dangerous ideas" emanating from scientific inquiry and methodology involves two types of costs. First are the foregone TFP gains that could be reaped from applications of

\footnotetext{
${ }^{26}$ For instance, Chaney [2013] documents how, in ancient Egypt, exceptionally low or high Nile floods led to an increased demand for religious goods and services provided by the priesthood and a concomitant strengthening of the latter's political power.

${ }^{27}$ Besides realism, the main purpose is simplification, as this also allows us to abstract from the issue of a (secular) government blocking religiosity-enhancing ideas and influences. While this certainly occurred in Communist countries, and can be incorporated in an extension of the model, it is outside our present focus. In particular, such shocks typically have no direct connection to scientific and technological progress, and their other potential effects on TFP are generally ambiguous -e.g., they can lead to more "moral" behavior, but also to religious strife and violent conflict.

${ }^{28}$ This also means that innovations that are blocked at date $t$ are lost forever, unless independently rediscovered or reinvented at some future date. In practice there will be some "leakage", so that blocking only slows down diffusion -but possibly for a long time, as with the Inquisition, the printing press and stem cell research.
} 
that knowledge. Second is the direct cost required to set up, in advance, a repressive apparatus that will stand ready to quash such ideas, or more generally impede their diffusion. Examples include functionaries devoted to monitoring and repressing "heretical" or "blasphemous" notions and their proponents (Inquisition, religious police); enforcing the censorship of school lessons and textbooks, if not banning printing outright; and subsidizing an official or parallel doctrine-friendly "science" (creationism, climate change denial, etc.) 29

Since resources must be committed before knowing what type of discovery (if any) will occur, setting or maintaining a repressive apparatus is a form of investment under uncertainty, paying off (for religious agents) with probability $\lambda p_{R}$. The normalized resource cost $\varphi_{t}$ required is assumed to depend only on society's current level of knowledge and TFP, $a_{t}$ :

$$
\varphi_{t}=\varphi\left(a_{t}\right)
$$

where $\varphi: \mathbb{R}_{+} \rightarrow \mathbb{R}_{+}$is a smooth and strictly increasing function with $\bar{\varphi} \equiv \lim _{a \rightarrow+\infty} \varphi(a)<$ $R(\hat{\tau})$. The fact that $a \varphi(a)$ rises more than proportionately with $a$ captures the idea that new knowledge is, on net, more difficult to contain, repress or counteract in a society that is intellectually and technologically more sophisticated. For instance, the dissemination of information becomes faster and less controllable with the availability of media such as the printing press, radio, TV, fax, the internet, etc. The upper bound on $\varphi$ ensures that repression nonetheless remains a fiscally feasible strategy for the government at any level of $a$.

In contrast to role of the stock of knowledge $a, \varphi_{t}$ is independent of the stock of religious capital, $b$. Indeed the costs (per unit of GDP) of impeding the flow of free information censoring, threatening scientists, controlling the press, etc.- seem fairly independent of the content of that information and of the strength of the beliefs it might impact 30

\subsection{The Church}

In addition to regular citizens and the government, there is also a small (zero-measure) set of agents, drawn from among the religious, who produce no income in either period but may engage in another type of work. Whenever a $B R$ scientific discovery occurs and is allowed to diffuse through society, this player, referred to as the Church or religious sector, can attempt to "repair" the damage done to the faith by the fact that the new knowledge invalidates or

\footnotetext{
${ }^{29}$ We assume that the state's repressive apparatus (or the privately operated but state-subsidized informationgarbling, pseudo-science sector) insulates not only religious citizens, but also the government in office, from learning or properly assimilating $B R$ discoveries. There is thus never any divergence of interest between the religious majority and the government representing them.

${ }^{30}$ More generally, the assumption serves as a neutral benchmark in which two offsetting effects cancel out: (i) more "explosive" and belief-damaging information may be, as such, more costly to block; (ii) more intensely religious citizens and functionaries may be more willing to believe and cooperate with politico-religious authorities proclaiming that heretics or apostates are disseminating sacrilegious lies and frauds.
} 
conflicts with its doctrine. This may occur through internal reform, such as working out and proclaiming a reinterpretation of the sacred texts more compatible with scientific facts. It could also take the form of a major schism or conflictual Reformation, or even the creation of new sects and religions by competing faith entrepreneurs. For simplicity we shall treat organized religion as a single actor, with preferences given by

$$
\mathbb{E}_{t}\left[b_{t+1} G_{t+1}-\rho_{t} \eta b_{t}\right]
$$

The Church thus cares primarily about the strength of beliefs $b_{t+1}$ in the religious population and the provision of complementary goods and services, $G_{t+1}$, which together generate benefits $b_{t+1} G_{t+1}$ for the faithful ${ }^{31}$ The second term in (4) reflects the effort costs involved if, following the diffusion of a $B R$ innovation, it undertakes the work required to prevent religious capital from eroding. This decision is denoted by $\rho_{t} \in\{0,1\}$, and the cost (per unit of TFP) of attempting repair is $\eta b_{t}$, where $\eta$ is a constant parameter and $b_{t}$ reflects the fact that a larger stock of religious capital (e.g., more devout beliefs) is more expensive to adapt and reform ${ }^{32}$ Consistent with the empirical results of Section 3.1, a key determinant of $\eta$ is religious freedom, namely the ease with which heterodox interpretations, new sects or cults are allowed to develop, and people allowed to switch affiliation 33

Repairing can only be attempted after the new discovery diffuses, as the revision in the doctrine must be appropriately tailored to it. It succeeds with probability $q \in[0,1]$, in which case the damage done by the innovation to the beliefs of the faithful is completely undone (for simplicity), so that $b_{t+1}=b_{t}$. If repairing fails, on the other hand, religious capital is eroded just as as much as if there had been no attempt to preserve it: $b_{t+1}=(1-\delta) b_{t}$. The expectation in (4) reflects the uncertain effectiveness of theological repair work.

\subsection{Timeline}

The timing of events and moves in each generation is illustrated in Figure 5:

\section{- First period ( $t$ even):}

1. The (religious) majority decides whether or not to invest in the capacity to block possible $B R$ innovations: $\chi_{t} \in\{0,1\}$, with corresponding cost $\chi_{t} \varphi\left(a_{t}\right)$, requiring taxes to be set at the level $\tau_{t}$ such that $R\left(\tau_{t}\right)=\chi_{t} \varphi\left(a_{t}\right)$.

\footnotetext{
${ }^{31}$ For our purposes, it does not matter whether the Church altruistically internalizes the spiritual welfare of its brethren or selfishly appropriates rents from it, e.g. by being the main conduit for the delivery of $G_{t+1}$.

${ }^{32}$ The cost is borne only by the Church in the form of costly effort (by priests, monks, etc.) so, unlike the cost of blocking it does not enter into the government's budget constraint.

${ }^{33}$ Other factors include specific "adaptability" features of the dominant religion: whether there are multiple sacred texts or a single one, whether it is / they are said to be written by men or dictated verbatim by God, how specific are the statements they make about the natural world, etc.
} 


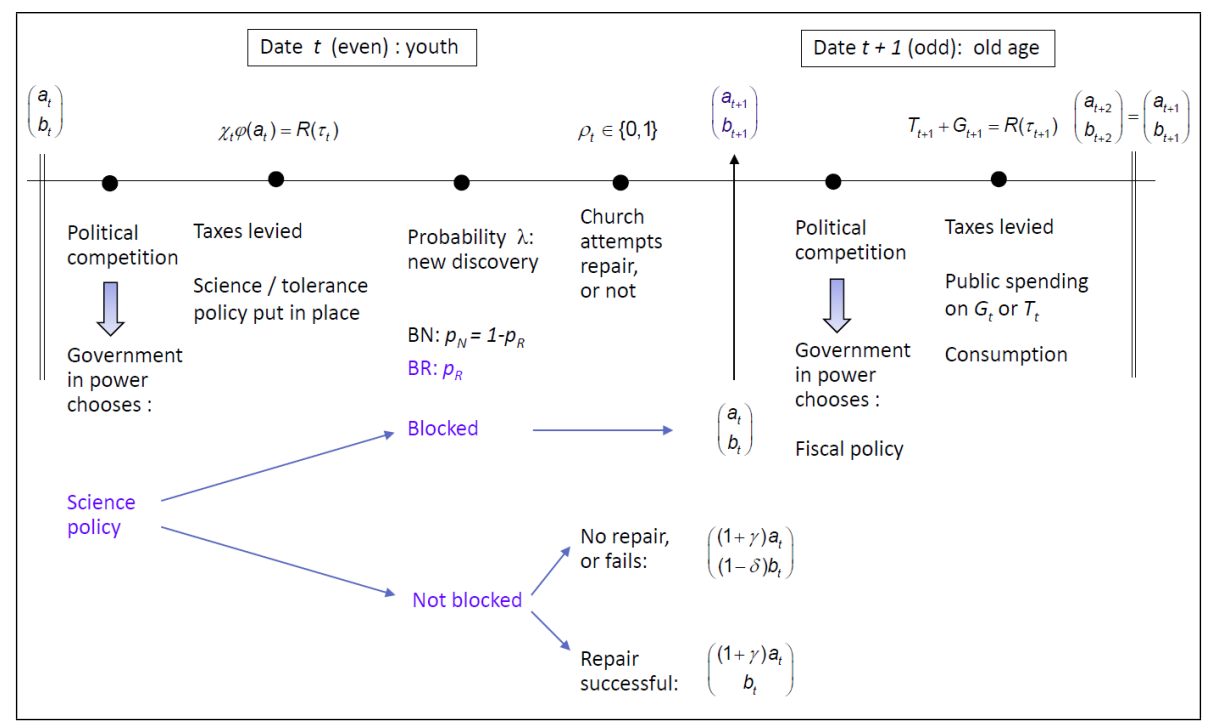

Figure 5: timing of events in each generation

2. With probability $\lambda$, a new discovery is made. If it is belief-neutral or if there is no blocking of belief-eroding ideas, it diffuses and becomes embodied in new technologies, so that $a_{t+1}=(1+\gamma) a_{t}$. If it is repressed, $a_{t+1}=a_{t}$.

3. If a $B R$ discovery occurred and the state allowed it to diffuse, the Church decides whether to repair the resulting damage to religious capital. Such attempts involve a cost of $\eta b_{t}$ and succeed with probability $q$, in which case $b_{t+1}=b_{t}$. If there is no attempt or if it fails, beliefs erode to $b_{t+1}=(1-\delta) b_{t}$.

- Second period $(t+1$ odd $)$ :

1. Given the realized values of $\left(a_{t+1}, b_{t+1}\right)$, the religious majority chooses fiscal and publicspending policy, $\left(\tau_{t+1}, T_{t+1}, G_{t+1}\right)$, subject to the government budget constraint.

2. The political stage game ends, a new generation is born at the beginning of (even) period $t+2$ and the same game is played again with the inherited stocks of knowledge and religiosity $\left(a_{t+2}, b_{t+2}\right)=\left(a_{t+1}, b_{t+1}\right)$.

Equilibrium. We focus on pure strategy subgame-perfect equilibria (SPE). Because there are no individual-level links across generations such as altruism or asset values, each cohort's timehorizon is limited to its two-period lifespan. The SPE's of the whole dynamic game therefore correspond to sequences of SPE's of the basic three-stage game played within each generation, linked through the evolution of the aggregate state variables $\left(a_{t}, b_{t}\right)$. 


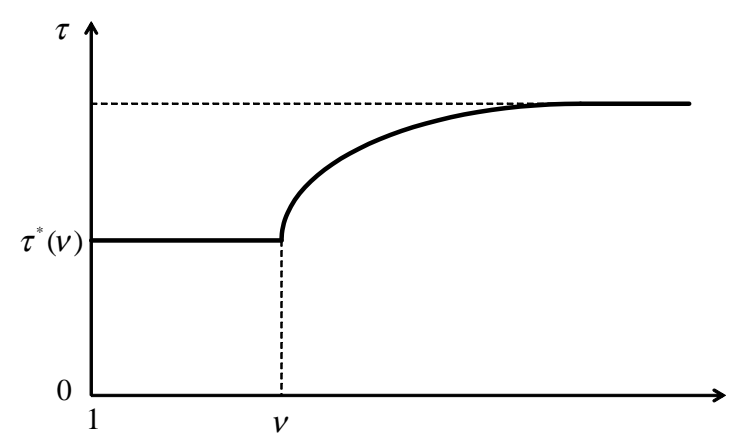

Figure 6: equilibrium tax rate as a function of religiosity

\section{Political Equilibrium}

\subsection{Fiscal Policy (Second Subperiod)}

The religious majority sets taxes and spending as follows:

$$
\max _{\tau \leq \hat{\tau}}\{1-\tau+\nu[R(\tau)-G]+b G \mid 0 \leq \tau \leq \hat{\tau}, G \leq R(\tau)]
$$

When beliefs are weak, $b<\nu$, secular public goods are valued more than religious ones, so $G=0$ and all revenue is spent on $T$. Furthermore, given the properties of $R(\cdot)$, the first-order condition uniquely yields $\tau=\tau^{*}(\nu)$, where

$$
\tau^{*}(x) \equiv\left(R^{\prime}\right)^{-1}(1 / x)
$$

defines a strictly increasing function $\tau^{*}: \mathbb{R}_{+} \longmapsto[0, \hat{\tau}]$. When beliefs are strong enough, $b \geq \nu$, all revenues are spent instead on $G: T=0$ and $\tau=\tau^{*}(b)$ Figure 6 displays the optimal tax rate as a function of $b$.

Proposition 1 The fiscal policy implemented in the second period is the following:

(1) If $b<\nu$, then $(\tau, T, G)=\left(\tau^{*}(\nu), R\left(\tau^{*}(\nu)\right), 0\right)$, with $\tau^{*}(\nu)$ and $R\left(\tau^{*}(\nu)\right)$ increasing in $\nu$.

(2) If $b \geq \nu$, then $(\tau, T, G)=\left(\tau^{*}(b), 0, R\left(\tau^{*}(b)\right)\right)$, with $\tau^{*}(b)$ and $R\left(\tau^{*}(b)\right)$ increasing in $b$ until $\tau^{*}(b)$ reaches $\hat{\tau}$ and constant afterwards.

For any $b$ and $\nu$, we shall denote second-period equilibrium spending on $G$ as

$$
G(b, \nu) \equiv\left\{\begin{array}{ll}
0 & \text { if } b<\nu \\
R\left(\tau^{*}(b)\right) & \text { if } b \geq \nu
\end{array} .\right.
$$

\footnotetext{
${ }^{34}$ When $b=\nu$ we break the indifference in favor of $G$, without loss of generality.
} 


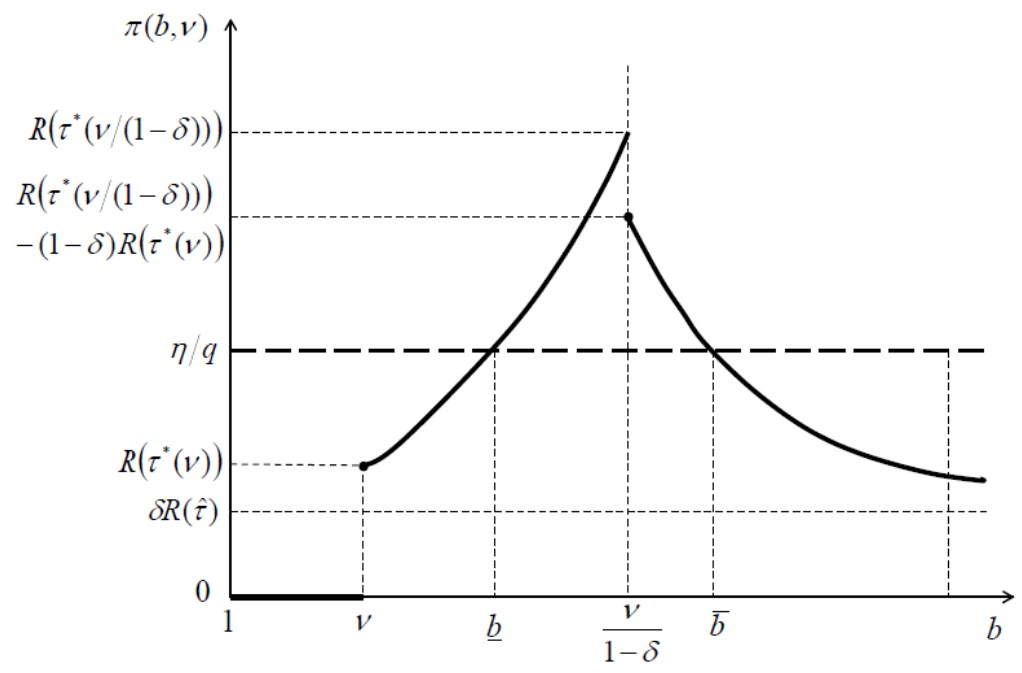

Figure 7: Church's expected value of repairing beliefs

\subsection{Church's Belief-Repairing Strategy}

Since working to repair the damage done to $b$ by a $B R$ innovation succeeds with probability $q$, the Church attempts it if and only if

$$
q b G(b, \nu)+(1-q)(1-\delta) b G((1-\delta) b, \nu)-\eta b \geq(1-\delta) b G((1-\delta) b, \nu) .
$$

Denote the payoff from successful repair, normalized by both TFP $a$ and religiosity $b$, as

$$
\pi(b, \nu) \equiv G(b, \nu)-(1-\delta) G((1-\delta) b, \nu)
$$

The Church therefore attempts repairs when

$$
\pi(b, \nu) \geq \eta / q
$$

The following result, illustrated in Figure 7, shows that $\pi(\cdot, \nu)$ is strictly single-peaked.

Lemma 1 The function $\pi(b, \nu)$ equals 0 for $b<\nu$, then jumps up to $\pi(\nu, \nu)=R\left(\tau^{*}(\nu)\right)$. It is continuous and strictly increasing on $[\nu, \nu /(1-\delta))$, then jumps down to $\pi(\nu /(1-\delta), \nu)=$ $R\left(\tau^{*}(\nu /(1-\delta))\right)-(1-\delta) R\left(\tau^{*}(\nu)\right)$. Finally, it is continuous and strictly decreasing on $[\nu /(1-$ $\delta),+\infty)$, with $\lim _{b \rightarrow+\infty} \pi(b, \nu)=\delta R(\hat{\tau})>0$.

These properties imply that, for all $y$ in $(\delta R(\hat{\tau}), \pi(\nu /(1-\delta), \nu))$, the set of $b$ 's where $\pi(b, \nu) \geq y$ is an interval $\left[b^{-}(\nu ; y), b^{+}(\nu ; y)\right]$, with $\nu \leq b^{-}(\nu ; y)<\nu /(1-\delta)<b^{+}(\nu ; y)$. The following condition then ensures that the repairing region of the state space is non-empty. 
Assumption $2 \delta R(\hat{\tau})<\eta / q<R\left(\tau^{*}(\nu /(1-\delta))\right)-(1-\delta) R\left(\tau^{*}(\nu)\right){ }^{35}$

Defining $\underline{b} \equiv b^{-}(\nu ; \eta / q)$ and $\bar{b} \equiv b^{+}(\nu ; \eta / q)$, we can now fully characterize the optimal (best-response) behavior of the Church.

Proposition 2 There exist a unique $\underline{b}$ and $\bar{b}$, with

$$
\nu \leq \underline{b}<\frac{\nu}{1-\delta}<\bar{b}
$$

such that the Church attempts to repair belief-eroding innovations (not blocked by the state) if and only if $b$ lies in $[\underline{b}, \bar{b}]$.

Intuitively, when religious capital is below $\underline{b}$ it is not worth repairing, given the cost $\eta$. Conversely, when it exceeds a finite threshold $\bar{b}$ there is enough of it (and therefore also enough demand for $G$ ) that the Church can afford to let it depreciate somewhat.

\subsection{State Policy Toward Science (First Subperiod)}

The only decision taken during period $t$ is whether to invest in blocking potential $B R$ discoveries, trading off the option value of preserving religious capital against the foregone TFP gains and the cost of setting up a repressive apparatus.

There are two cases in which the government (religious majority) clearly does not find it optimal to invest in blocking. First, when $b<\nu$ religious agents themselves prefer secular public goods (or transfers) to religious ones, so they set $G=0$ and derive no utility from organized religion $(b G=0)$; this will remain a fortiori true if $b$ falls to $(1-\delta) b$. Second, if the state expects the Church to attempt repair of unblocked $B R$ innovations, and if it has sufficient confidence that it will succeed, it prefers to strategically "take a pass" on blocking and let the Church do the work.

Assumption $3: q \geq 1 /(1+\gamma)$.

This condition, in which both $q$ and the opportunity cost of blocking (foregone productivity gains) enter in an intuitive manner, ensures that the government never finds it optimal to block when $b$ lies in $[\underline{b}, \bar{b}]$ (see Lemma 6 in Appendix 8.2).

We now analyze blocking policy in the remaining two no-repair regions, $b>\bar{b}$ and $\nu \leq b<\underline{b}$. As illustrated in Figure 8, in each case blocking will occur when $\left(a_{t}, b_{t}\right)$ lies above an upwardsloping locus in the state space, meaning that society is sufficiently religious, relative to its state of scientific and technical development. It will be useful to define, for all $u \geq 0$,

\footnotetext{
${ }^{35}$ The interval in which $\eta / q$ must lie is itself always nonempty, as the function $R\left(\tau^{*}(b)\right)-(1-\delta) R\left(\tau^{*}((1-\delta) b)\right)$ is decreasing (see Lemma 1). Even though $q$ will be constrained (see Assumption 3), $\eta$ is not, and therefore $\eta / q$ is unconstrained.
} 


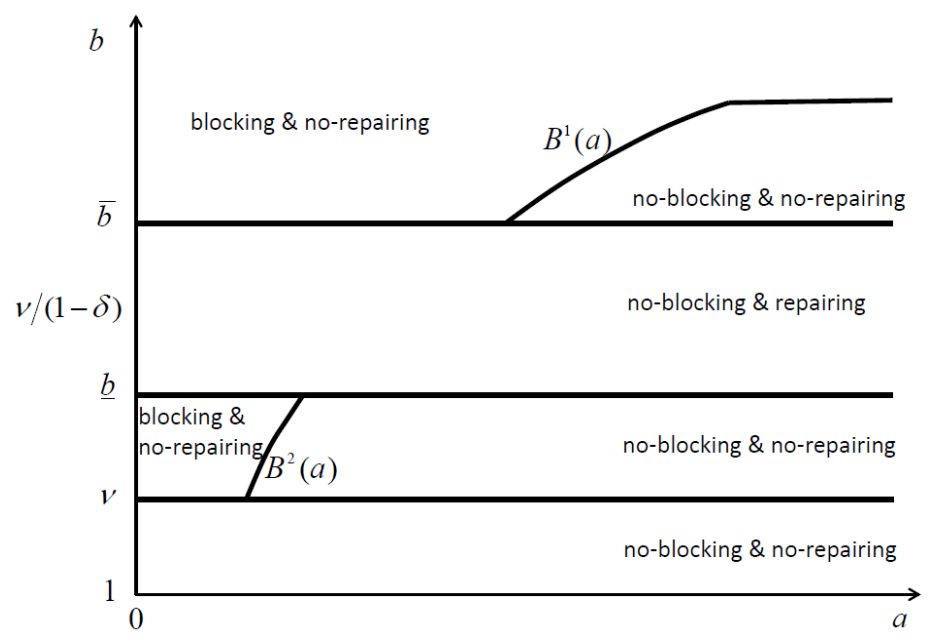

Figure 8: the repairing and blocking regions.

$$
V(u) \equiv 1-\tau^{*}(u)+u R\left(\tau^{*}(u)\right)
$$

corresponding to religious agents' old-age utility when the government finances a public good which they value at $u$ per unit relative to the numeraire, and does so by setting the tax rate at the corresponding optimal level $\tau^{*}(u)$. In equilibrium, $u=\max \{b, \nu\}$ by Proposition 1 .

\subsubsection{Region 1: $\mathrm{b}>\overline{\mathrm{b}}$. No repairing, continued provision of religious public goods}

Recall that blocking $B R$ discoveries requires an ex-ante investment of $\varphi(a)$, which must be financed by a tax rate of $\tau=R^{-1}(\varphi(a))$ on first-period consumption. Beliefs are then fully protected from erosion, so the expected intertemporal utility of the religious majority is

$$
V^{B}(a, b)=1-R^{-1}(\varphi(a))+\left[1-\lambda+\lambda p_{R}+\lambda\left(1-p_{R}\right)(1+\gamma)\right] V(b),
$$

where $V(b)$ is their second-period utility when no new idea is implemented, either because none occurred (probability $1-\lambda$ ) or it was of the $B R$ type and thus blocked (probability $\lambda p_{R}$ ). If a $B N$ innovation occurs, however, it is implemented, raising second-period TFP and utility by a factor of $1+\gamma$, as reflected in (12).

Suppose now that the government foregoes blocking; $B R$ innovations will then also diffuse and raise standards of living, but at the same time erode religious beliefs to $b^{\prime} \equiv(1-\delta) b$, and in this range Church does not repair. Since $b>\bar{b}>\nu /(1-\delta)$, religious capital nonetheless remains high enough that $G\left(b^{\prime}\right)>0$ is chosen over secular spending, so the intertemporal expected utility of religious agents is

$$
V^{N B}(a, b)=1+\left[1-\lambda+\lambda\left(1-p_{R}\right)(1+\gamma)\right] V(b)+\lambda p_{R}(1+\gamma) V\left(b^{\prime}\right)
$$


The government opts for blocking when $V^{B} \geq V^{N B}$, namely

$$
R^{-1}(\varphi(a)) \leq \lambda p_{R}\left[V(b)-(1+\gamma) V\left(b^{\prime}\right)\right] \equiv \Delta^{1}(b)
$$

The left-hand side is the direct cost of the repressive investment, which is increasing in current TFP $a$. The right-hand side is the net expected return: with probability $\lambda p_{R}$ a $B R$ innovation occurs, in which case beliefs are protected from erosion but the productivity gains are foregone. Using (11), this expected return can be rewritten as

$$
\Delta^{1}(b)=\lambda p_{R}\left\{1-\tau^{*}(b)+b R\left(\tau^{*}(b)\right)-(1+\gamma)\left[1-\tau^{*}\left(b^{\prime}\right)+b^{\prime} R\left(\tau^{*}\left(b^{\prime}\right)\right)\right]\right\}
$$

In Appendix 8.3 we show that where $\Delta^{1}(b) \geq 0$, it is strictly increasing in $b$; defining the function $B^{1} \equiv\left(\Delta^{1}\right)^{-1} \circ R^{-1} \circ \varphi$, it follows that:

Proposition 3 For $b>\bar{b}$, the state implements the blocking of $B R$ discoveries if and only if $(a, b)$ lies above the upward-sloping locus $b=B^{1}(a)$.

The assumption that $\varphi \leq \bar{\varphi}$ implies that $B^{1}(a)$ reaches an upper bound and subsequently becomes flat at a finite level of $a$, as illustrated in Figure 8 .

\subsubsection{Region 2: $\nu \leq \mathbf{b}<\underline{b}$. No repairing, no provision of religious public goods}

In this case $b^{\prime}=(1-\delta) b<\nu$ so an unblocked, unrepaired $B R$ discovery damages beliefs sufficiently that religious agents now prefer secular public spending: $G=0$ and $T=R\left(\tau^{*}(\nu)\right)$. Thus, while the value of blocking remains given by $(12)$, the value of not blocking is now

$$
V^{N B}(a, b)=1+\left[1-\lambda+\lambda\left(1-p_{R}\right)(1+\gamma)\right] V(b)+\lambda p_{R}(1+\gamma) V(\nu)
$$

The condition $V^{N B} \leq V^{B}$ therefore becomes

$$
R^{-1}(\varphi(a)) \leq \lambda p_{R}[V(b)-(1+\gamma) V(\nu)] \equiv \Delta^{2}(b) .
$$

Using (11), the right-hand side of (17) can be rewritten as

$$
\Delta^{2}(b)=\lambda p_{R}\left\{1-\tau^{*}(b)+b R\left(\tau^{*}(b)\right)-(1+\gamma)\left[1-\tau^{*}(\nu)+\nu R\left(\tau^{*}(\nu)\right)\right]\right\}
$$

In Appendix 8.3 we show that $\Delta^{2}(b)$ is increasing, hence so is $B^{2} \equiv\left(\Delta^{2}\right)^{-1} \circ R^{-1} \circ \varphi$.

Proposition 4 For $\nu \leq b<\underline{b}$, the state implements the blocking of BR discoveries if and only if $(a, b)$ lies above the upward-sloping locus $b=B^{2}(a)$. 
Figure 8 illustrates the two blocking loci, $B^{i}(a)$ for $i=1,2$, as well as the repairing and non-repairing regions.

\subsection{Dynamics of Scientific Progress and Religiosity}

We have now fully characterized the law of motion of $\left(a_{t}, b_{t}\right)$ within a generation. Between generations, the simplest case is where the young inherit, without change, the finals stocks of knowledge and religiosity of the old: $\left(a_{t+2}, b_{t+2}\right)=\left(a_{t+1}, b_{t+1}\right)$, as indicated in Figure 5. In this simple benchmark, however, religiosity can only decrease or, at best, remain constant. As discussed earlier, in practice there are also periodical events and societal changes than enhance religiosity. Because they are almost never linked to scientific discoveries, we shall take them as exogenous: at the start of each new generation $a_{t+2}=a_{t+1}$, but $b_{t+2}=b_{t+1}$ with probability $1-p_{E}$ and $b_{t+2}=(1+\mu) b_{t+1}$ with probability $p_{E}$, where $\mu>0{ }^{36}$

Figures $9 \mathrm{a}$ and $9 \mathrm{~b}$ respectively show the model's phase dynamics of $\left(a_{t}, b_{t}\right)$ without and with belief-enhancing shocks, in each of the key regions identified by the within-generation equilibrium analysis. While the underlying system of switching stochastic difference equations is too complicated to solve analytically, its key qualitative features are apparent from the graphs and from computing, inside each region, the expected (or average) trajectory of the state variable, which is governed by a simple linear difference equation. We focus on the three main regions of interest.

1. Non-blocking, non-repair "secularization" region: Western Europe, or the United States when $b_{t} / a_{t}$ is relatively low:

$$
\begin{aligned}
\mathbb{E}_{t}\left(a_{t+1}\right) / a_{t} & =1+\lambda \gamma \\
\mathbb{E}_{t}\left(b_{t+1}\right) / b_{t} & =\left(1-\lambda p_{R} \delta\right)\left(1+p_{E} \mu\right) .
\end{aligned}
$$

2. Non-blocking with repair region: United States when $b_{t} / a_{t}$ is moderately high, Singapore ${ }^{37}$

$$
\begin{aligned}
& \mathbb{E}_{t}\left(a_{t+1}\right) / a_{t}=1+\lambda \gamma \\
& \mathbb{E}_{t}\left(b_{t+1}\right) / b_{t}=\left[1-\lambda p_{R}(1-q) \delta\right]\left(1+p_{E} \mu\right) .
\end{aligned}
$$

3. Blocking region: Theocratic regimes (Medieval Europe, Ottoman Empire, Ancient China, Pakistan), United States when $b_{t} / a_{t}$ is very high 38

\footnotetext{
${ }^{36}$ One could also endogenize them. For instance, when the religious sector invests in adaptation following a $B R$ discovery, it may, when successful, do better than just offsetting the damage, i.e. reset to $b_{t+1}=(1+\mu) b_{t}>b_{t}$.

${ }^{37}$ Singapore is another country notable for successfully combining relatively high (and very diverse) religiosity with a strong emphasis on technology and innovation (Pereira (2006)).

${ }^{38}$ There is also a blocking region where $b$ is relatively low but $a$ is even lower, corresponding to a poor society with relatively little organized religion. This state is transient (though potentially long-lasting), as the system will always escape it, evolving into either the "modern-European" or the "American" regime.
} 


$$
\begin{aligned}
\mathbb{E}_{t}\left(a_{t+1}\right) / a_{t} & =1+\lambda\left(1-p_{R}\right) \gamma \\
\mathbb{E}_{t}\left(b_{t+1}\right) / b_{t} & =1+p_{E} \mu .
\end{aligned}
$$

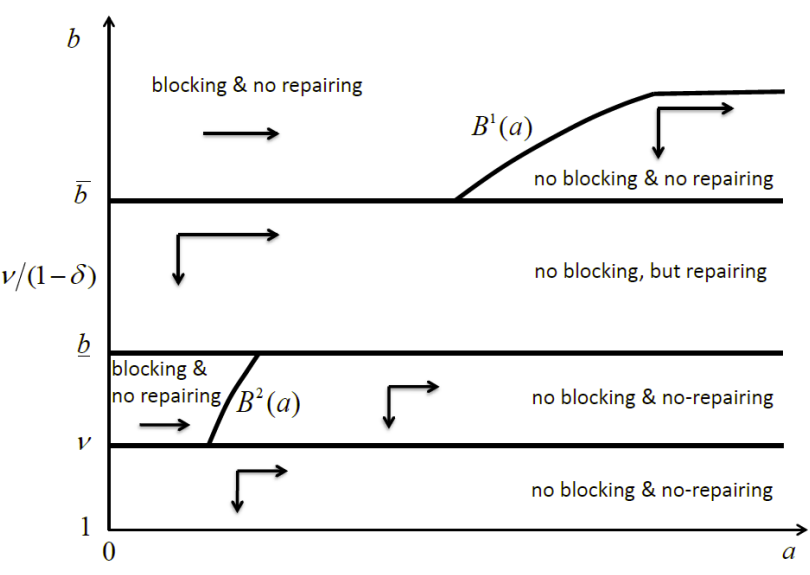

Figure 9a: dynamics without $B E$ shocks

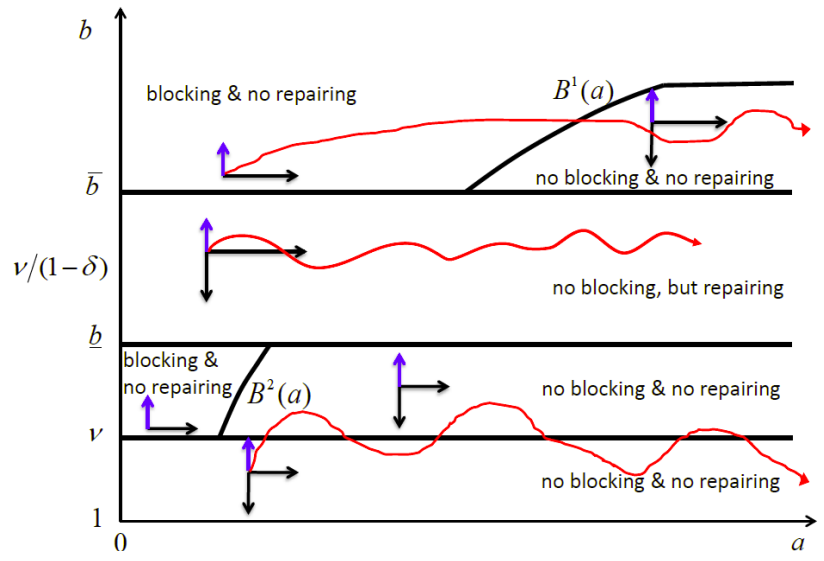

Figure 9b: dynamics with $B E$ shocks

Consider in particular the case where

$$
g_{R}^{E U} \equiv\left(1-\lambda p_{R} \delta\right)\left(1+p_{E} \mu\right)<1 \approx\left[1-\lambda p_{R}(1-q) \delta\right]\left(1+p_{E} \mu\right) \equiv g_{R}^{U S}
$$

"Western Europe" and the "United States" then grow at the same rate $1+\lambda \gamma$ (neither blocks), but in the former there is a downward trend in religiosity (with periodic upward shocks preventing a degenerate long-distribution), whereas in the latter it is mostly offset by the adaptation of the religious sector, resulting in trendless fluctuations or very slow-moving shifts in religiosity (if $g_{R}^{U S} \neq 1$ ). Provided a society is not excessively religious $(b<\bar{b})$, economic growth can thus occur both with and without secularization, as a result of (endogenously) different responses of the religious sector. In the "theocratic" region $b>\bar{b}$, meanwhile, religiosity trends up while knowledge and TFP stagnate, particularly if $\lambda_{R} \approx 1$.

For societies that are close to a boundary between two regimes, finally, a variety of economic and political shocks can precipitate a phase transition, with changes in both fiscal and science policy. We investigate below a particularly important channel for such shifts.

\section{Inequality, Religion and the Politics of Science}

We now enrich the model to investigate the interplay between religious and class differences. In each generation, a fraction $n<1 / 2$ of agents are rich and a majority $1-n>1 / 2$ are poor: their respective pretax incomes are $\theta_{H}$ and $\theta_{L}$ in both youth and old age (per unit of contemporary TFP). 
Assumption $4:$ Let $\theta_{L}<\nu<\theta_{H}$, with $n \theta_{H}+(1-n) \theta_{L} \equiv 1$.

Income and religiosity are distributed independently, so the four social groups in the economy and their respective sizes are: secular poor, $S P=(1-n)(1-r)$; religious poor, $R P=(1-n) r$; secular rich, $S R=n(1-r)$; and religious rich, $R R=n r$. To limit the number of cases to be considered, we assume:

Assumption 5 : Let $1 / 3<n<1 / 2<r$ and $2 r(1-n)<1<r(1+n)$.

Thus no group constitutes a majority on its own, but the total of all religious agents, as well as that of poor agents, do. Furthermore, the different groups can be ranked in size as follows: 39

$$
S R<S P<S R+S P<R R<R P<1 / 2<1-n<r .
$$

By Assumption 4, the $S R$ always desire $\tau=0$ in the second subperiod, whereas the $S P$ want to set $\tau>0$. In fact the rich, whether secular or religious, always have zero demand for public spending on $T$, as its value $\nu$ is less than the tax price $\theta_{H}$ they face. We can thus equivalently interpret $T$ as pure transfers, to which only the poor (secular or religious) attach a positive net value.

\subsection{The Political Process}

At both $t$ and $t+1$ there are now four groups vying for power, and furthermore the policy space in the latter period is two-dimensional (level and nature of public spending). Standard majority voting is thus not applicable. Instead, in each period political competition takes place -at the ballot box or as open conflict- according to the following sequential game:

1. In each social group, a randomly chosen member is selected as leader. The four leaders then simultaneously decide whether to make a bid for power, at no personal cost, or to stay out. Their entry choices are fully strategic and forward-looking, both within and across periods 40

2. Citizens independently choose which of current contenders for power to support -e.g., whom to vote or fight for. Since no individual has a measurable impact on the overall

\footnotetext{
${ }^{39}$ The condition $r(1+n)>1$, which means that $S R+S P<R R$, can be weakened to $r>1-n$, in which case $n>1 / 3$ is no longer necessary. The stronger version used here simplifies the analysis. Recall also that group sizes may be seen as adjusted by relative strength (e.g., military force, political influence of wealth, etc.).

${ }^{40}$ As there are neither personal entry costs nor private benefits from holding power, simple coordination among members suffices to ensure that a single leader is chosen. We thus abstract from potential free-rider problems within each group, in order to focus on conflict and coalitions across groups.
} 
outcome each one just chooses, sincerely, his preferred candidate 41

3. If a leader gains support from more than half of the population, he wins (is victorious in battle, elected, etc.). If not, a second round of competition takes place between the two candidates who received the most support in the first round; the one who receives support from a majority of citizens wins.

4. The victorious leader implements the policy that maximizes his own utility: as in the citizen-candidate models on which we build (Osborne and Slivinsky (1996), Besley and Coate (1997)), there is no way for politicians to credibly commit ex ante to following a given course of action once in power. Importantly, the leader's choices coincide here exactly with what his core constituency (socioreligious group of origin) wants him to do: their interests and his, summarized by $b$ and $\theta$, are aligned at both $t$ and $t+1.42$

As before, in any even period $t$ the government in power only chooses a blocking policy $\chi_{t} \in\{0,1\}$ and the implied level of taxes $\tau_{t}=R^{-1}\left(\chi_{t} \varphi\left(a_{t}\right)\right)$, while in any odd period $t+1$ the (possibly different) government holding office chooses the nature and level of public spending, together with the required taxes: $\left\{T_{t+1}, G_{t+1}, \tau_{t+1}=R^{-1}\left(T_{t+1}+G_{t+1}\right)\right\}$.

Equilibrium concept. With four groups, none of which constitutes a majority, coalitions will need to form in order to gain power. Because citizen-candidate-type models typically feature multiple Nash equilibria in which different coalitions arise to support different entry profiles, we impose a stronger requirement. We thus look, in the two-period $(t$ and $t+1)$ stage game played by each generation, for a pure-strategy Perfectly Coalition-Proof Nash equilibrium (PCPNE, Bernheim et al. (1987)). Unlike the standard Nash concept, CPNE for normal-form games takes into account joint deviations by coalitions; however, only self-enforcing deviations are considered to be credible threats ${ }^{43}$ In extensive-form games, the additional subgameperfection requirement further restricts admissible coalitional agreements and deviations to be dynamically consistent.

\footnotetext{
${ }^{41}$ When the members of a group are indifferent between several candidates, they split their support equally. The assumptions of sincere voting (or allegiance) and a runoff stage (described below) are similar to those in Osborne and Slivinsky (1996).

${ }^{42}$ At date $t$, the leader clearly has the same information on the empirical (in)adequacy of religious dogma as his own constituency, and the same preferences. This remains true for the leader at $t+1$, because when a $B R$ innovation is blocked by the state's repressive apparatus, no citizen, including the leader, learns of it. There is also no asymmetry of beliefs between groups and their leader in any other state of the world. It would be easy to allow for office rents, in which case religiously-backed leaders' incentive to block would be even greater.

${ }^{43}$ The definition is recursive: a deviation by $n$ players is self-enforcing if no subcoalition of size $n^{\prime}<n$ has a strict incentive to initiate a new deviation from it that is itself self-enforcing.
} 


\subsection{Equilibrium Fiscal Policy (Second Subperiod)}

Given state variables $(a, b)$ at $t+1$, we first characterize the preferred fiscal policies of each of the four groups, then the fiscal-policy outcome that emerges from their competition.

Consider first the poor. Normalizing incomes by $a$, the secular poor maximize $(1-\tau) \theta_{L}+$ $\nu R(\tau)$ over $\tau \in[0, \hat{\tau}]$, so the first-order condition yields $\tau=\tau^{*}\left(\nu / \theta_{L}\right)$ for all $\nu \geq \theta_{L}$. Similarly, the religious poor maximize $(1-\tau) \theta_{L}+\nu[R(\tau)-G]+b G$ over $\tau \in[0, \hat{\tau}]$ and $G \leq R(\tau)$. The linearity in $G$ implies that $G=0$ for $b<\nu$ and $G=R(\tau)$ for $b \geq \nu$; the optimization on $\tau$ yields $\tau=\tau^{*}\left(\nu / \theta_{L}\right)$ in the first case and $\tau=\tau^{*}\left(b / \theta_{L}\right)$ in the second. Hence:

Lemma 2 (1) The ideal policy of the secular poor is $(\tau, T, G)=\left(\tau_{L}(\nu), R\left(\tau_{L}(\nu)\right), 0\right)$, where $\tau_{L}(\nu) \equiv \tau^{*}\left(\nu / \theta_{L}\right)$ is increasing in $\nu / \theta_{L}$.

(2) The ideal policy of the religious poor is the same as that of the secular poor if $b<\nu$. If $b \geq \nu$ it is $(\tau, T, G)=\left(\tau_{L}(b), 0, R\left(\tau_{L}(b)\right)\right)$, where $\tau_{L}(b) \equiv \tau^{*}\left(b / \theta_{L}\right)$ is increasing in $b / \theta_{L}$.

Consider next the rich. Secular ones maximize $(1-\tau) \theta_{H}+\nu R(\tau)$ over $\tau \in[0, \hat{\tau}]$. Since $\nu<\theta_{H}$ and $R^{\prime}(\tau)<1, \tau=0$ is clearly optimal. As to religious ones, they maximize (1$\tau) \theta_{H}+\nu[R(\tau)-G]+b G$ over $\tau \in[0, \hat{\tau}]$ and $G \leq R(\tau)$. If $b<\theta_{H}$, then $\tau=0$ is again optimal. If $b>\theta_{H}>\nu$, then $G=R(\tau)$ is optimal and maximization yields $\tau=\tau^{*}\left(b / \theta_{H}\right)$.

Lemma 3 (1) The ideal policy of the secular rich is $(\tau, T, G)=(0,0,0)$.

(2) The ideal policy of the religious rich is the same if $b<\theta_{H}$. If $b \geq \theta_{H}$ it is $(\tau, T, G)=$ $\left(\tau_{H}(b), 0, R\left(\tau_{H}(b)\right)\right)$, where $\tau_{H}(b) \equiv \tau^{*}\left(b / \theta_{H}\right)<\tau_{L}(b)$ is increasing in $b / \theta_{H}$.

We now examine when the religious poor prefer to side with the secular poor or with the religious rich. When in power, the former provide a lot of $T$ and no $G$, the latter no $T$ and a positive $G$, but (due to their distaste for taxes) at a level less than what the religious poor desire. Naturally, the first policy is preferred when beliefs $b$, which are complements to $G$, are relatively low compared to the value $\nu$ attached by poor agents to secular spending.

Lemma 4 (1) For any $\nu$ there exists a unique $b^{*}\left(\nu ; \theta_{H}, \theta_{L}\right)>\theta_{H}>\nu$, or $b^{*}(\nu)$ for short, such that the religious poor prefer the ideal policy of the secular poor (defined by $\tau_{L}(\nu)$ ) to that of the religious rich (defined by $\tau_{H}(b)$ ) if and only if $b \leq b^{*}(\nu)$.

(2) The function $b^{*}$ is strictly decreasing in $\theta_{L}$ and strictly increasing in $\theta_{H}$.

(3) The function $b^{*}$ is strictly increasing in $\nu$.

Using these key properties of the different groups' preferences, we prove (in appendix) the existence and uniqueness of a CPNE in the political subgame of period $t+1$. 


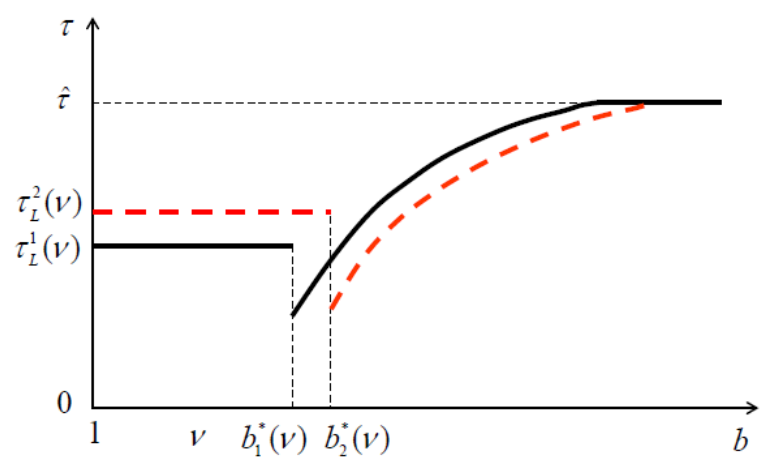

Figure 10: effects of greater income inequality on the equilibrium tax rate

Proposition 5 The equilibrium fiscal policy in the second period is unique:

(1) If $b<b^{*}(\nu)$, either the secular poor come to power and implement their preferred policy $(\tau, T, G)=\left(\tau_{L}(\nu), R\left(\tau_{L}(\nu)\right), 0\right)$, or the religious poor do and implement that same policy ${ }_{4}^{44}$

(2) If $b \geq b^{*}(\nu)$, the religious rich come to power and implement their preferred policy, $(\tau, T, G)=\left(\tau_{H}(b), 0, R\left(\tau_{H}(b)\right)\right)$.

Religion as a "wedge" issue. The equilibrium tax rate is illustrated in Figure 10. In countries with low religiosity, secular governments come to power and implement welfare-statelike policies that (mostly) benefit the poor. Such countries tax more and have a larger public sector than somewhat more religious ones, which provide not only a different set of public goods but also at a lower level. In those latter countries, such as the United States, religion splits the standard pro-redistribution coalition of the poor; the decisive class is then not only more religious, but also richer. This result closely echoes that in Roemer (1998), although the political mechanism involved is quite different 45

Effects of rising income inequality. The above results also imply (see again the figure) that greater income inequality leads to the usual effect of higher taxes and government spending in low-religiosity countries such as those of Western Europe, but to lower levels of both (as well as a different mix of public goods) in more religious countries, such as the United States.

\footnotetext{
${ }^{44}$ In this first case there may be (for $b<\nu$ ) two equilibria in terms of political-entry decisions, but since both yield the same outcome this multiplicity is inconsequential. Without loss of generality, we can for instance select the one with the secular poor in power. Indeed, this seems more "natural", as it is their policy that is implemented in all cases, and it is also the unique equilibrium for $b<\nu<b^{*}(\nu)$.

${ }^{45}$ In Roemer's model of intra-party competition (with two parties), strong enough religious preferences in the population force the otherwise pro-redistribution "Labour" party to adopt a biding electoral platform that caters to voters with (close to) median religious preferences. If median-religiosity voters have above-average wealth, this means that even Labour will commit to a low tax rate. In our case there are four parties, no credible commitment, and the median-religiosity voter is poor rather than rich (as income is uncorrelated with religiosity). High religiosity leads the religious poor to support the religious rich, who gain power as a result.
} 


\subsection{Equilibrium Policy of the Church}

The Church's behavior is similar to that in Section 5.2, except that it takes into account that allowing religious beliefs to erode below $b^{*}(\nu)$ will now lead to a drastic reallocation of power towards secular (poor) agents. The latter will then cut $G$ not only in relation to the decline in $b$, but all the way to zero. Formally, the decision to repair the doctrine is still given by (9) with $\pi(b, \nu)$ defined in $(8)$, but the provision of religious public goods is now

$$
G(b, \nu) \equiv\left\{\begin{array}{cc}
0 & \text { if } b<b^{*}(\nu) \\
R\left(\tau_{H}(b)\right) & \text { if } b \geq b^{*}(\nu)
\end{array}\right.
$$

rather than (7), by Proposition 5. The properties of the return-to-repairing function $\pi(b, \nu)$ also remain unchanged from those in Lemma 1, except that $b^{*}(\nu)$ replaces $\nu$ and $\tau_{H}(b)$ replaces $\tau^{*}(b)$, as depicted in Figure 11 the formal statement and proof are given in Appendix 8.6. The set of $b$ 's where $\pi(b, \nu) \geq y$ is thus again an interval $\left[b^{-}(\nu ; y), b^{+}(\nu ; y)\right]$.

Let us now examine how (small or moderate) changes in the income distribution affect the Church's incentive to undertake doctrinal repair and adaptation. In the notation, we make explicit the dependence of $\pi$ (via $\tau_{H}(b)$ and $b^{*}(\nu)$ ) on $\theta_{L}$ and $\theta_{H}$.

Lemma 5 (1) As $\theta_{L}$ rises, the graph of $\pi\left(b, \nu ; \theta_{L}, \theta_{H}\right)$ shifts (weakly) to the left, so that $b^{-}(\nu ; y)$ and $b^{+}(\nu ; y)$ both (weakly) decrease.

(2) As $\theta_{H}$ rises, the graph of $\pi\left(b, \nu ; \theta_{L}, \theta_{H}\right)$ shifts (weakly) to the right, so that $b^{-}(\nu ; y)$ and $b^{+}(\nu ; y)$ both (weakly) increase.

These properties are illustrated in Figure 11 by the shift from solid to dashed lines. Recalling that the Church repairs when $\pi \geq \eta / q$, the relevant analogue of Assumption 2 is now:

Assumption $6: R\left(\tau_{H}\left(b^{*}(\nu) /(1-\delta)\right)\right)-(1-\delta) R\left(\tau_{H}\left(b^{*}(\nu)\right)\right)<\eta / q<\delta R(\hat{\tau})$.

With the above properties of $\pi$, it leads to the following set of results, which not only characterize the optimal behavior of the Church (thus generalizing Proposition 2 but also describe how it responds to income inequality.

Proposition 6 (1) There exist a unique $\underline{b}$ and $\bar{b}$, with

$$
b^{*}(\nu) \leq \underline{b}<\frac{b^{*}(\nu)}{1-\delta}<\bar{b}
$$

such that the Church attempts repair of a belief-eroding innovation (not blocked by the government) if and only if $b$ lies in $[\underline{b}, \bar{b}]$.

(2) Both $\underline{b}$ and $\bar{b}$ are increasing in $\theta_{H}$ and weakly decreasing in $\theta_{L}$, hence strictly increasing with income inequality (a marginal or moderate mean-preserving change in $\theta$ ). 


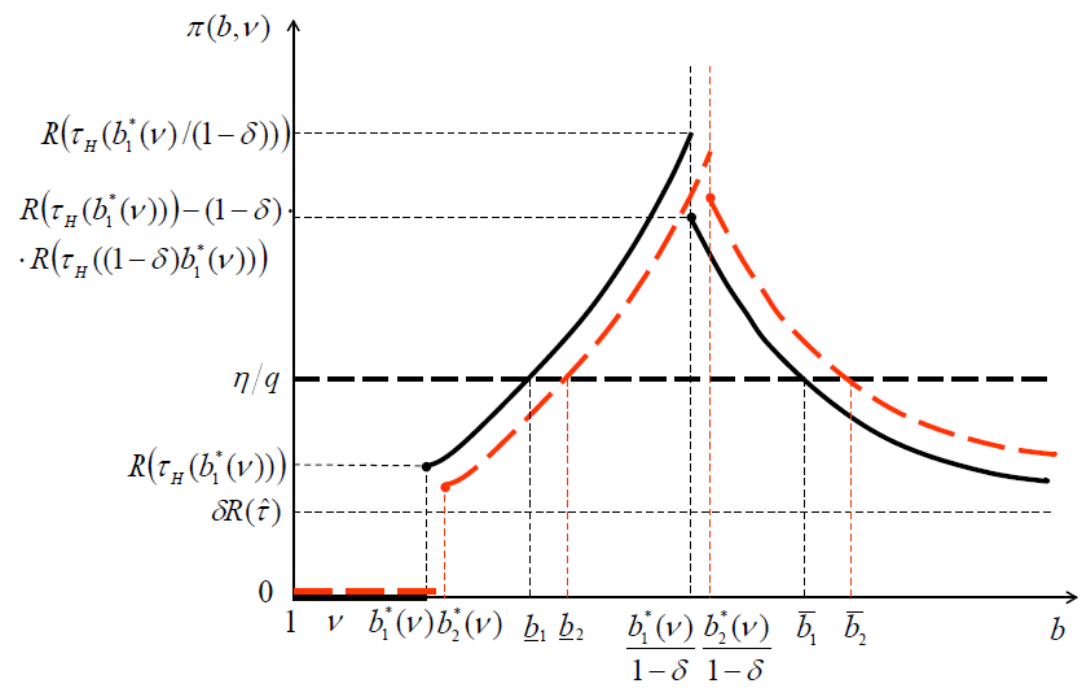

Figure 11: effects of increasing inequality on Church's repairing policy

The novel results are those concerning inequality, which are quite intuitive. At $\bar{b}$, power reallocation is not an issue: the $R R$ will be in power at $t+1$ no matter what, but if their faith erodes, will provide a lower level of $G_{t+1}$. As they become relatively richer and thus face a higher tax price for $G$ this effect is amplified, so the Church, which cares about $b_{t+1} G_{t+1}$, has a greater incentive to preserve $b_{t+1}$. At $\underline{b}$, on the other hand, repairing or not determines whether the $R R$ or the $S P$ come to power at $t+1$. The $S P$ always set $G=0$, while the level provided by the $R R$ declines with their relative income, reducing the Church's incentive to preserve $b_{t+1}$ in order to ensure their victory.

\subsection{State's Policy Toward Science (First Subperiod)}

The only decision of the government in place at date $t$ is the choice of a science policy tolerating or blocking $B R$ innovations. While the aggregate costs of blocking are the same as before (lower consumption at $t$ to finance the repressive apparatus and foregone TFP gains at $t+1$ ), their incidence is different for rich and poor. As to the benefits, they now differ not only between secular and religious but also by income, since an erosion of beliefs can trigger a reallocation of political power from (religious) rich to (secular) poor agents at $t+1$.

We start with some intuitive points, formally proved in Appendix 8.8. First, the $S P$ are always against blocking. Not only does a $B R$ innovation raise productivity, but the erosion of beliefs it generates is always beneficial for them, for two reasons: (i) it reduces taxation and spending on the religious public good $G$ (which they do not care about) if the $R R$ are in power at $t+1$, namely if $b_{t+1}$ remains above $b^{*}(\nu)$; (ii) it (weakly) increases the chance that the $S P$ themselves will gain power at $t+1$, which occurs if $b_{t+1}$ falls below $b^{*}(\nu)$. 
We impose in this section an additional simplifying assumption, which will ensure that the $S R$ also never want to block.

Assumption $7:(1+\gamma)\left[1-\tau_{L}(\nu)\right] \geq 1-\tau_{H}\left(b^{*}(\nu)\right)$.

In words, the productivity gains from implementing new $(B R)$ discoveries are large enough that, even if the erosion of beliefs brings the secular poor to power, aftertax incomes at $t+1$ are higher than if blocking had occurred and the (lower-taxing) religious rich held power as a result. A simple sufficient condition for this to be the case is $(1+\gamma)\left[1-\tau_{L}(\nu)\right] \geq 1$.

Next, as in the absence of income heterogeneity, there are two regions in which even a religious government never engages in blocking. First, when $b<b^{*}(\nu)$ the $S P$ will always be in power at $t+1$ and set $G_{t+1}=0$, so there is no point for anyone to invest in blocking. Second, when $b \in[\underline{b}, \bar{b}]$, the Church will attempt to repair unblocked $B R$ discoveries. Provided it is sufficiently likely to succeed (Assumption 3), any first-period government disliking such innovations will let repair be attempted rather than make its own costly investment in blocking.

Our analysis below therefore concentrates on the two remaining no-repairing regions, $b>\bar{b}$ and $b^{*}(\nu) \leq b<\underline{b}$, in which we characterize the ideal blocking policy of the $R R$ (who, as we shall see, always end up being pivotal at date $t$ ). Those of the $R P$ and $S R$ classes are then be obtained through simple parameter substitutions.

\subsubsection{Region 1: $\mathbf{b}>\overline{\mathbf{b}}>\mathbf{b}^{*}(\nu) /(1-\delta)$. No repairing nor power reallocation}

Since $(1-\delta) b \geq b^{*}(\nu)$, the religious rich will be in power at $t+1$ even if beliefs are eroded by a new discovery. Their expected value at date $t$ of setting up a blocking apparatus is therefore

$$
V_{R R}^{B}(a, b)=\left[1-R^{-1}(\varphi(a))\right] \theta_{H}+\left[1-\lambda+\lambda p_{R}+\lambda\left(1-p_{R}\right)(1+\gamma)\right] V_{R R}(R R \mid b),
$$

where, for all $b, V_{R R}(R R \mid b) \equiv\left[1-\tau_{H}(b)\right] \theta_{H}+b R\left(\tau_{H}(b)\right)$ represents their utility in old age. As to their expected value of not blocking, it is

$$
V_{R R}^{N B}=\theta_{H}+\left[1-\lambda+\lambda\left(1-p_{R}\right)(1+\gamma)\right] V_{R R}(R R \mid b)+\lambda p_{R}(1+\gamma) V_{R R}\left(R R \mid b^{\prime}\right),
$$

where $b^{\prime} \equiv(1-\delta) b$. The $R R$ 's blocking condition, $V_{R R}^{N B} \leq V_{R R}^{B}$, thus takes the form

$$
R^{-1}(\varphi(a)) \theta_{H} \leq \lambda p_{R}\left[V_{R R}(R R \mid b)-(1+\gamma) V_{R R}\left(R R \mid b^{\prime}\right)\right] \equiv \Delta_{R R}^{1}(b) .
$$

Substituting in old-age utilities, the right-hand side can be rewritten as

$$
\Delta_{R R}^{1}(b)=\lambda p_{R}\left\{\left[1-\tau_{H}(b)\right] \theta_{H}+b R\left(\tau_{H}(b)\right)-(1+\gamma)\left[\left(1-\tau_{H}\left(b^{\prime}\right)\right) \theta_{H}+b^{\prime} R\left(\tau_{H}\left(b^{\prime}\right)\right)\right]\right\} .
$$




\subsubsection{Region 2: $\mathbf{b}^{*}(\boldsymbol{\nu}) \leq \mathbf{b}<\underline{b}<\mathbf{b}^{*}(\boldsymbol{\nu}) /(1-\delta)$. No repairing, power reallocation}

The $R R$ hold power at $t+1$ if beliefs remain intact, while the $S P$ take over if a $B R$ innovation occurs and is not blocked, as there is no repairing in this range. Replacing $V_{R R}\left(R R \mid b^{\prime}\right)$ in (29)-(30) by $V_{R R}(S P) \equiv\left[1-\tau_{L}(\nu)\right] \theta_{H}+\nu R\left(\tau_{L}(\nu)\right)$, the blocking condition becomes

$$
R^{-1}(\varphi(a)) \theta_{H} \leq \lambda p_{R}\left\{V_{R R}(R R \mid b)-(1+\gamma) V_{R R}(S P)\right\} \equiv \Delta_{R R}^{2}(b)
$$

where the right-hand side can be rewritten as

$$
\Delta_{R R}^{2}(b)=\lambda p_{R}\left\{\left[1-\tau_{H}(b)\right] \theta_{H}+b R\left(\tau_{H}(b)\right)-(1+\gamma)\left[\left(1-\tau_{L}(\nu)\right) \theta_{H}+\nu R\left(\tau_{L}(\nu)\right)\right]\right\}
$$

\subsubsection{Equilibrium Blocking Policy}

The blocking preferences of the religious poor are obtained, in each region, by simply replacing $\theta_{H}$ with $\theta_{L}$; those of secular agents by similarly replacing $b R\left(\tau_{H}(b)\right)$ and $b R\left(\tau_{H}(b)\right)$ with zero. The resulting analogues to (31) and (33) are given in Appendix 8.8 (Lemma 9)). By studying and comparing the four groups' blocking loci, we then show that their relative rankings remain invariant throughout the state space:

(i) Whenever the $R R$ block, then so do the $R P$.

(ii) The $S R$ never want to block, as is the case for the $S P$.

These properties imply that the $R R$ are always pivotal in the date- $t$ political competition that determines science policy. Intuitively, when they are against blocking the $S P$ and the $S R$ agree with them, resulting in an absolute majority by $(25)$. When the $R R$ do want to block, the $R P$ agree with them, again adding up to an absolute majority. Formally, we prove the following results, illustrated by the solid lines in Figure 12 .

Proposition 7 The unique Perfectly Coalition-Proof Nash Equilibrium (PCPNE) of the twoperiod game always implements the preferred science policy of the religious rich. The corresponding blocking boundary is an upward-sloping line $b=B(a)$ in the state space.

\subsubsection{Income Inequality and Science Policy}

Keeping the sizes $(n, 1-n)$ of the rich and poor classes constant, consider a relatively small mean-preserving change in their income levels: $\left(d \theta_{H}, d \theta_{L}\right)$, with $n d \theta_{H}+(1-n) d \theta_{L}=0$. We assume that, initially, there is already a certain degree of inequality in society (recall that average income is normalized to 1$)$ :

Assumption $8 \theta_{H}-1 \geq \nu \frac{(1-n)^{2}}{n}\left[-R^{\prime \prime}(\hat{\tau})\right]\left(1+\frac{R^{-1}(\bar{\varphi})}{\lambda p_{R}(1+\gamma)}\right)$. 


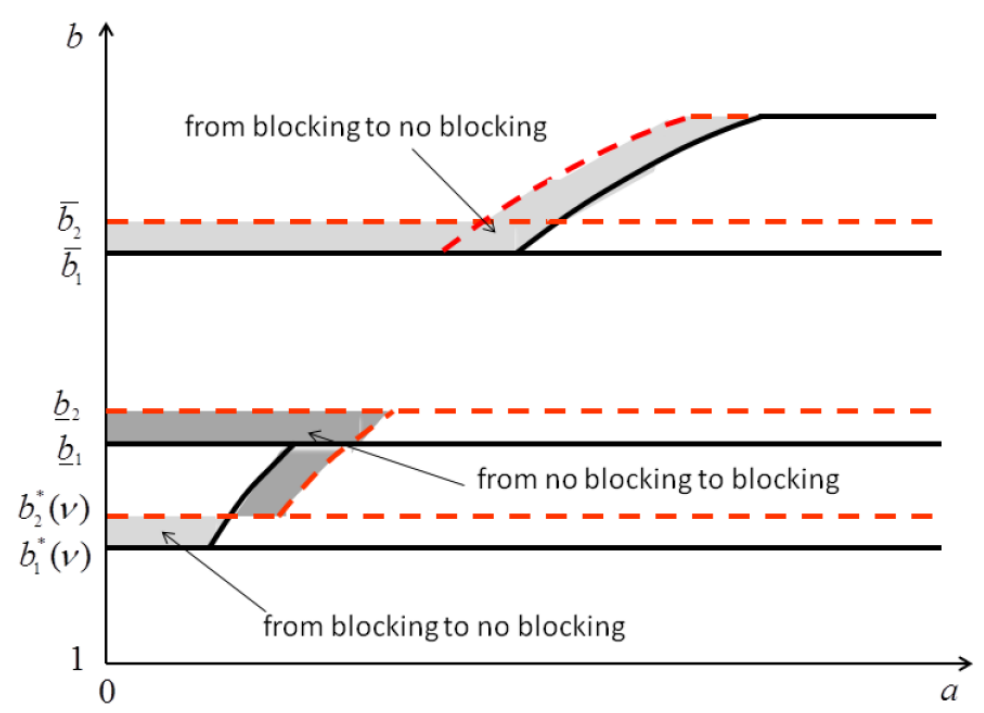

Figure 12: effects of higher inequality on science-blocking policy

We now examine the impact of distributional changes of the $R R$ 's blocking policy.

Proposition 8 A marginal increase in income inequality (mean-preserving spread) causes the equilibrium blocking locus to:

1. Shift up in the high-religiosity region $b>\bar{b}$, where there is neither repairing nor power reallocation.

2. Shift down in the moderate-religiosity region $b^{*}(\nu) \leq b<\underline{b}$ where there is no repairing and $B R$ discoveries potentially trigger a reallocation of power toward the secular poor.

3. These shifts lead, ceteris paribus (i.e. if there is no simultaneous change in the Church's repairing behavior), to less blocking in the first case and more the second.

Figure 12 illustrates, through the shift from solid to dashed lines, the combined effects of an increase in income inequality on science policy by the state, repairing by the Church and public spending, leading in turn lead to Proposition 9 below.

(i) The second-period fiscal-policy threshold $b^{*}(\nu)$ shifts up. When their income rises, the $R R$ face a higher tax price for provision of the religious public good $G$ and consequently want to reduce its supply. The $R P$, on the other hand, want to increase redistributive transfers, $T$. For the $R P$ to still prefer allying themselves with the $R R$ rather than the $S P$ therefore requires a higher level of religiosity; their indifference threshold $b^{*}(\nu)$ thus increases.

(ii) The Church's repairing region shifts up. The lower demand for $G$ by the $R R$ as they become relatively richer gives the Church, which cares about $b_{t+1} G_{t+1}$, a greater incentive to 
preserve beliefs near $\bar{b}$ (where the $R R$ will be in power no matter what), but a lower one near $\underline{b}$, where the purpose of repairing is to prevent the $S P$ from gaining power and setting $G=0$.

(iii) The State's blocking locus $B(a)$ shifts upwards at high levels of religiosity $(b>\bar{b})$ and downward at low levels of $b(b<\underline{b})$. Blocking is most costly to the rich as they must forego more income, but it can also prevent a shift of power to the $S P$ at $t+1$. When the $R R$ become richer, the first effect dominates at high levels of $b$, as even with eroded beliefs the $R P$ will not switch allegiance (Region 1). The second effect prevails when religiosity is intermediate, as power is now at stake if beliefs come to be eroded (Region 2).

Proposition 9 In the "American" regime, corresponding to intermediate values of $b / a$, greater income inequality leads to more blocking of "threatening" scientific findings, and to (weakly) greater doctrinal rigidity (less adaptation) of the religious sector. At high enough levels of religiosity, corresponding to "theocratic" regimes, it has the opposite ("Arab Spring") effects.

While the underlying details are somewhat involved (each potential coalition at $t$ must envision all possible coalitions at $t+1$ that its actions can empower or defeat), the main intuition for how increased inequality leads to the emergence of a religious-right alliance in (the appropriate region of) the "American" regime is simple. When it comes to choices over fiscal policy and public spending (date $t+1$ ), if the $R P$ 's faith has eroded they will ally themselves with the $S P$ and implement a high level of redistribution - clearly the worst possible outcome for the $R R$. If they remain sufficiently pious, on the other hand, they will support instead the $R R$ 's "compromise" policy of moderate taxes but religion-favoring spending, which then wins. Looking forward at date $t$, the $R R$ realize that in order to hold power at date $t+1$ they must preserve the religiosity of the $R P$, which may require blocking certain economically valuable innovations. When the stakes of who will control taxes and spending at $t+1$ are high enough (i.e., when there is a lot of inequality), this concern dominates over the fact that rich agents benefit most from productivity gains. Consequently, the $R R$ strategically give priority to religion over science at date $t$, and in so doing they have the support of the $R P$, who are always those with the greatest incentive to block. The dynamic outcome is that the $R R$ gain power at date $t$, and thanks to blocking they keep it at date $t+1$.

\section{Concluding Comments}

Several extensions of our framework can be envisioned. Besides being a source utility for some agents, religiosity could also have a direct effect on growth, e.g. by promoting greater trust and trustworthiness among individuals (at least, up to the point where it becomes a source of civil strife), or by legitimizing the authority of the ruler and state, thereby reducing agency problems. The key tradeoff with allowing belief-eroding ideas to diffuse would then remain, 
and a hill-shaped relationship between religiosity and growth would likely emerge. Interstate conflict offers another interesting direction for research: an intensely religious population and strong state-church links are valuable assets in the short to medium run (increasing people's willingness to fight and die for the cause), but in the long run the associated drag on scientific knowledge and technological innovation leads to military backwardness -as was the case for the Ottoman Empire.

The leading examples of "forbidden fruits" discussed in the paper involved the hard sciences on the one hand, religion stricto sensu (belief in deities and spirits, creation, afterlife, etc.) on the other. It should be clear from the model, however, that both concepts should be taken in a much more general sense. Two concrete cases perhaps best demonstrate this point.

The first is that of Lysenkoism in the Soviet Union between 1935 and 1964. During three decades, Inquisition-like methods (forced denunciations, imprisonments, executions) were used to repress "bourgeois" scientific knowledge and methodology in evolutionary biology and agronomy, with adverse spillovers onto many other areas. Meanwhile, the Stalinist regime also promoted and enforced a pseudoscience which it saw as more compatible with its dogma of Man's and society's malleability to rapid social change.

The second case is modern contraception, a very applied innovation though directly derived from fundamental advances in human biology. Here again we find the four key characteristics of $B R$ innovations in our model: (i) a large positive impact on long-term productivity, by allowing greater participation of women in the labor force and increasing their return to human capital investment; (ii) a conflict with several of the world's major religious doctrines and their teachings about the divinely ordered role of women, purpose of sexuality and sacrality of the body; (iii) as a result, its condemnation by religious authorities and initial proscription by the state; (iv) over time (and not in all places), as society becomes more secular or/and religious doctrine is "modernized", the innovation is allowed to diffuse, affecting both productivity and mentalities.

Many other examples could be drawn from medicine or the social sciences. As much as individual discoveries and ideas, it is to a large extent the scientific method itself, with its emphasis on systematic doubt, contradictory debate and empirical falsifiability, that inevitably runs afoul of preestablished dogmas. The model could also be used to study the interactions between many types of new ideas (scientific, social, political) and vested beliefs (religious, cultural, ideological, corporate), leading to the emergence of stable regimes where either form of "reasoning and knowing" gains primacy, or the two manage to coadapt. On the empirical side, the robust inverse relationship between religiosity and innovation uncovered by our simple analysis, across both countries and US states, surely deserves further investigation. Work in this direction will include finding plausible instruments to assess both directions of causality (as emphasized in the model), individual-level analyses, and perhaps even experiments. 


\section{Proofs Appendix}

\subsection{Proof of Lemma 1}

(1) For $b<\nu, G(b, \nu)=G((1-\delta) b, \nu)=0$, hence $\pi(b, \nu)=0$. For $\nu \leq b<\nu /(1-\delta)$, the religious switch to the provision of the secular public good when religiosity is eroded from $b$ to $b^{\prime} \equiv(1-\delta) b$. Therefore, over this range $\pi(b, \nu)=R\left(\tau^{*}(b)\right)$, which is strictly increasing and continuous in $b$; at $b=\nu$, the function $\pi(b, \nu)$ thus has an upward jump of $R\left(\tau^{*}(\nu)\right)$.

(2) For $\nu /(1-\delta) \leq b$, the religious provide $G$ even when $b$ falls to $(1-\delta) b$, so

$$
\pi(b, \nu)=R\left(\tau^{*}(b)\right)-(1-\delta) R\left(\tau^{*}((1-\delta) b)\right)
$$

From the first-order condition $b R^{\prime}\left(\tau^{*}(b)\right)=1$ follows that

$$
\begin{aligned}
\tau^{* \prime}(b) & =\frac{1}{-b^{2} R^{\prime \prime}\left(\tau^{*}(b)\right)}>0, \text { so } \\
\frac{\partial \pi(b, \nu)}{\partial b} & =R^{\prime}\left(\tau^{*}(b)\right) \tau^{* \prime}(b)-(1-\delta)^{2} R^{\prime}\left(\tau^{*}((1-\delta) b)\right) \tau^{* \prime}((1-\delta) b) \\
& =\frac{1}{b^{2}}\left[\frac{R^{\prime}\left(\tau^{*}(b)\right)}{-R^{\prime \prime}\left(\tau^{*}(b)\right)}-\frac{R^{\prime}\left(\tau^{*}\left(b^{\prime}\right)\right)}{-R^{\prime \prime}\left(\tau^{*}\left(b^{\prime}\right)\right)}\right]
\end{aligned}
$$

This expression is negative if $-R^{\prime}(\tau) / R^{\prime \prime}(\tau)$ is decreasing (as $\tau^{*}(b)$ is increasing), which is implied by Assumption 1. The function $\pi(b, \nu)$ in A.1) is therefore decreasing on $[\nu /(1-$ $\delta),+\infty)$; at $b=\nu /(1-\delta)$ it has a downward jump of $-(1-\delta) R\left(\tau^{*}(\nu)\right)$. As $b$ tends to $+\infty$, finally, both $\tau^{*}(b)$ and $\tau^{*}((1-\delta) b)$ tend to $\hat{\tau}$, so by (A.1) $\pi(b, \nu)$ tends to $\delta R(\hat{\tau})>0$.

\subsection{Proof of No Blocking When Repairing, i.e. When $b \in[\underline{b}, \bar{b}]$}

(1) When $b \in[\nu /(1-\delta), \bar{b}]$, the Church's attempt of repairing $B R$ innovations is successful with probability $q$, and in this case beliefs and the level of the religious public good provided is unchanged. With probability $1-q$ repairing fails, the level of religious beliefs drops to $b^{\prime} \geq \nu$, which implies that the amount of religious public good is still provided but at a lower level. Therefore, the value of not blocking in this case is

$$
V^{N B}=1+\left[1-\lambda+\lambda\left(1-p_{R}\right)(1+\gamma)+\lambda p_{R} q(1+\gamma)\right] V(b)+\lambda p_{R}(1-q)(1+\gamma) V\left(b^{\prime}\right),
$$

where $V\left(b^{\prime}\right)$ is given by 11). Combining A.4 and (12), the blocking condition $V^{N B}<V^{B}$ can be written as

$$
R^{-1}(\varphi(a)) \leq \lambda p_{R}\left\{[1-q(1+\gamma)] V(b)-(1-q)(1+\gamma) V\left(b^{\prime}\right)\right\} \equiv \Delta^{3 I}(b)
$$


(2) When $b \in[\underline{b}, \nu /(1-\delta))$ and repair fails, religiosity falls to $b^{\prime}<\nu$, so $G_{t+1}=0$ and the value of not blocking becomes

$$
V^{N B}=1+\left[1-\lambda+\lambda\left(1-p_{R}\right)(1+\gamma)+\lambda p_{R} q(1+\gamma)\right] V(b)+\lambda p_{R}(1-q)(1+\gamma) V(\nu)
$$

which is equivalent to A.4 with $V(\nu)$ replacing $V\left(b^{\prime}\right)$. Hence, the blocking condition becomes

$$
R^{-1}(\varphi(a)) \leq \lambda p_{R}\{[1-q(1+\gamma)] V(b)-(1-q)(1+\gamma) V(\nu)\} \equiv \Delta^{3 I I}(b)
$$

Lemma 6 There exists a $q=q^{*}<1 /(1+\gamma)$ such that, for any $q>q^{*}$, the religious majority prefers not to block $\left(V^{N B}>V^{B}\right)$ for any $(a, b) \in \mathbb{R}_{+} \times[\underline{b}, \bar{b}]$. Consequently, under Assumption 3, the State does not block in this region.

Proof. Consider A.5 and note that $\Delta^{3 I}(b)<0$ for all $q \geq 1 /(1+\gamma)$. Moreover $V(b)$ is increasing in $b$, so $\partial \Delta^{3 I}(b) / \partial q=-\lambda p_{R}(1+\gamma)\left[V(b)-V\left(b^{\prime}\right)\right]<0$. Hence, there exists a $q_{I}^{*}<1 /(1+\gamma)$ such that $\Delta^{3 I}(b)$ has the sign of $q_{I}^{*}-q$. Similarly, A.7 implies, for all $b>\nu, \partial \Delta^{3 I}(b) / \partial q=-\lambda p_{R}(1+\gamma)[V(b)-V(\nu)]<0$, so there exists a $q_{I I}^{*}<1 /(1+\gamma)$ such that $\Delta^{3 I I}(b)$ has the sign of $q_{I I}^{*}-q$. Under Assumption $3, q>\max \left\{q_{I}^{*}, q_{I I}^{*}\right\} \equiv q^{*}$, so there is no blocking for $b \in[\underline{b}, \bar{b}]$.

\subsection{Proof that $\Delta^{i}(b), i=1,2$, Is Increasing in $b$}

Differentiating (15) and using the envelope theorem (note that $\Delta^{1}(b)$ is the difference between two maximized functions) yields

$$
\frac{\partial \Delta^{1}(b)}{\partial b}=\lambda p_{R}\left[R\left(\tau^{*}(b)\right)-(1+\gamma)(1-\delta) R\left(\tau^{*}\left(b^{\prime}\right)\right)\right]
$$

Any blocking of $B R$ innovations requires that $\Delta^{1}(b) \geq 0$, which by 15 takes the form

$$
R\left(\tau^{*}(b)\right)-(1+\gamma)(1-\delta) R\left(\tau^{*}\left(b^{\prime}\right)\right) \geq(1 / b)\left[(1+\gamma)\left(1-\tau^{*}\left(b^{\prime}\right)\right)-\left(1-\tau^{*}(b)\right)\right]
$$

Since $\tau^{*}(b)$ is nondecreasing and $b^{\prime} \equiv(1-\delta) b$, the right-hand side of A.9 is strictly positive. Therefore, $\Delta^{1}(b) \geq 0$ implies that $\partial \Delta^{1}(b) / \partial b>0$ in A.8. Similarly, from (18) we obtain $\partial \Delta^{2}(b) / \partial b=\lambda p_{R} R\left(\tau^{*}(b)\right)$, which is always positive.

\subsection{Proof of Lemma 4}

(1) The utility of the religious poor under the ideal policy of the religious rich is

$$
f(b) \equiv\left[1-\tau_{H}(b)\right] \theta_{L}+b R\left(\tau_{H}(b)\right) \quad \text { for } \quad b \geq \theta_{H}, \quad f(b) \equiv \theta_{L} \quad \text { otherwise, }
$$


whereas under that of the secular poor it equals

$$
g(\nu) \equiv\left[1-\tau_{L}(\nu)\right] \theta_{L}+\nu R\left(\tau_{L}(\nu)\right)
$$

For $b \leq \theta_{H}, f(b)<g(\nu)$. For $b \geq \theta_{H}, f(b)$ is an increasing function, since

$$
f^{\prime}(b)=R\left(\tau_{H}(b)\right)+\left[b R^{\prime}\left(\tau_{H}(b)\right)-\theta_{L}\right] \tau_{H}^{\prime}(b)=R\left(\tau_{H}(b)\right)+\left[\theta_{H}-\theta_{L}\right] \tau_{H}^{\prime}(b)>0 .
$$

Finally, as $b$ tends to $+\infty, \tau_{H}(b)=\tau^{*}\left(b / \theta_{H}\right)$ tends to $\hat{\tau}$, so $f(b)$ tends to $+\infty$. This shows the existence of a unique indifference point, $b^{*}(\nu)>\theta_{H}>\nu$. To determine its comparative-statics, we first prove two simple properties linking the preferred tax rates of poor and rich agents.

Lemma 7 For any $\nu \in\left(\theta_{L}, \theta_{H}\right)$, let $\tilde{b}(\nu) \equiv \nu\left(\theta_{H} / \theta_{L}\right)>\theta_{H}$. Then $\tau_{L}(\nu)=\tau_{H}(\tilde{b}(\nu))>$ $\tau_{H}\left(b^{*}(\nu)\right)$.

Proof. The equality follows from $\tau_{L}(\nu)=\tau^{*}\left(\nu / \theta_{L}\right)$ and $\tau_{H}(b)=\tau^{*}\left(b / \theta_{H}\right)$ for $b \geq \theta_{H}$. The inequality then holds if $\tilde{b}(\nu)>b^{*}(\nu)$ or, by monotonicity of $f, f(\tilde{b}(\nu))>f\left(b^{*}(\nu)\right)$. We have

$$
\begin{aligned}
f(\tilde{b}(\nu)) & =\left[1-\tau_{H}(\tilde{b}(\nu))\right] \theta_{L}+\tilde{b}(\nu) R\left(\tau_{H}(\tilde{b}(\nu))\right)=\left[1-\tau_{L}(\nu)\right] \theta_{L}+\tilde{b}(\nu) R\left(\tau_{L}(\nu)\right) \\
& >\left[1-\tau_{L}(\nu)\right] \theta_{L}+\nu R\left(\tau_{L}(\nu)\right)=g(\nu) \equiv f\left(b^{*}(\nu)\right)
\end{aligned}
$$

using the definition of $b^{*}(\nu)$, hence the result. $\|$

(2) Making the dependence of $f$ and $g$ on $\left(\theta_{L}, \theta_{H}\right)$ explicit, we have

$$
\begin{aligned}
\frac{\partial f\left(b ; \theta_{L}, \theta_{H}\right)}{\partial \theta_{L}} & =1-\tau_{H}(b), \\
\frac{\partial g\left(\nu ; \theta_{L}\right)}{\partial \theta_{L}} & =1-\tau_{L}(\nu)+\left[-\theta_{L}+\nu R^{\prime}\left(\tau_{L}(\nu)\right)\right] \frac{\partial \tau_{L}(b)}{\partial \theta_{L}}=1-\tau_{L}(\nu),
\end{aligned}
$$

by the first-order condition of the $S P$. Therefore,

$$
\frac{\partial f\left(b ; \theta_{L}, \theta_{H}\right)}{\partial \theta_{L}}-\frac{\partial g\left(\nu ; \theta_{L}\right)}{\partial \theta_{L}}=\tau_{L}(\nu)-\tau_{H}(b),
$$

which is always positive at $b=b^{*}$ since $\tau_{H}\left(b^{*}(\nu)\right)<\tau_{L}(\nu)$, by Lemma 7. (2) above. Since $f(b)-g(\nu)$ is also increasing in $b$, its unique zero, $b^{*}(\nu)$, is therefore strictly decreasing in $\theta_{L}$. Similarly, $\partial b^{*} / \partial \theta_{H}>0$ follows from the fact that

$$
\frac{\partial f\left(b ; \theta_{L}, \theta_{H}\right)}{\partial \theta_{H}}-\frac{\partial g\left(\nu ; \theta_{L}\right)}{\partial \theta_{H}}=\left[-\theta_{L}+b R^{\prime}\left(\tau_{H}(b)\right)\right] \frac{\partial \tau_{H}(b)}{\partial \theta_{H}}=\left(\theta_{H}-\theta_{L}\right) \frac{\partial \tau_{H}(b)}{\partial \theta_{H}}<0,
$$


where we used first-order condition of the $R R$, namely $b R^{\prime}\left(\tau_{H}(b)\right)=\theta_{H}$, which implies

$$
\frac{\partial \tau_{H}(b)}{\partial \theta_{H}}=\frac{1}{b R^{\prime \prime}\left(\tau_{H}(b)\right)}<0
$$

(3) Recall that $b^{*}(\nu)$ is uniquely defined by the indifference condition

$$
\left[1-\tau_{H}\left(b^{*}(\nu)\right)\right] \theta_{L}+b^{*}(\nu) R\left(\tau_{H}\left(b^{*}(\nu)\right)\right)=\left[1-\tau_{L}(\nu)\right] \theta_{L}+\nu R\left(\tau_{L}(\nu)\right)
$$

Differentiation with respect to $\nu$ yields

$$
b^{* \prime}(\nu)=\frac{R\left(\tau_{L}(\nu)\right)}{\left(\theta_{H}-\theta_{L}\right) \tau_{H}^{\prime}\left(b^{*}(\nu)\right)+R\left(\tau_{H}\left(b^{*}(\nu)\right)\right)},
$$

where we have used the first-order condition of the $S P, \nu R^{\prime}\left(\tau_{L}(\nu)\right)=\theta_{L}$, and the first-order condition of the $R R$ at $b=b^{*}(\nu), b^{*}(\nu) R^{\prime}\left(\tau_{H}\left(b^{*}(\nu)\right)\right)=\theta_{H}$. From the first-order condition of the $R R$ defining $\tau_{H}(b)$, it also follows that

$$
\tau_{H}^{\prime}(b)=\frac{\theta_{H}}{-b^{2} R^{\prime \prime}\left(\tau_{H}(b)\right)}>0
$$

and therefore that $b^{* \prime}(\nu)>0$.

\subsection{Proof of Proposition 5}

\section{A - Region $\nu<b<b^{*}(\nu)$}

Case 1: $\theta_{H} \leq b<b^{*}(\nu){ }^{46}$ In this case, the optimal tax rate of the $R R$ is $\tau_{H}(b)>0$. This implies that the $S P$ strictly prefer the $S R$ to the $R R$, and the $R P$ strictly prefer the $R R$ to the $S R$. The Table 1 displays the rankings of each group $i$ over the ideal fiscal policies of the four groups $j$; naturally, its own policy is always ranked first.

\begin{tabular}{|c|c|c|c|c|}
\hline & $S P$ & $R P$ & $R R$ & $S R$ \\
\hline$S P$ & 1 & 4 & 3 & 2 \\
\hline$R P$ & 2 & 1 & 3 & 4 \\
\hline$R R$ & $x$ & $y$ & 1 & $z$ \\
\hline$S R$ & $x^{\prime}$ & 4 & $y^{\prime}$ & 1 \\
\hline
\end{tabular}

where $(x, y, z)=(3,4,2)$ [subcase $(\mathrm{a})]$, or $(4,2,3)$ or $(4,3,2)$ [subcase b]; $\left(x^{\prime}, y^{\prime}\right)=(2,3)$ or $(3,2)$.

Table 1. Fiscal preferences of each group when $\theta_{H} \leq b<b^{*}(\nu)$

\footnotetext{
${ }^{46}$ We use the weak inequality $\theta_{H} \leq b$ because in Lemma 2 we are breaking the indifference at $b=\theta_{H}$ in favor of the $R R$ providing the religious public good.
} 
The first two rows are self-explanatory. In the third, subcase (a) refers to the situation where the $R R$ prefer the $S P$ to the $R P$ (they will then also prefer the $S R$ to the $S P$ ), whereas in subcase (b) they prefer the $R P$ to the $S P$; we then do not know a priori how the $S R$ are ranked relative to the $R P$. The last row of Table 1 shows that for the $S R$ 's least preferred policy is that of the $R P$, and that they may rank that of the $S P$ ahead of that of the $R R$, or vice versa.

We now show that the $S P$ winning -implementing their preferred fiscal policy- in the second period of the political game (a generation's old age) is a CPNE outcome (Claim 1), and then that this equilibrium is unique (see Claims 2-4).

Claim 1: The $S P$ winning at $t+1$ is a CPNE outcome.

Proof: Consider the case where only the $S P$ and the $R R$ candidates enter in the context, so that the strategy profile is $(S P=E, R P=N, R R=E, S R=N)$ where $E$ and $N$ denote respectively the entry and non-entry of the candidate. The $S P$ are the winner, as they get the support of the $R P$ and the poor are the majority in the population. It is immediate that this is a Nash Equilibrium (NE) as no player has an incentive to deviate; we next show that there is no self-enforcing coalitional deviation.

Note first that any winning deviating coalition must contain the $R P$ and that the $S P$ are the $2^{\text {nd }}$ choice for the $R P$. The coalition $(R P, R R)$ get $(2, x)$ when the $S P$ wins. The only available vector that could Pareto-dominate $(2, x)$ is $(1, y)$, achieved in subcase (b) by $(R P=E, R R=N)$, with the $R P$ winning, since $(x, y, z) \in\{(4,2,3),(4,3,2)\}$. But this coalition is not self-enforcing. If the $R R$ stays in, no one gets the absolute majority in the first round (where there are at least three candidates - $S P, R P$ and $R R$ ). By condition (25), the $S P$ (and eventually the $S R$ ) drops out, and the $R R$ wins against the $R P$ in the second round, so it is optimal for the $R R$ to deviate by playing $E$ rather than $N$. This shows that the only possible coalitional deviation is not self-enforcing, and therefore that the NE with the $S P$ winning is coalition-proof.

Claim 2: The $R R$ winning (implementing their preferred policy) at $t+1$ cannot be a CPNE outcome.

Proof: Assume that there is a NE with the $R R$ winning. Then, it cannot be coalition-proof. Let us consider the deviation $(S P=E, R P=N)$. The $S P$ wins with the support of the $R P$ and this deviation is profitable as $(1,2)<(3,3)$; see Table 147 The deviation is also self-enforcing, so that a NE with the $R R$ winning cannot be coalition-proof. In fact, if the $R P$ deviates and stays in, there will be at least three candidates in the first round and no one getting the absolute majority. By condition 25), the $S P$ (and eventually the $S R$ ) drops out,

\footnotetext{
${ }^{47}$ The decisions of the $S R$ in terms of entry/non-entry and whom to support are irrelevant in this case.
} 
and the $R R$ wins in the second round against the $R P$. The $R P$ get their $3^{r d}$ rather than $2^{n d}$ choice, which means that they have no incentive to deviate.

Claim 3: The RP winning at $t+1$ cannot be a CPNE outcome.

Proof: Again, assume there is a NE with the $R P$ winning. The deviation $(S P=N, R R=E)$ brings the $R R$ to power ${ }^{48}$ and is profitable as $(3,1)<(4, y)$ (since $y \geq 2$ ). This deviation is also self-enforcing. If the $S P$ deviates and stays in, there will be at least three candidates in the first round. By condition (25), the $R R$ and the $R P$ go to the second round where the $R R$ will win anyway.

Claim 4: The SR winning at $t+1$ cannot be a CPNE outcome.

Proof: We again show that if there is a NE with the $S R$ winning, it cannot be coalition-proof.

Subcase (a). The deviation $(S P=E, R P=N$ ) leads the $S P$ to power (supported by the $R P)$ and it is profitable, since $(1,2)<(2,4)$. To establish that it is also self-enforcing, note in Table 1 that, since $y=4$, the $R P$ are ranked last by every other group and consequently can never win (in either round). Therefore it is not profitable for them to deviate and enter against the $S P$; conversely it is not optimal for the $S P$ to let them enter alone.

Subcase (b). A profitable deviation is $(R P=N, R R=E)$, since it brings the $R R$ to power, and $(3,1)<(4, z)$, as $z \geq 2$. The deviation is also self-enforcing: if the $R P$ deviate from it, the $S P$ (and eventually the $S R$ ) candidate drops out in round 1 by (25), and the $R R$ wins anyway against the $R P$ in round 2 .

Case 2: $\nu<b<\theta_{H}$. The preference structure, reported in Table 2, differs from the previous one because the $R R$ and the $S R$ now have the same ideal policy (zero tax rate). This implies that the $S P$ and the $R P$ are both indifferent between the $R R$ and the $S R$. Moreover, the $S R$ will always rank the $R R^{\prime} s$ policy $2^{\text {nd }}$, and vice-versa. It is easily verified that the analysis of Case 1 applies here as well (with now only subcase (a) relevant in Claim 4).

\begin{tabular}{|l|l|l|l|l|}
\hline & $S P$ & $R P$ & $R R$ & $S R$ \\
\hline$S P$ & 1 & 3 & 2 & 2 \\
\hline$R P$ & 2 & 1 & 3 & 3 \\
\hline$R R$ & $x$ & $y$ & 1 & 2 \\
\hline$S R$ & 3 & 4 & 2 & 1 \\
\hline
\end{tabular}

where $(x, y)=(3,4)$ [subcase $(\mathrm{a})]$, or $(4,3)$ [subcase $(\mathrm{b})]$.

Table 2. Fiscal preferences of each group when $\nu<b<\theta_{H}$

\footnotetext{
${ }^{48}$ When the $S R$ do not enter, all groups but the $R P$ support the $R R$, who win in round 1 . When $S R=E$ and the sum of $R R$ and $S P$ is less than $50 \%$, the $R R$ and the $R P$ go to round 2, and the $R R$ wins.
} 
B - Region $b^{*}(\nu)<b$. Table 3 reports the preference structure for this case.

\begin{tabular}{|l|l|l|l|l|}
\hline & $S P$ & $R P$ & $R R$ & $S R$ \\
\hline$S P$ & 1 & 4 & 3 & 2 \\
\hline$R P$ & 3 & 1 & 2 & 4 \\
\hline$R R$ & $x$ & $y$ & 1 & $z$ \\
\hline$S R$ & $x^{\prime}$ & 4 & $y^{\prime}$ & 1 \\
\hline
\end{tabular}

where $(x, y, z)=(3,4,2)$ [subcase $(\mathrm{a})]$, or $(4,2,3)$ or $(4,3,2)$ [subcase $(\mathrm{b})] ;\left(x^{\prime}, y^{\prime}\right)=(2,3)$ or $(3,2)$.

Table 3. Fiscal preferences of each group when $b^{*}(\nu)<b$

Claim 1: The RR winning at $t+1$ is the unique Nash equilibrium outcome.

Proof: We show that if the $R R$ enter, they always win, independently of all other groups' strategies; the result will immediately follows. Let the $R R$ enter (either on or off the equilibrium path), and suppose first that $R P$ stay out. They then back the $R R$ (whom they rank second), who thus win in the first round. If the $R P$ do enter, there are two possible subcases:

(a) If neither the $S P$ nor the $S R$ enter, both support the $R R$ (whom they always prefer to the religious poor), who thus again win immediately.

(b) If either or both of these groups enter, no one has a majority in the first round. The $R P$ and the $R R$, being the two largest contestants, make it to the second round and here again win with the support of both the $S P$ and the $S R$.

Claim 2: The RR winning at $t+1$ is a (unique) CPNE outcome.

Proof: Let the $R R$ enter alone: $(S P=N, R P=N, R R=E, S R=N)$. By Claim 1 no group would gain from deviating, since the $R R$ will win anyway. To show that it is coalition-proof, note that the minimal winning coalition is $(S P, R P)$, who obtain $(3,2)$ when the $R R$ win. As there is no policy vector that Pareto-dominates $(3,2)$, there is no profitable deviating coalition, hence the result. Uniqueness follows from Claim 1.

C - Locus $b=b^{*}(\nu)$. The only difference with the previous case is that the $R P$ are now indifferent between the $S P$ and the $R R$ : the preference structure is still given by Table 3, except that the second row is now (2 12124$)$. The preceding reasoning remains unchanged since, in cases (first or second round) where the $R P$ have a choice between $R R$ and $S P$, it is enough that they split their vote equally to ensure the latter's victory: by Assumption 5 $R R+R P / 2=r(1+n) / 2>1 / 2$. The $R R$ winning is thus again the only NE and CPNE outcome.

D - Region $b<\nu$. The $S P$ and $R P$ have the same preferred policy, so either on entering, backed by the other, wins a majority. Moreover, the $R R$ winning cannot be an CPNE outcome, as that same majority of $S P$ plus $R P$ can deviate (e.g., $(R P=E, S P=N))$ and win. 


\subsection{Church's Repairing Policy with Income Heterogeneity}

Lemma 8 (1) The function $\pi(b, \nu)$ equals 0 for $b<b^{*}(\nu)$, then jumps up to $\pi\left(b^{*}(\nu), \nu\right)=$ $R\left(\tau_{H}\left(b^{*}(\nu)\right)\right)$. It is continuous and strictly increasing on $\left[b^{*}(\nu), b^{*}(\nu) /(1-\delta)\right)$, then jumps down to $\pi\left(b^{*}(\nu) /(1-\delta), \nu\right)=R\left(\tau_{H}\left(b^{*}(\nu) /(1-\delta)\right)\right)-(1-\delta) R\left(\tau_{H}\left(b^{*}(\nu)\right)\right)$. Finally, it is continuous and strictly decreasing on $\left[b^{*}(\nu) /(1-\delta),+\infty\right)$, with $\lim _{b \rightarrow+\infty} \pi(b, \nu)=\delta R(\hat{\tau})>0$.

Proof. The proof is the same as for Lemma 1, except that for $b^{*}(\nu) /(1-\delta) \leq b$,

$$
\begin{aligned}
\pi(b, \nu) & =R\left(\tau_{H}(b)\right)-(1-\delta) R\left(\tau_{H}((1-\delta) b)\right) \equiv \rho\left(b ; \theta_{H}\right), \\
\frac{\partial \rho\left(b ; \theta_{H}\right)}{\partial b} & =R^{\prime}\left(\tau_{H}(b)\right) \tau_{H}^{\prime}(b)-(1-\delta)^{2} R^{\prime}\left(\tau_{H}((1-\delta) b)\right) \tau_{H}^{\prime}((1-\delta) b) \\
& =\frac{\theta^{H}}{b^{2}}\left[\frac{R^{\prime}\left(\tau_{H}(b)\right)}{-R^{\prime \prime}\left(\tau_{H}(b)\right)}-\frac{R^{\prime}\left(\tau_{H}\left(b^{\prime}\right)\right)}{-R^{\prime \prime}\left(\tau_{H}\left(b^{\prime}\right)\right)}\right]
\end{aligned}
$$

now replace (A.1) and A.17 respectively, with $\tau_{H}^{\prime}(b)$ given by A.15.

\subsection{Proof of Lemma 5}

(1) (i) The function $\pi\left(b, \nu ; \theta_{L}, \theta_{H}\right)$ depends on $\theta_{L}$ only trough the cutoffs $b^{*}(\nu)$ and $b^{*}(\nu) /(1-$ $\delta$ ) at which $\pi(b)$ jumps, respectively up from 0 to $\left(R \circ \tau_{H}\right)\left(b^{*}(\nu)\right)$ and down from $(R \circ$ $\left.\tau_{H}\right)\left(b^{*}(\nu) /(1-\delta)\right)$ to $\left(R \circ \tau_{H}\right)\left(b^{*}(\nu)\right)-\left(R \circ \tau_{H}\right)\left((1-\delta) b^{*}(\nu)\right)$; note that these four values are independent of $\theta_{L}$. Consider now an increase in $\theta_{L}$ to $\tilde{\theta}_{L} \in\left(\theta_{L}, \theta_{H}\right)$; by Lemma 4 . (2), the two cutoffs $b^{*}(\nu)$ and $b^{*}(\nu) /(1-\delta)$ decrease, to values which we shall denote $\tilde{b}^{*}(\nu)$ and $\tilde{b}^{*}(\nu) /(1-\delta)$, with

$$
\tilde{b}^{*}(\nu)<b^{*}(\nu)<\tilde{b}^{*}(\nu) /(1-\delta)<b^{*}(\nu) /(1-\delta)
$$

provided the change in $\theta_{L}$ is not too large. Moreover, by the property just noted, the new function $\tilde{\pi}(b) \equiv \pi\left(b, \nu ; \tilde{\theta}_{L}, \theta_{H}\right)$ coincides with the old $\pi(b) \equiv \pi\left(b, \nu ; \theta_{L}, \theta_{H}\right)$ on $\left[0, \tilde{b}^{*}(\nu)\right)$, on $\left[b^{*}(\nu), \tilde{b}^{*}(\nu) /(1-\delta)\right]$ and on $\left[b^{*}(\nu) /(1-\delta),+\infty\right)$. They differ only on $\left[\tilde{b}^{*}(\nu), b^{*}(\nu)\right)$, where $\tilde{\pi}(b)=R\left(\tau_{H}(b)\right)>0=\pi(b)$ and on $\left[\tilde{b}^{*}(\nu) /(1-\delta), b^{*}(\nu) /(1-\delta)\right)$, where $\tilde{\pi}(b)=R\left(\tau_{H}(b)\right)-$ $(1-\delta) R\left(\tau_{H}((1-\delta) b)\right)<R\left(\tau_{H}(b)\right)=\pi(b)$.

(ii) Omitting the dependence on $y$ to simplify the notation, let now $b^{-}(\nu)$ and $b^{+}(\nu)$ denote the two points where, by Property (1)(i) above, the graph of $\pi(b)$ intersects the horizontal $\pi=y\left(\right.$ we shall denote $b^{-}(\nu)=b^{*}(\nu)$ when $\left.\pi\left(b^{*}(\nu)\right)=R\left(\tau_{H}\left(b^{*}(\nu)\right)\right)>y\right)$; let $\tilde{b}^{-}(\nu)$ and $\tilde{b}^{+}(\nu)$ similarly denote those intersections for the graph of $\tilde{\pi}$ (with $\tilde{b}^{-}(\nu)=\tilde{b}^{*}(\nu)$ when $\tilde{\pi}\left(\tilde{b}^{*}(\nu)\right)=$ $\left.R\left(\tau_{H}\left(\tilde{b}^{*}(\nu)\right)\right)>y\right)$. By construction, $b^{-}(\nu)$ lies in the range where $\pi(b)$ is increasing (including the upward discontinuity), and by Property (1)(i) the graph of $\tilde{\pi}$ is above that of $\pi$ in that range -strictly when $b \in\left[\tilde{b}^{*}(\nu), b^{*}(\nu)\right)$. This implies that $\tilde{b}^{-}(\nu)$ must lie to the left of $b^{-}(\nu)$. 
Similarly, $\tilde{b}^{+}(\nu)$ lies in the range where $\tilde{\pi}(b)$ is decreasing; by Property (1)(i), in that range the graph of $\pi$ is either above that $\tilde{\pi}$ (for all $b \in\left[\tilde{b}^{*}(\nu) /(1-\delta), b^{*}(\nu) /(1-\delta)\right.$ )) or equal to it (for all $b \geq b^{*}(\nu) /(1-\delta)$ ), so it must be that $\tilde{b}^{+}(\nu)$ lies to the left of $b^{+}(\nu)$.

(2) (i) To show that an increase in $\theta_{H}$ shifts (weakly) the graph of $\pi\left(\cdot, \nu ; \theta_{L}, \theta_{H}\right)$ to the right, note the following three features of this function.

First, over the range $\left[b^{*}(\nu), b^{*}(\nu) /(1-\delta)\right)$, the function $\pi\left(b, \nu ; \theta_{L}, \theta_{H}\right)=R\left(\tau_{H}(b)\right)$ is strictly increasing and continuous in $b$ and is strictly decreasing in $\theta_{H}$ as

$$
\frac{\partial \pi\left(b, \nu ; \theta_{L}, \theta_{H}\right)}{\partial \theta_{H}}=R^{\prime}\left(\tau_{H}(b)\right) \frac{\partial \tau_{H}(b)}{\partial \theta_{H}}<0
$$

given that $\partial \tau_{H}(b) / \partial \theta_{H}<0$ from A.12.

Second, over the range $\left[b^{*}(\nu) /(1-\delta),+\infty\right)$, the function $\pi\left(b, \nu ; \theta_{L}, \theta_{H}\right)$ is given by (A.16), it is decreasing and continuous in $b$ and is strictly increasing in $\theta_{H}$. In fact,

$$
\begin{aligned}
\frac{\partial \rho\left(b ; \theta_{H}\right)}{\partial \theta_{H}} & =R^{\prime}\left(\tau_{H}(b)\right) \frac{\partial \tau_{H}(b)}{\partial \theta_{H}}-(1-\delta) R^{\prime}\left(\tau_{H}((1-\delta) b)\right) \frac{\partial \tau_{H}(b)}{\partial \theta_{H}} \\
& =\frac{1}{b}\left[\frac{R^{\prime}\left(\tau_{H}\left(b^{\prime}\right)\right)}{-R^{\prime \prime}\left(\tau_{H}\left(b^{\prime}\right)\right)}-\frac{R^{\prime}\left(\tau_{H}(b)\right)}{-R^{\prime \prime}\left(\tau_{H}(b)\right)}\right]
\end{aligned}
$$

where we have used A.12 and $b^{\prime} \equiv(1-\delta) b$. This expression is positive as $\tau_{H}(b)$ is increasing in $b$ and Assumption 1 ensures that $-R^{\prime}(\tau) / R^{\prime \prime}(\tau)$ is decreasing in $\tau$.

Third, by Lemma 4. (2), the two cutoffs $b^{*}(\nu)$ and $b^{*}(\nu) /(1-\delta)$ are increasing in $\theta_{H}$. Therefore, if we consider an increase in $\theta_{H}$ to $\tilde{\theta}_{H}$, the two cutoffs $b^{*}(\nu)$ and $b^{*}(\nu) /(1-\delta)$ increase to values which we shall denote $\tilde{b}^{*}(\nu)$ and $\tilde{b}^{*}(\nu) /(1-\delta)$ with

$$
b^{*}(\nu)<\tilde{b}^{*}(\nu)<\frac{b^{*}(\nu)}{1-\delta}<\frac{\tilde{b}^{*}(\nu)}{1-\delta},
$$

provided the change in $\theta_{H}$ is not too large. The above three properties of $\pi\left(b, \nu ; \theta_{L}, \theta_{H}\right)$ imply that an increase in $\theta_{H}$ shifts (weakly) to the right the graph of this function.

Summarizing, the new function $\tilde{\pi}(b) \equiv \pi\left(b, \nu ; \theta_{L}, \tilde{\theta}_{H}\right)$ has the following graph. Over the range $\left[0, b^{*}(\nu)\right)$, it equals zero and coincides with the old $\pi(b) \equiv \pi\left(b, \nu ; \theta_{L}, \theta_{H}\right)$. Over the range $\left[b^{*}(\nu), \tilde{b}^{*}(\nu)\right), \pi(b)=R\left(\tau_{H}(b)\right)>0=\tilde{\pi}(b)$, and $\pi(b)=R\left(\tau_{H}(b)\right)>R\left(\tilde{\tau}_{H}(b)\right)=\tilde{\pi}(b)$ over $\left[\tilde{b}^{*}(\nu), b^{*}(\nu) /(1-\delta)\right)$, where $\tilde{\tau}_{H}(b)$ denotes the optimal tax rate of the religious rich when their income is $\tilde{\theta}_{H}$. The function $\tilde{\pi}(b)=R\left(\tilde{\tau}_{H}(b)\right)$ is continuous and increasing over the range $\left[b^{*}(\nu) /(1-\delta), \tilde{b}^{*}(\nu) /(1-\delta)\right)$, while the function $\pi(b)=R\left(\tau_{H}(b)\right)-(1-\delta) R\left(\tau_{H}((1-\delta) b)\right)$ is decreasing over this range and has a downward jump at $b^{*}(\nu) /(1-\delta)$. The function $\tilde{\pi}(b)=$ $R\left(\tilde{\tau}_{H}(b)\right)-(1-\delta) R\left(\tilde{\tau}_{H}((1-\delta) b)\right)$ has a downward discontinuity at $\tilde{b}^{*}(\nu) /(1-\delta)$, and it is decreasing over the range $\left[\tilde{b}^{*}(\nu) /(1-\delta),+\infty\right)$ with $\tilde{\pi}(b)=R\left(\tilde{\tau}_{H}(b)\right)-(1-\delta) R\left(\tilde{\tau}_{H}((1-\delta) b)\right)>$ 
$\pi(b)=R\left(\tau_{H}(b)\right)-(1-\delta) R\left(\tau_{H}((1-\delta) b)\right)$.

(ii) By construction, $b^{-}(\nu)$ lies in the range where $\pi(b)$ is increasing (including the upward discontinuity), i.e. $b^{-}(\nu) \in\left[b^{*}(\nu), b^{*}(\nu) /(1-\delta)\right)$, and by Property (2)(i) the graph of $\tilde{\pi}$ is below that of $\pi$ on that range (strictly where $\pi>0$ ). This implies that $\tilde{b}^{-}(\nu)$ must lie to the right of $b^{-}(\nu)$. Similarly, $b^{+}(\nu)$ lies in the range where $\pi(b)$ is decreasing, i.e. $b^{+}(\nu) \in$ $\left[b^{*}(\nu) /(1-\delta),+\infty\right)$. By Property (i) above, on that range the graph of $\tilde{\pi}$ is either increasing or decreasing and above that $\pi$. There will never be $\tilde{b}^{+}(\nu)$ in the range where $\tilde{\pi}$ is increasing but, eventually, only $\tilde{b}^{-}(\nu)$ can be in this range. This means that $\tilde{b}^{+}(\nu)$ belongs to the range where $\tilde{\pi}$ is decreasing and above that $\pi$, i.e. $\tilde{b}^{+}(\nu) \in\left[\tilde{b}^{*}(\nu) /(1-\delta),+\infty\right)$, which in turn implies that $\tilde{b}^{+}(\nu)$ lies to the right of $b^{+}(\nu)$.

\subsection{Proof of Proposition 7}

Given any values of the state variables at the start of date $t+1$, the ensuing Church decision and political competition lead to the unique CPNE outcome described in Proposition 5. The intertemporal expected utilities for each type of agent that will result under blocking and no blocking thus define the payoffs of the date- $t$ political game, which we now show also has a unique CPNE outcome. Together with its unique continuation, it will therefore constitute the unique PCPNE of generation $t$ 's two-period, three-stage game.

(1) We first show, in Lemma 9 below, that: (i) the $R R$ are always the pivotal group at date- $t$-they want to block (weakly) less than the $R P$, whereas neither the $S P$ nor the $S R$ ever want to; (ii) for $q \geq 1 /(1+\gamma)$, even the $R P$ prefer not to block in the repairing region, $b \in[\underline{b}, \bar{b}]$.

Recall that the $R R$ want to block, $V_{R R}^{N B} \leq V_{R R}^{B}$, if and only if (31) and (33) exceed $R^{-1}(\varphi(a)) \theta_{H}$, in Regions 1 and 2 respectively. We first derive more general conditions for all four types, then rank them.

If all $B R$ innovations are blocked, the $R R$ will be in power at $t+1$, so the expected utility of any agent with income $\theta \in\left[\theta_{L}, \theta_{H}\right]$ and religiousness $\beta \in\{0,1\}$ is

$$
\left[1-R^{-1}(\varphi(a))\right] \theta+\left[1-\lambda+\lambda\left(1-p_{R}\right)(1+\gamma)\right]\left[\left(1-\tau_{H}(b)\right) \theta+\beta b R\left(\tau_{H}(b)\right)\right]
$$

Suppose now that $B R$ innovations are not blocked, but that their damage to beliefs gets repaired with probability $\tilde{q} \in[0,1]$. While the optimal strategy of the Church implies $\tilde{q}=$ $\mathbf{1}_{\{b \in[\underline{b}, \bar{b}]\}} \cdot q$, for now we treat $\tilde{q}$ as a parameter. There are two cases to consider.

Case I: $\mathbf{b} \geq \mathbf{b}^{*}(\boldsymbol{\nu}) /(\mathbf{1}-\boldsymbol{\delta})$. The $R R$ will be in power at $t+1$ even repair fails, so the expected 
utility of agents in $\operatorname{group}(\theta, \beta)$ is now

$$
\begin{aligned}
& \theta+\left[1-\lambda+\lambda\left(1-p_{R}(1-\tilde{q})\right)(1+\gamma)\right]\left[\left(1-\tau_{H}(b)\right) \theta+\beta b R\left(\tau_{H}(b)\right)\right] \\
& +\lambda p_{R}(1-\tilde{q})(1+\gamma)\left[\left(1-\tau_{H}\left(b^{\prime}\right)\right) \theta+\beta b^{\prime} R\left(\tau_{H}\left(b^{\prime}\right)\right)\right]
\end{aligned}
$$

with $b^{\prime} \equiv(1-\delta) b$. The group of $(\theta, \beta)$-types therefore wants to block if and only if

$$
\begin{aligned}
R^{-1}(\varphi(a)) \theta \leq & \lambda p_{R}\left\{[1-\tilde{q}(1+\gamma)]\left[\left(1-\tau_{H}(b)\right) \theta+\beta b R\left(\tau_{H}(b)\right)\right]\right. \\
& \left.-(1-\tilde{q})(1+\gamma)\left[\left(1-\tau_{H}\left(b^{\prime}\right)\right) \theta+\beta b^{\prime} R\left(\tau_{H}\left(b^{\prime}\right)\right)\right]\right\} \equiv \Delta_{I}(b ; \theta, \beta, \tilde{q}) .
\end{aligned}
$$

Case II: $\mathbf{b} \in\left[\mathbf{b}^{*}(\boldsymbol{\nu}), \mathbf{b}^{*}(\boldsymbol{\nu}) /(\mathbf{1}-\boldsymbol{\delta})\right)$. When repair fails, it is now the $S P$ who come to power at $t+1$, implementing $(T, G)=\left(R\left(\tau_{L}(\nu)\right), 0\right)$. The expected utility of any group $(\theta, \beta)$ is thus obtained by simply replacing $\beta b^{\prime}$ by $\nu$ and $\tau_{H}\left(b^{\prime}\right)$ by $\tau_{L}(\nu)$ in A.21. Its utility under blocking is unchanged from A.19, so the blocking condition is given by similar substitutions in A.21):

$$
\begin{aligned}
R^{-1}(\varphi(a) \theta \leq & \lambda p_{R}[1-\tilde{q}(1+\gamma)]\left(1-\tau_{H}(b)\right) \theta+\beta b R\left(\tau_{H}(b)\right) \\
& -(1-\tilde{q})(1+\gamma)\left[\left(1-\tau_{L}(\nu)\right) \theta+\nu R\left(\tau_{L}(\nu)\right)\right] \equiv \Delta_{I I}(b, \nu ; \theta, \beta, \tilde{q})
\end{aligned}
$$

Lemma 9 Let $b \geq b^{*}(\nu)$. Then:

1. For all $b \geq b^{*}(\nu) /(1-\delta)$ where $\Delta_{I}(b ; \theta, 1, \tilde{q}) \geq 0$, the function $\Delta_{I}(b ; \theta, 1, \tilde{q}) / \theta$ is strictly decreasing in $\theta$. Similarly, for all $b<b^{*}(\nu) /(1-\delta)$ where $\Delta_{I I}(b ; \theta, 1, \tilde{q}) \geq 0, \Delta_{I I}(b, \nu ; \theta, 1, \tilde{q}) / \theta$ is strictly decreasing in $\theta$. Therefore, whenever the $R R$ want to block, so do the $R P$.

2. For all $b \geq b^{*}(\nu) /(1-\delta), \Delta_{I}(b ; \theta ; 0, \tilde{q})<0$, while for all $b<b^{*}(\nu) /(1-\delta)$, Assumption 7 implies that $\Delta_{I I}\left(b, \nu ; \theta_{H} ; 0, \tilde{q}\right)<0$. In both cases, no secular agent wants to block.

3. For all $q \geq 1 /(1+\gamma), \Delta_{I}(b ; \theta, \beta, q)<0$ and $\Delta_{I I}(b, \nu ; \theta, \beta, q)<0$. Therefore, under Assumption 3, no group finds it optimal to block in the repairing region, $b \in[\underline{b}, \bar{b}]$.

Proof. The last claim is immediate. For the other two, note that $\Delta_{I}(b ; \theta ; 1, \tilde{q}) / \lambda p_{R}$ is affine in $\theta$, of the form $\beta b A_{I}+B_{I} \theta$, where

$$
\begin{aligned}
A_{I} & \equiv[1-\tilde{q}(1+\gamma)] R\left(\tau_{H}(b)\right)-(1-\tilde{q})(1+\gamma)(1-\delta) R\left(\tau_{H}\left(b^{\prime}\right)\right), \\
B_{I} & \equiv[1-\tilde{q}(1+\gamma)]\left[1-\tau_{H}(b)\right]-(1-\tilde{q})(1+\gamma)\left[1-\tau_{H}\left(b^{\prime}\right)\right]<0,
\end{aligned}
$$

since $\tau_{H}$ is weakly increasing and $\gamma>0$. By A.21), a minimal condition for $(\theta, \beta)$ types to want to block is $\Delta_{I} \geq 0$, which implies that $\beta b A_{I} \geq-B_{I} \theta>0$. For $\beta=0$ (the secular) this cannot be, while for $\beta=1$ (the religious) this implies that $\Delta_{I} / \theta=b A_{I} / \theta+B_{I}$ is decreasing 
in $\theta$. Similarly, $\Delta_{I I} / \lambda p_{R}$ is of the form $A_{I I}(\beta)+B_{I I} \theta$, where

$$
\begin{aligned}
A_{I I}(\beta) & \equiv \beta \cdot[1-\tilde{q}(1+\gamma)] b R\left(\tau_{H}(b)\right)-(1-\tilde{q})(1+\gamma) \nu R\left(\tau_{L}(\nu)\right) \\
B_{I I} & \equiv[1-\tilde{q}(1+\gamma)]\left[1-\tau_{H}(b)\right]-(1-\tilde{q})(1+\gamma)\left[1-\tau_{L}(\nu)\right]<0
\end{aligned}
$$

Moreover, $\left.A_{I I}(0)<[1-\tilde{q}(1+\gamma)]\left[1-\tau_{H}(b)\right]-(1-\tilde{q})(1+\gamma)\left(1-\tau_{L}(\nu)\right)\right]$ by (A.22 and $b \geq b^{*}(\nu)$; the rest of the proof proceeds as in the other case. $\|$

Having thus proved Lemma 9, we now show formally that the only CPNE outcome always involves implementing the preferred policy of $R R$.

(a) Consider first the case where they want to block. Then so do the $R P$, whereas the $S P$ and $S R$ never want to. At least one (or both) of $R R$ or $R P$ then finds optimal to enter: indeed, if only one of them does it is supported by the other and thus wins in the first round; if both do and it leads to anything else than their common preferred outcome, i.e., blocking, it is optimal for one of them to deviate and back the other. Thus, in any Nash equilibrium, blocking must occur. Furthermore, the profiles $(S P=N, R P=N, R R=E, S R=N)$ $(S P=N, R P=E, R R=N, S R=N)$ are both CPNE's (with the same outcome): for a deviation to be profitable it would need to result in a different outcome, and this can occur only if $R R$ or $R P$ or both deviate(s); they could only lose, however, and so never will.

(b) Suppose now that $R R$ do not want to block. The $R P$ is the only group that might want to. They will never win, however, as it would be optimal for at least one the three groups to enter, and beat the $R P$ with the support of the other two. Thus, in any Nash equilibrium, blocking cannot occur. Finally, it is easy to verify that $(S P=N, R P=E, R R=N, S R=N)$ is again a CPNE.

This concludes the proof of Part (1) of Proposition 7.

(2) In each Region $k=1,2$, the equilibrium blocking boundary is defined by $R^{-1}(\varphi(a)) \theta_{H}=$ $\Delta_{R R}^{k}(b)$, with the left-hand side increasing in $a$. We show i each case $\partial \Delta_{R R}^{k}(b) / \partial b>0$, implying that $B(a) \equiv\left(R \circ \Delta_{R R}^{k}\right)^{-1}(\varphi(a)) \theta_{H}$ is well-defined and increasing in $a$. Indeed, setting $\beta=1$ and $\theta=\theta_{H}$ in $\mathrm{A} .21$ and $\mathrm{A} .22$, the envelope theorem implies that

$$
\begin{aligned}
\frac{1}{\lambda p_{R}} \cdot \frac{\partial \Delta_{I}}{\partial b}\left(b ; \theta_{H}, 1, \tilde{q}\right) & \left.=[1-\tilde{q}(1+\gamma)] R\left(\tau_{H}(b)\right)\right]-(1-\tilde{q})(1+\gamma)(1-\delta) R\left(\tau_{H}\left(b^{\prime}\right)\right)=A_{I}, \\
\frac{1}{\lambda p_{R}} \cdot \frac{\partial \Delta_{I I}}{\partial b}\left(b, \nu ; \theta_{H}, 1, \tilde{q}\right) & =[1-\tilde{q}(1+\gamma)] R\left(\tau_{H}(b)\right)>0,
\end{aligned}
$$

with $A_{I}>0$ whenever $\Delta_{I}\left(b ; \theta_{H}, 1, \tilde{q}\right) \geq 0$, as shown earlier. Setting $\tilde{q}=0$ proves the desired results. 


\subsection{Proof of Proposition 8}

Region 1: $b>\bar{b}>b^{*}(\nu) /(1-\delta)$. No repairing and no power reallocation.

The blocking condition is here $\Delta_{R R}^{1}(b)-R^{-1}(\varphi(a)) \theta_{H} \geq 0$; see 30. Differentiating the left-hand side with respect to $\theta_{H}$ and using the envelope theorem yields

$$
\frac{\partial \Delta_{R R}^{1}(b)}{\partial \theta_{H}}-R^{-1}(\varphi(a))=\lambda p_{R}\left[1-\tau_{H}(b)-(1+\gamma)\left(1-\tau_{H}\left(b^{\prime}\right)\right)\right]-R^{-1}(\varphi(a))<0,
$$

since $\tau_{H}\left(b^{\prime}\right)<\tau_{H}(b)$.

Region 2. $b^{*}(\nu) \leq b<\underline{b}$. No repairing, leading to a power reallocation.

The blocking condition is now $\Delta_{R R}^{2}(b)-R^{-1}(\varphi(a)) \theta_{H} \geq 0$; see 32. A similar differentiation, using the first-order condition of the $S P, \nu R^{\prime}\left(\tau_{L}(\nu)\right)=\theta_{L}$, yields

$$
\begin{aligned}
& \frac{\partial \Delta_{R R}^{2}(b)}{\partial \theta_{H}}-R^{-1}(\varphi(a)) \\
= & \lambda p_{R}\left\{1-\tau_{H}(b)-(1+\gamma)\left[1-\tau_{L}(\nu)\right]+(1+\gamma)\left(\theta_{H}-\theta_{L}\right) \frac{\partial \tau_{L}(\nu)}{\partial \theta_{H}}\right\}-R^{-1}(\varphi(a)),
\end{aligned}
$$

Greater inequality thus leads to more blocking if

$$
1-\tau_{H}(b)-(1+\gamma)\left(1-\tau_{L}(\nu)\right)+(1+\gamma)\left(\theta_{H}-\theta_{L}\right) \frac{\partial \tau_{L}(\nu)}{\partial \theta_{H}}>\frac{R^{-1}(\varphi(a))}{\lambda p_{R}} .
$$

Since $\max \left\{\tau_{H}(b), \tau_{L}(\nu)\right\}<1$, a sufficient condition for A.24 to hold is

$$
\left(\theta_{H}-\theta_{L}\right) \frac{\partial \tau_{L}(\nu)}{\partial \theta_{H}}>1+\frac{R^{-1}(\varphi(a))}{\lambda p_{R}(1+\gamma)}
$$

Differentiating implicitly the first order condition of the $S P, \nu R^{\prime}\left(\tau_{L}(\nu)\right)=\theta_{L}$, with respect to $\theta_{L}$, and taking into account that $\partial \theta_{L} / \partial \theta_{H}=-n /(1-n)$, we have

$$
\frac{\partial \tau_{L}(\nu)}{\partial \theta_{H}}=\left(\frac{n}{1-n}\right) \frac{1}{\nu\left[-R^{\prime \prime}\left(\tau_{L}(\nu)\right)\right]}>0 .
$$

Substituting A.26 into A.25, the latter can be rewritten as

$$
\theta_{H}>1+\frac{(1-n)^{2}}{n} \nu\left[-R^{\prime \prime}\left(\tau_{L}(\nu)\right)\right]\left(1+\frac{R^{-1}(\varphi(a))}{\lambda p_{R}(1+\gamma)}\right)
$$

Since $R\left(\tau_{L}(\nu)\right)$ is $\mathcal{C}^{3}$ and $R^{\prime \prime}\left(\tau_{L}(\nu)\right)$ is nonincreasing (by Assumption $\left.1, R^{\prime \prime \prime} \leq 0\right),-R^{\prime \prime}\left(\tau_{L}(\nu)\right.$ ) is positive, nondecreasing and bounded from above by $-R^{\prime \prime}(\hat{\tau})$, while $\varphi(a)$ has an upper bound at $\bar{\varphi}$. Therefore, condition A.27 holds under Assumption 8. In this region, greater income inequality thus leads, ceteris paribus, to more blocking. 


\section{$9 \quad$ References}

Acemoglu, Daron, Simon Johnson and James A. Robinson (2005) "The Rise of Europe: Atlantic Trade, Institutional Change and Economic Growth," American Economic Review, 95(3), 546-579.

Acemoglu, Daron and James A. Robinson (2006) "Economic Backwardness in Political Perspective," American Political Science Review 100, 115-131.

Acemoglu, Daron and James A. Robinson (2008) "Persistence of Power, Elites and Institutions," American Economic Review, 98(1), 267-93.

Acemoglu, Daron, Davide Ticchi and Andrea Vindigni (2011) "Emergence and Persistence of Inefficient States," Journal of the European Economic Association, 9 (2). 177-208.

Aghion, Philippe, Cahuc, Pierre and Yann Algan (2011) "Civil Society And The State: The Interplay Between Cooperation And Minimum Wage Regulation," Journal of the European Economic Association, 9(1), 3-42.

Alesina, Alberto and Marios Angeletos (2005) "Fairness and Redistribution," American Economic Review, 95(4), 960-80.

Alesina, Alberto, Reza Baqir and William Easterly (1999). "Public Goods and Ethnic Divisions," Quarterly Journal of Economics, 114(4), 1243-84.

Alesina, Alberto and Eliana La Ferrara (2005) "Preferences for Redistribution in the Land of Opportunities," Journal of Public Economics, 89(5-6), 897-931

Alesina, Alberto and Paola Giuliano (2013) "Culture and Institutions," NBER Working Paper 19750, December.

Al-Khalili, Jim (2010) The House of Wisdom. How Arabic Science Saved Ancient Knowledge and Gave Us the Renaissance, New York, NY: The Penguin Press.

Barro, Robert J. and Jong-Wha Lee (2013) "A New Data Set of Educational Attainment in the World, 1950-2010," Journal of Development Economics, 104, 184-198.

Barro, Robert J. and Rachel M. McCleary (2003a) "Religion and Economic Growth Across Countries," American Sociological Review, 68(5), 760-781.

Barro, Robert J. and Rachel M. McCleary (2003b) Religion Adherence Data. (link),

Barro, Robert J. and Rachel M. McCleary (2005) "Which Countries Have State Religions?", Quarterly Journal of Economics, 120, 1331-1370.

Becker, Sascha O. and Ludger Woessmann (2009) Was Weber Wrong? A Human Capital Theory Of Protestant Economic History," Quarterly Journal of Economics, 128(4), 531-596.

Bellettini, Giorgio and Gianmarco I.P. Ottaviano, (2005) "Special Interests and Technological Change," Review of Economic Studies, 72, 43-56.

Bénabou, Roland (1996) "Inequality and Growth," NBER Macroeconomics Annual, B. Bernanke and J. Rotemberg eds., 11(74), 96-129. 
Bénabou, Roland (2000) "Unequal Societies: Income Distribution and the Social Contract," American Economic Review, 90(1), 96-129.

Bénabou, Roland (2008) "Ideology," Journal of the European Economic Association, 6(2-3), 321-352.

Bénabou, Roland and Jean Tirole (2006) "Belief in a Just World and Redistributive Politics," Quarterly Journal of Economics, 121(2), 699-746.

Bénabou, Roland and Jean Tirole (2011) "Identity, Morals and Taboos: Beliefs as Assets," Quarterly Journal of Economics, 126, (2011), 805-855.

Bernheim, B. Douglas, Bezalel Peleg, and Michael D. Whinston (1987) "Coalition-Proof Nash Equilibria I: Concepts," Journal of Economic Theory, 42(1), 1-12.

Besley, Timothy and Stephen Coate (1997) "An Economic Model of Representative Democracy," Quarterly Journal of Economics, 112(1), 85-11

Bisin, Alberto and Thierry Verdier (2000) "Beyond the Melting Pot: Cultural Transmission, Marriage, and the Evolution of Ethnic and Religious Traits," Quarterly Journal of Economics, 115, 955-988.

Botticini, Maristella and Zvi Eckstein (2012) The Chosen Few: How Education Shaped Jewish History, 70-1492. Princeton, NJ: Princeton University Press.

Bridgman, Benjamin R., Igor D. Livshits and James C. MacGee (2007) "Vested Interests and Technology Adoption," Journal of Monetary Economics, 54, 649-666.

Bureau of Economic Analysis (2008). International Economic Accounts.(link).

Caselli, Francesco (1999) "Technological Revolutions," American Economic Review, 89(1), 78102.

Cavalcanti, Tiago V., Stephen L. Parente and Rui Zhao (2007) "Religion in Macroeconomics: A Quantitative Analysis of Weber's Thesis," Economic Theory, Symposium in Honor of Edward C. Prescott, 32(1), 105-123.

Chaney, Eric (2008) "Tolerance, Religious Competition and the Rise and Fall of Muslim Science," mimeo, Harvard University. (link)

Chaney, Eric (2011) "Islam and Human Capital Formation: Evidence from Premodern Muslim Science," in The Oxford Handbook of the Economics of Religion, edited by Rachel M. McCleary, ch. $4,81-92$.

Chaney, Eric (2013) "Revolt on the Nile: Economic Shocks, Religion and Political Power," Econometrica, 81(5), 2033-2053.

Chari, V. V. and Hugo Hopenhayn (1991) "Vintage Human Capital, Growth, and the Diffusion of New Technology," Journal of Political Economy, 99(6), 1142-65.

Childress, Diana (2008) Johannes Gutenberg and the Printing Press, Minneapolis, MN: TwentyFirst Century Books. 
Deming, David (2010) Science and Technology in World History: Early Christianity, the Rise of Islam and the Middle Ages: 2, Jefferson, NC: McFarland.

Diner, Dan (2009) Lost In The Sacred: Why the Muslim World Stood Still, Princeton, NJ: Princeton University Press.

Freeman, Charles (2005) The Closing of the Western Mind: The Rise of Faith and the Fall of Reason. New York, NY: Vintage.

Gelman, Andrew (2009) Red State, Blue State, Rich State, Poor State: Why Americans Vote the Way They Do, Princeton NJ: Princeton University Press.

Glaeser, Edward L. and Bruce I. Sacerdote (2008) "Education and Religion," Journal of Human Capital, 2(2), 188-215.

Goldstone, Jack A. (2000) "The Rise of the West-Or Not? A Revision to Socio-Economic History," Sociological Theory, 18(2), 175-194.

Gorodnichenko, Yuriy and Gerard Roland (2011) "Which Dimensions of Culture Matter for Long-Run Growth?" American Economic Review, 101(3), 492-98.

Grant, Edward (2004) Science And Religion, 400 B.C. To A.D. 1550: From Aristotle To Copernicus, Westport, CT: Greenwood Press.

Greif, Avner (1994) "Cultural Beliefs and the Organization of Society: A Historical and Theoretical Reflection on Collectivist and Individualist Societies," Journal of Political Economy, $102(5), 912-950$.

Greif, Avner (2005) Institutions and the Path to the Modern Economy: Lessons from Medieval Trade, Cambridge: Cambridge University Press.

Guiso, Luigi, Sapienza, Paola and Luigi Zingales (2003) "People's Opium? Religion and Economic Attitudes," Journal of Monetary Economics 50(1), 225-282.

Guiso, Luigi, Sapienza, Paola and Luigi Zingales (2013) "Long-term Persistence," Einaudi Institute for Economics and Finance mimeo, July.

Gusdorf, Georges (1969) La Révolution Galiléenne, Paris: Payot.

Hameed, Salam (2008) "Bracing for Islamic Creationism," Science, December 12, 322(5908), 1637-1638.

Hoodboy, Pervez Amirali (2007) "Science and the Islamic World - The Quest for Rapprochement," Physics Today, 49-55.

Indiana Business Research Center, Kelley School of Business, Indiana University. States in Profile. (link)

Jacob, Margaret C. (1997) Scientific Culture and the Making of the Industrial West, Oxford, UK: Oxford University Press.

Jacob, Margaret C. and Larry Stewart (2004) Practical Matter: Newton's Science in the Service of Industry and Empire, 1687-1851, Cambridge, MA: Harvard University Press. 
Kertcher, Zack and Ainat N. Margalit (2005) "Challenges to Authority, Burden of Legitimisation: The Printing Press and the Internet," International Journal of Communications Law $\&$ Policy, 10, 1-30.

Koyré, Alexandre (1957) From the Closed World to the Infinite Universe, Baltimore, MD: The Johns Hopkins Press.

Krusell, Per and José-Víctor Ríos-Rull (1996) "Vested Interests in a Positive Theory of Stagnation and Growth," Review of Economic Studies, 63(2), 301-329.

Kuran, T. (2011) The Long Divergence: How Islamic Law Held Back the Middle East. Princeton, NJ: Princeton University Press.

Huber, John and Piero Stanig (2011) "Church-State Separation and Redistribution," Journal of Public Economics, 95 (7-8), 828-836.

Landes, David (1998) The Wealth and Poverty of Nations: Why Some are So Rich and Some So Poor. New York, NY: W.W. Norton.

Levy, Gilat and Ronny Razin (2012) "Religious Beliefs, Religious Participation, and Cooperation," American Economic Journal: Microeconomics, 2012, 4(3), 121-151.

Levy, Gilat and Ronny Razin (2013) "Calvin's Reformation in Geneva: Self and Social Signalling," forthcoming, Journal of Public Economic Theory.

Luttmer, Erzo (2001) "Group Loyalty and the Taste for Redistribution," Journal of Political Economy, 109(3), 500-528.

Maddison, Angus (2007) Contours of the World Economy, 1-2030 AD. Essays in MacroEconomic History, Oxford, UK: Oxford University Press.

Lewis, B. (2003) What Went Wrong? The Clash Between Islam and Modernity in the Middle East. Oxford, UK: Oxford University Press.

McLennan III, James E. and Harold Dorn (2006) Science and Technology in World History, Baltimore PA: The Johns Hopkins University Press.

Merton, Robert K. (1938) "Science, Technology and Society in Seventeenth-Century England," Osiris, 4, 360-632.

Mokyr, Joel (1992) The Lever of Riches: Technological Creativity and Economic Progress, Oxford, UK: Oxford University Press.

Mokyr, Joel (1998) "The Political Economy of Technological Change: Resistance and Innovation in Economic history," in Maxine Bergand and Kristin Bruland eds., Technological Revolutions in Europe, Cheltenham: Edward Elgar Publishers, 39-64.

Mokyr, Joel (2004) The Gifts of Athena: Historical Origins of the Knowledge Economy, Princeton, NJ: Princeton University Press.

Joel Mokyr (2012) "Culture, Institutions, and Modern Growth," Prepared for the Conference: Understanding Institutions and Development Economics: the Legacy and Work of Douglas C. North, St. Louis, Nov. 4-6, 2010. 
Mooney, Chris (2005) The Republican War on Science. Cambridge, MA: Perseus Books. Norris, Pippa and Ronald Inglehart (2011) Sacred and Secular: Religion and Politics Worldwide. Cambridge Studies in Social Theory, Religion and Politics. Cambridge, UK: Cambridge University Press.

North, Douglass (1990) Institutions, Institutional Change and Economic Performance. Cambridge, UK: Cambridge University Press.

Osborne, Martin J. and Al. Slivinsky (1996) "A Model of Political Competition with CitizenCandidates," Quarterly Journal of Economics, 111(1), 65-96.

Parente, Stephen L. and Edward C. Prescott (1999) "Monopoly Rights: A Barrier to Riches," American Economic Review, 89(5), 1216-1233.

Parkin, Alice (2010) "George W. Bush and the Stem Cell Research Funding Ban," Time. Health and Family, Aug. 20.

Pereira, Alexius A. (2006) "Religiosity and Economic Development in Singapore," Journal of Contemporary Religion, 161-177.

Pew Research Center (2008) Pew Forum on Religion and Public Life, Religion Landscape Survey. (link)

Persson, Torsten and Guido Tabellini (2009) "Democratic Capital: The Nexus of Political and Economic Change," American Economic Journal: Macroeconomics, 1(2), 88-126.

Phillips, K. (2006) American Theocracy: The Perils and Politics of Radical Religion, Oil, and Borrowed Money in the 21st Century. New York, NY: Viking Press.

Piketty, Thomas (1995) "Social Mobility and Redistributive Politics," Quarterly Journal of Economics, 110(3), 551-584.

Restuccia, Diego (2004) "Barriers to Capital Accumulation and Aggregate Total Factor Productivity," International Economic Review, 45(1), 225-238.

Roemer, John (1998), "Why the Poor Do Not Expropriate the Rich in Democracies: An Old Argument in New Garb," Journal of Public Economics, 70, 399-426.

Ruse, Michael (2005) The Evolution-Creation Struggle, Cambridge, MA: Harvard University Press.

Saint-Paul, Gilles (2010) "Endogenous Indoctrination: Occupational Choices, the Evolution of Beliefs and the Political Economy of Reforms," Economic Journal, 120(544), 325-353.

Saleh, Mohammed (2012a) "From Kuttabs to Schools: Educational Modernization, Religion, and Human Capital in Twentieth Century Egypt," TSE Working Paper, 12-366, September. Saleh, Mohammed (2012b) "The Reluctant Transformation: Modernization, Religion, and Human Capital in Nineteenth Century Egypt," TSE Working Paper 13-434, October.

Saliba, George (2007) Islamic Science and the Making of the European Renaissance. Cambridge, MA: MIT Press. 
Stark, Rodney, Laurence R. Iannaccone and Roger, Finke (1996) "Religion, Science, and Rationality," American Economic Review, 86(2), 433-37.

Kenneth Scheve and David Stasavage (2006) "Religion and Preferences for Social Insurance," Quarterly Journal of Political Science, 1(3), 255-286.

Swatos, William H. Jr. and Kevin J. Christiano (1999) "Secularization Theory: The Course of a Concept," Sociology of Religion, 60(3), 209-228.

Tabellini, Guido (2008) "The Scope of Cooperation: Values and Incentives," Quarterly Journal of Economics, 123(3), 905-950.

Tabellini, Guido (2010) "Culture and Institutions: Economic Development in the Regions of Europe," Journal of the European Economic Association, 8(4), 677-716

Ticchi, Davide, Thierry Verdier and Andrea Vindigni (2013) "Democracy, Dictatorship and the Cultural Transmission of Political Values," mimeo, IMT Lucca. (link)

Trevor-Roper, Hugh (1967) The Crisis of the Seventeenth Century, New York, NY: Harper \& Row.

U.S. Patent And Trademark Office (2007). Patent Counts by Patent Type and by State and Country of Origin. (link)

Vander Hook, Sue (2010) Johannes Gutenberg: Printing Press Innovator. Minnesota, MN: ABDO Publishing Company.

Vidal-Robert, Jordi (2011) "An Economic Analysis of the Spanish Inquisition's Motivations and Consequences," mimeo, Boston University. (link)

Weber, Max [1905] (2002) The Protestant Ethic and the Spirit of Capitalism, Los Angeles, LA: Roxbury Company.

World Intellectual Policy Organization (WIPO): IP Statistics Data Center, Total Patent Applications (Direct and PCT National-Phase Entries).(link)

Wuthnow, Robert (2011) Red State Religion: Faith and Politics in America's Heartland, Princeton, NJ: Princeton University Press.

Young, Cristobal (2009) "Religion and Economic Growth in Western Europe: 1500-2000," mimeo, Stanford University. (link) 